\title{
Improving Psychotherapy Outcome: The Use of Immediate Electronic Feedback and Revised Clinical Support Tools
}

\author{
Karstin Lee Slade \\ Brigham Young University - Provo
}

Follow this and additional works at: https://scholarsarchive.byu.edu/etd

Part of the Psychology Commons

\section{BYU ScholarsArchive Citation}

Slade, Karstin Lee, "Improving Psychotherapy Outcome: The Use of Immediate Electronic Feedback and Revised Clinical Support Tools" (2008). Theses and Dissertations. 1587.

https://scholarsarchive.byu.edu/etd/1587

This Dissertation is brought to you for free and open access by BYU ScholarsArchive. It has been accepted for inclusion in Theses and Dissertations by an authorized administrator of BYU ScholarsArchive. For more information, please contact scholarsarchive@byu.edu, ellen_amatangelo@byu.edu. 


\title{
IMPROVING PSYCHOTHERAPY OUTCOME: \\ THE USE OF IMMEDIATE ELECTRONIC FEEDBACK AND REVISED CLINICAL SUPPORT TOOLS
}

\author{
By \\ Karstin Slade
}

\begin{abstract}
A dissertation submitted to the faculty of
Brigham Young University

in partial fulfillment of the requirements for the degree of

Doctor of Philosophy
\end{abstract}

Department of Clinical Psychology

Brigham Young University

August 2008 


\title{
BRIGHAM YOUNG UNIVERSITY
}

\section{GRADUATE COMMITTEE APPROVAL}

\author{
of a dissertation submitted by \\ Karstin Slade
}

This dissertation has been read by each member of the following graduate committee and by majority vote has been found to be satisfactory.

Date

Date

Date

Date

Date
Michael J. Lambert, Chair

Sally Barlow

Jared Warren

Patrick Steffen

David W. Smart 


\section{BRIGHAM YOUNG UNIVERSITY}

As chair of the candidate's graduate committee, I have read the dissertation of Karstin Slade in its final form and have found that (1) its format, citations, and bibliographical style are consistent and acceptable and fulfill university and department style requirements; (2) its illustrative materials including figures, tables, and charts are in place; and (3) the final manuscript is satisfactory to the graduate committee and is ready for submission to the university library.

Date

Accepted for the Department
Michael J. Lambert

Chair, Graduate Committee
Ramona Hopkins

Department Chair

Accepted for the College

David Magelby

Dean, College of Family, Home and Social Sciences 


\begin{abstract}
ENHANCING PSYCHOTHERAPY OUTCOME:

THE USE OF IMMEDIATE ELECTRONIC FEEDBACK AND REVISED CLINICAL SUPPORT TOOLS
\end{abstract}

\author{
Karstin Slade \\ Department of Clinical Psychology \\ Doctor of Philosophy
}

While the beneficial effects of psychotherapy have been well documented, the fact remains that 5 to 10 percent of clients get worse while in treatment (Lambert \& Ogles, 2004) and a large minority of patients show little response (Hansen, Lambert, \& Forman, 2003). The effects of four interventions, aimed at reducing deterioration and enhancing positive outcomes were examined in an Immediate Electronic Feedback sample of 1101 patients whose outcome was contrasted across experimental groups and with two archival groups: the Week-Delayed Feedback group, consisting of archival data from 1374 patients and the treatment-as-usual control group consisting of archival data from 1445 patients. Results indicate that feedback to therapists improved outcome across clients, especially for signal-alarm cases. Therapist feedback effects were enhanced by the use of manually based Clinical Support Tools, but not by providing direct feedback to clients about their progress. There were no significant differences in outcome between the Week-Delayed CST feedback and the 2-Week-Delayed CST feedback groups; however, clients in the Week-Delayed CST feedback condition, attended 3 less sessions, on 
average, than their 2-Week-Delayed CST feedback counterparts. Furthermore, a significantly greater number of people in the Week-Delayed CST Feedback group ended treatment in the Recovered/Improved classification of the Jacobson/Truax model.

Keywords: Deterioration, Patient-Focused Research, Quality Assurance, Quality Management, Outcome Management, Patient Profiling, Feedback, Decision Tree 
Abstract $\quad$ iv

List of Tables $\quad$ viii

$\begin{array}{ll}\text { List of Figures } & \text { ix }\end{array}$

Chapter 1: Introduction 1

Chapter 2: Literature Review $\quad 4$

Factors Effecting Feedback Effectiveness 4

$\begin{array}{ll}\text { Effects of Providing Feedback } & 15\end{array}$

Psychotherapy Outcome and the Effects of Feedback 19

$\begin{array}{ll}\text { Current Trends in Outcome Research } & 20\end{array}$

Previous Findings from the Current Line of Research 28

$\begin{array}{ll}\text { Clinical Support Tools } & 30\end{array}$

$\begin{array}{ll}\text { Therapeutic alliance } & 31\end{array}$

Motivation for treatment 33

$\begin{array}{ll}\text { Social support. } & 34\end{array}$

Perfectionism Inventory (PI) 35

$\begin{array}{ll}\text { Time Limitations } & 40\end{array}$

$\begin{array}{ll}\text { Current Study } & 40\end{array}$

$\begin{array}{ll}\text { Chapter 3: Method } & 42\end{array}$

$\begin{array}{ll}\text { Participants } & 42\end{array}$

$\begin{array}{ll}\text { Measures } & 44\end{array}$

Outcome Questionnaire-45 44

Clinical Support Tools measures. 45 
OQ-45 Feedback

Clinical Support Tools Feedback and Decision Tree $\quad 48$

Procedure

Chapter 4: Results

Pretreatment

Pre-Post Changes 53

The Effect of Feedback $\quad 54$

$\begin{array}{ll}\text { On-Track. } & 56\end{array}$

Not-On-Track.

$\begin{array}{ll}\text { Session Effects } & 58\end{array}$

Effect of Clinical Support Tools on Outcome $\quad 59$

$\begin{array}{ll}\text { Session Effects } & 63\end{array}$

$\begin{array}{ll}\text { Analysis of Clinical Significance } & 64\end{array}$

$\begin{array}{ll}\text { Chapter 5: Discussion } & 66\end{array}$

Appendix A: Tables and Figures $\quad 89$

Appendix B: Therapist and Client Messages 99

$\begin{array}{ll}\text { References } & 100\end{array}$

V vii 


\section{LIST OF TABLES}

$\begin{array}{ll}\text { Table } 1 & 89\end{array}$

$\begin{array}{ll}\text { Table } 2 & 91\end{array}$

$\begin{array}{ll}\text { Table } 3 & 93\end{array}$

$\begin{array}{ll}\text { Table } 4 & 94\end{array}$

v i i i 


\section{LIST OF FIGURES}

Figure 1.1: Treatment as Usual Archival Design 95

Figure 1.2 Week-Delayed OQ-45 Feedback Archival Design 95

Figure 1.3 Immediate Electronic OQ-45 Feedback Design 96

Figure 2.1 Feedback Timing NOT change scores $\quad 97$

Figure 2.2 Feedback Type NOT change scores $\quad 97$ 


\section{Chapter 1: Introduction}

Continuous Outcome Management is an action-based research strategy that attempts to track individual client treatment response in an effort to improve psychological service delivery by reducing treatment deterioration and non-response rates, while increasing the percentage of treatment responders. Negative treatment outcomes, in the form of clients who deteriorate or experience little or no change, during the course of treatment is a serious problem in both controlled research (clinical trials) and naturalistic studies (Hansen et al., 2002). Unfortunately, clinicians have a tendency to overlook or ignore the fact that a minority of clients not only do not respond well to treatment, but leave treatment worse off than when they started (Lambert \& Ogles, 2004; Mohr 1995).

Furthermore, the need for tracking client progress is reinforced by data indicating that therapists need independent data to alert them when treatment is not having its intended effects (Hannan et al., 2005). These results are consistent with past research on clinical versus actuarial predictions (Dawes, 1989; Grove \& Meehl, 1996; Grove, Zald, Lebow, Snitz, \& Nelson, 2000), and support the conclusion that formal methods of monitoring client treatment response with the use of standardized measures and predictors for negative treatment response should increase the likelihood that clinicians will reduce treatment failure.

An emphasis on quality assurance of mental health services coupled with researchers' and clinicians' (e.g., Persons \& Silberschatz, 1998) dissatisfaction with the clinical utility of efficacy and effectiveness research spurred the development of a new research paradigm called patient-focused research. With a focus on the enhancement of treatment quality, Howard and colleagues ((Howard, Moras, Brill, Martinovich, \& Lutz, 
1996) advocated the systematic evaluation of a patient's response to treatment during the course of therapy. To further establish the clinical validity of this approach, they recommended providing therapists with information relevant to a patient's progress in treatment. With knowledge of a patient's lack of response to a particular treatment, they believed that clinicians possess information that can contribute to timely alternative interventions, thereby increasing the likelihood of a successful outcome. This focus on the individual patient represents a departure from earlier research in which the progress of an individual client was largely ignored, in favor of focusing on the outcome of the aggregate. Patient focused research, however, has shown itself to be an important, viable avenue for improving psychotherapy outcome, given the focus on identifying at risk cases in an attempt to alter the course and outcome of treatment.

Accumulating research evidence making use of this research paradigm now shows that treatment deterioration can be reduced through the use of outcome monitoring systems that compare an individual client's treatment response against actuarial data (Harmon et al., 2007; Hawkins, Lambert, Vermeersch, Slade, \& Tuttle, 2004; Lambert, Hansen et al., 2001; Lambert, Whipple, Vermeersch, et al., 2002; Whipple et al., 2003).

The current research is designed to identify likely treatment failures while they are still in treatment (Not On Track; NOT cases), by monitoring their progress on a session by session basis, and providing immediate electronic feedback (IEF) interventions to both patients and therapists. Additionally, this study assessed the impact of providing therapists with feedback on the non-responding client's assessment of the therapeutic alliance, readiness for change, perception of social support, and perfectionism (termed "Clinical 
Support Tools" or "CSTs"), with the aim of altering the course of therapy, where indicated. The material in this dissertation is organized in the traditional format.

Chapter two provides an overview of research literature related to factors that may affect feedback effectiveness, attempts to apply patient-focused research to real-time practice, and an overall evaluation of how patient-focused research has been successful to this end. The last part of chapter two will address the current program of research and the recent attempts to employ patient-focused research to improve outcome for clients predicted to be treatment failures or non-responders.

Chapter three describes the methods of the current study with overviews of the participants, measures, research design, and procedures.

Chapter four provides the results of the current study. Chapter five discusses the results, draws conclusions, and provides recommendations.

Appendix $\mathrm{b}$ contains a submission ready article summarizing important findings from the study that is intended for publication in an appropriate scientific journal. 


\section{Chapter 2: Literature Review}

In a recent survey of 143 counselors $39 \%$ rated their performance as a counselor as average and $61 \%$ rated themselves as above average. Furthermore, when asked to grade themselves as counselors on a scale from $\mathrm{A}+$ to $\mathrm{F}, 66 \%$ rated themselves as $\mathrm{A}$ or better (Dew \& Riemer, 2002), suggesting that most mental health providers perceive their own performance as being equal to, if not better than, other counselors, further suggesting the need for systematic, objective feedback to be delivered to clinicians in lieu of the apparent presence of self-serving biases regarding a clinician's work. Although recent research has shown feedback to therapists to be a particularly useful intervention (Lambert, Whipple, Smart,,et al., 2001; ES = .44), a meta-analysis of the effectiveness of feedback interventions in several different fields by Kluger and DeNisi (1996) showed that a significant number were not successful. Although they found an overall effect size of .41 for feedback interventions, they also found that one-third of the studies of feedback decreased performance of the subjects, indicating that certain conditions need to be met for feedback interventions to successfully change professionals' behavior and improve performance. Several theoretical perspectives have attempted to explain the mechanisms of effective feedback.

\section{Factors Affecting Feedback Effectiveness}

Although feedback interventions have generally been considered to consistently increase performance (e.g., Ammons, 1956; Ashford \& Cummings, 1983). Kluger and DeNisi (1996), in a meta-analytic review, found that over one third of all feedback interventions negatively affected performance. A thorough review of the literature, indicated the following factors that affect feedback effectiveness for therapists as it pertains 
to the current topic: cognitive dissonance theory, self-concept and centrality of selfconcept, types of feedback, degree of negative and positive feedback, perceived level of control, and how feedback is delivered. Less research has been conducted on the effects of patient feedback in individual psychotherapy, but there is more literature regarding interventions designed to change behavior, and an understanding, or more developed theories of the mechanisms that influence performance, which will also be addressed.

The basic tenet of cognitive dissonance theory is that an individual with two personally relevant cognitions that are dissonant is in a state of arousal and is psychologically uncomfortable, and is, thereby, motivated to reduce the dissonance (Festinger, 1957; Aronson, 1999; Harmon-Jones \& Mills, 1999). Aronson expanded on the theory of cognitive dissonance, introducing the label of hypocrisy to describe the idea that: the self-concept is in conflict with behavior, suggesting that in the context of psychotherapy, a therapist's perception that the therapy he or she is providing is ineffective, or even harmful (through the use of feedback), is dissonant with his or her goal to provide help for his or her client. Aronson (1999) also links self persuasion to his theory stating: What characterized a self-persuasion situation is that no direct attempt is made to convince anyone of anything. Rather, individuals find themselves in a circumstance where it becomes efficacious to convince themselves that a particular thing is the case...Self-persuasion is almost always a more powerful form of persuasion (deeper, longer lasting) than more traditional persuasion techniques... Where selfpersuasion occurs, people are convinced that the motivation for change has come from within... self-persuasion can have profound and long-lasting effects on important aspects of behavior (pp. 882-883). 
Festinger (1957) theorized that the level of motivation to reduce dissonance depends on the magnitude of the dissonance and that dissonance can be reduced by "removing dissonant cognitions, adding new cognitions, reducing the importance of dissonant cognitions, or increasing the importance of consonant cognitions" (HarmonJones \& Mills, 1999).

One's self-concept typically includes goals, or standards, that serve as a reference value for the evaluation of behavior and that more difficult and specific goals lead to higher performance than very easy or general goals (Locke, Shaw, Saari, \& Latham, 1981), but only if a certain level of goal commitment can be assumed (Hollenbeck \& Klien 1987), which is determined by the goals' attractiveness and the individual's expectation to accomplish the goal. Bandura (1982) and others (Lent, Brown, \& Larkin, 1987; Locke, Frederick, Lee, \& Bobko, 1984) have found that the overall expectation to accomplish the goal depends on self-efficacy judgment as well.

Kurt Lewin (1947) was the first to apply feedback to the behavioral sciences, borrowing the term from electrical engineering, with his initial conceptualization of feedback as "the impact of others' behavior". Claiborn, Goodyear, and Horner (2001) summarize feedback as (a) information provided to a person (b) from an external source (c) about the person's behavior or its effects. Others lend support to this general conceptualization of, feedback. Kluger and DeNisi (1996) indicated that feedback is typically provided through external agents. Taylor, Fischer, and Ilgen (1984) suggest that both the perceived credibility of the feedback source and the content and form of the feedback message are factors that influence the processing of feedback. Regarding credibility, the source of feedback should be perceived by the individual to have enough 
expertise and should be trusted to provide accurate feedback. The feedback should contain new and useful information regarding the recipient's progress, as well as suggestions as to how the outcomes can be improved (Wilson, Boni, \& Hogg, 1997).

When feedback is negative, professionals are more likely to reject the feedback than to change their belief about their effectiveness as a therapist, which is likely an important part of his or her self-identity. Rejection of the feedback can be explained by referring to the theory of cognitive dissonance mentioned previously. The tendency to reject feedback is also congruent with the idea that in order to preserve one's self-integrity people tend to seek out and accept feedback information that is more aligned with their positive selfimage (Blanton, Pelham, DeHart, \& Carvallo, 2001; Sherman \& Cohen, 2002), which can be seen as an attempt to avoid dissonance-arousing information. It is also a common observation that clinicians are often very skeptical with regard to standardized outcome measures (Bickman et al., 2000). Thus there is reason to believe that in most cases mental health professionals will be biased against using the external feedback as a basis for judging their performance (client treatment response) if the feedback is negative (e.g., the client is more disturbed). It is important to note that the design used by Lambert, Whipple, and colleagues (2003; Harmon et al., 2007) in past research allows for the negative feedback to be interspersed throughout a majority of positive feedback that is delivered to therapists; if the algorithms identify $25 \%$ as being signal cases (worsening in therapy), then the therapists are only getting negative feedback about their performance $25 \%$ of the time, while $75 \%$ of the feedback delivered is of a positive nature, making it more likely that the therapist will pay attention to the negative feedback received. 
It is important to note that when designing a feedback intervention, one keep in mind the factors that influence a clinician's likelihood of accepting or rejecting the feedback and the factors that affect the likelihood that they will alter their approach based on the feedback. Factors that affect the tendency to accept or reject feedback include the degree of negative feedback received by the therapist and whether this negative feedback will create too much dissonance, thereby, leading the therapist to reject the negative feedback. One factor that affects the tendency for a therapist to initiate change includes controllability over the ability to alter factors that would change the negative feedback. If the perceived level of control is low, the professional might quit the job as a clinician or, because that is probably not a feasible option, will withdraw emotionally from the client instead (Maslach, Schaufeli, \& Leiter, 2000). However, if the perceived level of control is high, such as commitment to learning new skills or gaining new knowledge, the professional may be motivated to change problematic stable conditions to increase the chance that in the future the outcomes will be more consistent with her expectations. Feedback regarding the therapeutic alliance delivered by the therapist, as well as ways to improve it, as used by Whipple, et al. (2003) is an example of how one might effectively intervene in the event of a poor alliance rating.

Another factor related to the acceptance of feedback is the centrality of the feedback as it relates to the clinicians self-concept. The more important or central an element is, the greater the probability that changing this cognitive schema will cause dissonance with other important cognitions and the less willing the person will be to make that change (Festinger, 1957; Walster, Berscheid, \& Barclay, 1967; Wicklund \& Brehm, 1976). Thus, negative feedback accompanied by positive feedback is more likely to promote feedback acceptance 
and feedback accompanied by ideas for how to alter negative aspects is also likely to foster feedback acceptance. The Vanderbilt efforts (e.g., Bickman, et al. 2000) suggest that the current practical attempt to give feedback has a theoretical justification from other areas of study. That is to say, the way feedback is currently designed and delivered to therapists is supported by the scientific literature, rather than an unsophisticated assumption about what would improve outcome.

Wells, Moorman, and Werner (2007) reported that for monitoring employee performance, when it is viewed as developmental, it is judged as fairer than when it is perceived as a deterrent to future behavior. This type of monitoring was also associated with higher levels of job satisfaction, organizational commitment, and felt obligation. They elaborate on their findings by suggesting that those individuals will respond more positively to electronic performance monitoring when managers and human resource development professionals carefully frame the reasons for monitoring and feedback in constructive, developmental terms. Although these findings do not translate directly to feedback to therapists about client progress, these identified factors that relate to perceived monitoring may have an iatrogenic effect on the way therapists view electronic feedback in relation to performance evaluation. Barone et al. (2005) investigated the effects of practice and feedback on empathy accuracy in a graduate level psychology interviewing course. They concluded that those who received immediate feedback, regarding their empathy judgments, had greater accuracy of feelings, but not thoughts, at the end of the course, than those in the class who did not receive feedback about their judgments.

While the majority of the experimental designs utilized in feedback research, reviewed in the previous sections, have consisted of controlled investigations assessing the 
impact of feedback interventions on a variety of tasks such as test performance (e.g., spatial dimension intellectual tests, discrimination of a pattern test, memory related tasks, physical tasks, and attendance behavior), the current line of research is expanding the understanding of this latter subject as it relates to assessment feedback in a therapeutic setting.

Feedback has long been used as an intervention designed to change behavior. The actual mechanisms that influence performance vary according to theory. Although theories representing social cognition (e.g., Bandura, 1991), learned helplessness (e.g., Mikulincer, 1994), control (e.g., Podsakoff, 1989), and goal setting (e.g., Locke \& Latham, 1990) disagree about how feedback initiates a change in behavior, each concedes that providing performance results to individuals enforces a relatively universal evaluation process. Specifically, feedback provides a comparison with intended goals or standards of performance. Either positive or negative evaluations resulting from this comparison determine an individual's reaction. For example, control theorists suggest that once individuals are apprised of their performance discrepancy, effort is made to reduce this difference. In contrast, goal-setting theorists argue that the desire to achieve goals motivates the behavior of individuals. Regardless of the theoretical differences, it is assumed that acknowledgment of a performance discrepancy leads to strategies designed to eliminate it. For example, if initial performance of hitting a target is considered below an expected standard and the standard is perceived as desirable and attainable, it has been found that individuals increase their effort to attain the standard (Kluger \& DeNisi, 1996).

However, it is also possible that individuals react to the discrepancy by simply rejecting the standard of performance. Indeed, there is evidence that when the standard is perceived as unachievable, abandonment of the expected standard is the likely reaction to 
the discrepancy (e.g., Bandura, 1991). For example, a study in which university participants were asked to identify a particular configuration of letters and shapes, Mikulincer (1988), found that university participants exposed to a large number of failures reacted with helplessness and indicated that the problems were unsolvable. A third potential strategy is the modification of an existing standard rather than complete rejection of it. In the case of this strategy, it is likely that an individual acknowledging the discrepancy has some investment in meeting a less stringent standard, and believes that the modified standard is attainable.

The last strategy, resolving the discrepancy by rejecting the accuracy or importance of the feedback, is perhaps the most relevant to the remainder of the discussion. The former three approaches are contingent on the actions of the receiver of feedback, and thus are less capable of influence or experimenter control. However, steps can be taken to reduce the likelihood that the feedback is rejected.

The results of the Kluger and DeNisi (1996) meta-analytic review suggest that the use of obvious praise has been found to impair the performance on demanding cognitive tasks (Baumeister, Hutton, \& Cairns, 1990). Negative feedback interventions have had similar effects on performance (Mikulincer, Glaubman, Ben-Artzi, \& Grossman, 1991). In particular, there is strong evidence indicating that feedback interventions that are discouraging attenuate the beneficial effects $(d=-.20)$ of providing individuals with information about their results on the performance of specific intellectual and discrimination tasks (Kluger \& DeNisi, 1996). Findings from a series of experiments also suggest that the degree to which the self and an appointed standard are discrepant has implications in how an individual reacts to performance knowledge (Duval, Duval, \& 
Mulilis, 1992). Participants led to believe early in the experimental process that their ability to match two-dimensional figures with three-dimensional figures was largely deficient were more likely to work on the tasks for shorter periods of time, particularly if they received feedback suggesting that they were not progressing quickly.

In contrast, there is evidence that specific characteristics of some feedback positively influence the effects of feedback interventions. Performance knowledge that conveys the amount of progress since the last provision of feedback, a characteristic called velocity, appears to augment the effects of feedback interventions (Carver \& Scheier, 1990). For example, Hsee and Abelson (1991) showed that persons asked to imagine hypothetical stock earnings (e.g., persons were provided with the initial price of stock purchased) were more satisfied when receiving updates that indicated rates of appreciation. Kluger and DeNisi (1996) found velocity to be one of the qualities systematically affecting performance $(\mathrm{d}=.14)$. Likewise, feedback interventions including a solution for improving performance have also been found to augment the effects of feedback interventions $(\mathrm{d}=.19)$

The form of feedback interventions, though less influential, relate to the overall effect of feedback interventions as well. Feedback interventions delivered by computers yielded stronger effects than identical descriptions provided by persons (Earley, 1988; Kluger \& DeNisi, 1996). Additionally, there is evidence that written and graphic performance results augment the effects of feedback that have been delivered verbally. Finally, the frequency of feedback interventions appears to positively impact performance with more frequent feedback being relatively superior to less frequent feedback. 
The basic tenets of social comparison (e.g. Festinger, 1954; Wills, 1981) and social learning theories (Rotter, 1954) suggest that most individuals are desirous of personal feedback because they are interested in learning more about themselves. However, it appears that not all feedback is desired equally. Persons receiving feedback that is consistent with their self-image find such feedback particularly desirable (Dana \& Graham, 1976). Snyder, Ingram, Handelsman, Wells, and Huwieler (1982) conducted a study designed to investigate the individual differences in those who desire and do not desire feedback. They reported that, in general, nonclinical participants were desirous of feedback. In a separate but related study, these same investigators compared the desirability of feedback in a clinical and nonclinical sample. The results of their analysis suggested that a difference between the two samples existed, with the clinical sample reporting a lower desire for feedback (Snyder et al., 1982). It was also reported that a group of clinical participants who volunteered to participate in an alcoholic treatment program reported a higher desire for feedback than a similarly diagnosed group of participants who did not volunteer to participate in treatment.

Of note in the Snyder and colleagues study is the apparent resistance to feedback for the members in the clinical sample. It may suggest that persons requiring treatment are more likely to avoid acknowledgment of reports describing their progress, at least in substance abuse samples. However, it appears this finding is somewhat tempered by the differences reported between patients who volunteer for treatment and those that refuse treatment. It is unclear from the results of these studies whether persons volunteering for treatment are less inclined to want feedback than persons representing the nonclinical sample. An additional weakness of the above studies is the small clinical samples collected 
for the desire for feedback $(n=44)$, as well as the small samples collected for motivation for treatment (volunteer; $\mathrm{n}=24$; nonvolunteer; $\mathrm{n}=18$ ).

Swann and Hill (1982) described the idea of self-verification theory and posed that people in an interpersonal context prefer to have others see them as they see themselves. He indicated that the reasons for such a preference may be related to a desire to maintain a sense of coherence or to allow for smoother interactions with others. As a result of this desire, people seek feedback that is consistent with their own self-conceptions. According to Swann, people are likely to reject inconsistent self-conception feedback. However, the therapeutic clinic can be a context for change as a result of giving feedback that is inconsistent with the self-concept (Young, Klosko, \& Weishaar, 2003). Self-Verification Theory indicates - and has demonstrated - that people in need of therapeutic change (e.g., depressed people) may show a preference for negative (self-consistent) feedback over positive (self-inconsistent) feedback (Giesler, Josephs, \& Swann, 1996). The clinical implications indicate that clients with negative self-conceptions may resist therapists' attempts to generate positive therapeutic change.

In a review of the research on the effects of test interpretation, Goodyear (1990) concluded "...that patients who receive test interpretations -- regardless of format or of the particular outcome criteria employed -- do experience greater gains than do those in control conditions" (p.242). It should be noted, however, that the focus of his review was on studies consisting of career counseling. Results from a study assessing therapist status and client attitude toward therapy on reaction to personality feedback indicate that participants may be susceptible to self-concept change or to self-fulfilling prophecy effects in therapy 
when they have a positive attitude toward therapy or are working with a high-status therapist (Collins \& Stukas, 2006).

In an effort to further understand the differential effects of test interpretation, Hanson, Clairborn, and Kerr (1997) conducted a study investigating two styles of test interpretation; delivered and interactive. The interactive mode of providing feedback was based on a social influence perspective, which suggests that a counselor influences patients through a series of interactions, from the reported purpose of the test to the test interpretation itself, all with the intended purpose of changing patients' perceptions of themselves. The findings of note included two differences that suggested more favorable results for the patients in the interactive condition: 1) in the perceived depth of the feedback session; and, 2) the expertness, trustworthiness, and attractiveness of the counselor. However, on measures designed to determine the number of relevant and favorable thoughts generated by the interpretation the patient had received, no differences were found between the interpretative and delivered conditions. Thus, regardless of the method used to communicate feedback, it appears that the message given made an impact on the recipients.

Much of the above research has dealt with performance feedback in analogue situations and laboratory designs that are mostly unrelated to psychotherapy outcome. In research that is more closely tied to clinical psychology, feedback in group psychotherapy has been studied extensively because feedback from group members has been theorized to be an essential curative aspect of group therapy. The ability of group therapy to improve a person's functioning has been considered. A review of feedback used in group psychotherapy suggests that positive feedback about a member's participation in the group is considered more credible, desirable, and helpful than negative feedback (Kivlighan, 
1985). Additionally, negative feedback unaccompanied by positive feedback is less likely to be "heard" by the intended party, especially in the early phase of group development (Flowers, 1979; Rose \& Bednar, 1980). However, Flowers reported that the absence of negative feedback prohibited optimal therapeutic benefit. He found that patients who experienced the most change in treatment were those who received the greatest levels of both positive and negative feedback. Thus, it appears that a blend of positive and negative feedback contributed to the best outcomes, but that such feedback should be weighted in favor of positive feedback, especially during the initial stages of treatment.

\section{Effects of Providing Feedback}

To date, it appears that the behavioral health field has most seriously considered the utility of providing patient-related information, from patients with HIV to patients addicted to smoking. With the aim of improving a patient's quality of life and preventative care behaviors, a number of patient centered studies have been conducted. Gustafson et al., (1999) tested a computerized system designed to provide HIV-positive patients with information, decision support, and channels of communication to experts in the field as well as patients similarly diagnosed. Participants of this randomized controlled trial were provided with Comprehensive Health Enhancement Support System (CHESS) computers for periods of time ranging from three to six months. Quality of life and health service utilization variables were obtained after the computers were in patients homes for durations of 3 and 6 months. In addition, a 9-month follow-up of these variables was measured.

Gustafson and et al. (1999) reported that compared to a control group of patients without access to CHESS, patients receiving the 6-month intervention endorsed a more active life, greater social support, and increased health care participation at a 9-month 
follow-up. On average, they reported fewer negative emotions as well. Their findings also suggest that patients receiving the CHESS computers were more efficient users of health care. In addition to spending less time during visits and utilizing more phone consultations, they also endorsed fewer and shorter hospitalizations.

In a series of studies designed to develop and evaluate the efficacy of a computerbased system for managing the diets of patients with hyperlipidemia, a condition characterized by a high plasma cholesterol level, Clark et al., (1997) provided results supporting the use of a computerized self-management system. In addition to performing assessments of dietary intake, their system provided dietary management strategies and delivered feedback of progress to patients. Perhaps most promising were the results associated with a condition in which the participants received feedback without receiving any assistance from health counselors. Of the 305 patients in this particular study, 193 were able to progress to a lower-fat dietary classification, 94 remained in the same dietary classification, and 18 worsened, moving to a higher-fat dietary classification. The reduction in plasma cholesterol levels for the three groups was $5.8 \%, 3.8 \%$, and $0.9 \%$, respectively.

Lash and Blosser (1999) examined whether personalized feedback, given to persons completing substance abuse treatment, enhanced adherence to aftercare group therapy. Feedback consisted of an appointment card indicating the date and time of the next session, the number of sessions a patient completed and missed, and the number of sessions each patient had remaining to meet the aftercare contract. Additionally, patients in the feedback condition received an automated phone message stating the date and time of their next appointment. Each patient in the feedback condition also received a handwritten letter 
from the group therapist after the first session, indicating that the therapist was pleased by the patient's decision to join the aftercare group, and looking forward to seeing the patient at the next scheduled meeting.

Patients missing an aftercare group session were notified by the group therapist in a handwritten letter and phone call and encouraged to continue work in the aftercare group. This final feedback measure was performed a maximum of two times for each patient. Compared to a no feedback condition, they found that persons in the feedback condition were more likely to begin aftercare treatment, and received more aftercare treatment sessions.

To reduce drinking among college drinkers, brief interventions that included an hour of health related information and personalized feedback on consumption were found to be effective in decreasing the number of alcoholic drinks consumed per week (Baer et al., 1998). Agostinelli, Brown, and Miller (1995) reported an average decrease of 7.9 drinks per week in college drinkers receiving mailed personalized feedback concerning the quantity and frequency of their consumption, blood alcohol content levels, and other risk factors. In a similarly conducted study, Walters (2000) reported an average reduction in college students defined as heavy drinkers of 13.8 drinks per week, a calculated effect size of 1.01 .

Curry, McBride, Grothaus, Louie, \& Wagner (1995) successfully used computer generated personalized feedback, designed to increase smokers' confidence in their ability to benefit from a self-help program, to significantly increase rates of program use, initial cessation, and short-term abstinence (three months). Self-confidence was enhanced by emphasizing the similarities between smokers' previous reasons for attempting to cease 
smoking behavior and their experience during the prior attempt to stop smoking, and the motivations and experience of successful quitters. The components of the feedback were designed to consider the smokers' stage of readiness to stop smoking and included a number of written components: Acknowledgement of smoker's baseline stage of readiness to stop smoking, background information regarding smoker's previous experience of cessation attempts (e.g., number of attempts, longest abstinence period, participation in cessation programs), health concerns, and list of potential concerns and specific references to a self-help booklet.

In a study designed to increase cessation among smokers, Prochaska, DiClemente, Velicer, and Rossi (1993) found that personalized feedback framed within the context of smokers' readiness to quit smoking, based on the Transtheoretical Model of Change (Prochaska \& DiClemente, 1982), resulted in a significant increase in cessation among smokers using self-help materials. Feedback in this study consisted of two to three page reports addressing a smoker's readiness to change, personal pros and cons of quitting smoking, and information regarding a smoker's progress compared to smokers who successfully completed the stages of smoking cessation. In addition, smokers were compared to their previous period of assessment (measures were given at the start of treatment, 1 month, and 6 months), and were given information about how to improve their self-efficacy in situations that could potentially tempt their commitment to quit smoking. The treatment condition using personalized feedback showed superior outcomes at all measured stages of change. Contrary to previous findings regarding feedback and smoking cessation, Lipkus and Prokhorov (2007) found that by providing college smoker's with feedback regarding their lung age, respiratory symptoms, and perceived risks does not 
translate into motivation to quit. The individual's worries were correlated with a stronger desire to quite. Furthermore, with increasing lung age, smokers rated the feedback as less relevant and reported exerting less effort breathing in and out while undergoing spirometry. Psychotherapy Outcome and the Effects of Feedback

Studies investigating the efficacy of feedback on psychotherapy outcome have examined the benefits of sharing personality test results with patients. Finn and Tonsager (1992) conducted one of the first controlled studies investigating the claim that sharing psychological test information with patients is beneficial. Participants were students seeking services at a university counseling/mental health center who were placed on a waiting list because of the low severity level of their symptoms. Participants in the treatment group completed the MMPI-2 as well as relevant self -report measures, and received verbal interpretations of their MMPI-2 results, whereas participants randomly assigned to the control group received attention in the form of 30-minute meetings with one of the researchers conducting the study but were given no feedback. Interpretations were provided in what the authors called an interactive mode, in which the patients were encouraged to play an active role in the feedback session led by a therapist.

In addition to completing the MMPI-2, participants completed the Symptom Checklist-90-Revised (SCL-R-90; Derogatis, 1983) immediately after receiving their personality assessment results and two weeks following receipt of their feedback results. The results of their analyses suggested that the patients in their treatment condition reported significantly lower levels of self-reported symptomatic distress than did the patients in the attention only group, as measured by the SCL-90-R. From a significant group by time interaction, they were able to conclude that much of the change was attributed to the 
feedback intervention, as there was little difference between the two groups prior to the participants in the experimental condition receiving their results from the MMPI-2.

To replicate the main finding and resolve the main methodological shortcoming of the Finn and Tonsager (1992) study, Newman and Greenway (1997) conducted a similar study but required that each patient in the study complete a MMPI-2 to ensure that the beneficial effect found in the former study was not the result of a confounding effect related to completion of the self-report instrument. Patients in the control group received personality assessments one week after the completion of the data collection. Similar to the main finding in the Finn and Tonsager study, participants in the feedback group reported a significant drop in their symptomatology compared to the control group. The results of these two controlled studies represent empirical evidence in support of the beneficial effects of assessment feedback on psychotherapy outcome.

University counseling center patients of therapists receiving patient progress information reported statistically different levels of improvement when compared to a group of patients whose therapists did not receive progress information based on the OQ45. From a review of the literature presented, the utility and efficacy of providing feedback to patients appears promising. Specifically, some combination of positive and negative feedback has been found to produce maximal therapeutic benefits (Kivlighan, 1985). Individuals who voluntarily seek mental health services are generally interested in receiving feedback regarding their personality assessment results (Snyder et al., 1982). Additionally, patients seem to consider feedback information both relevant and favorable regardless of whether information is communicated in an interactive or delivered method. 


\section{Current Trends in Outcome Research}

Harmon et al. (2007) described the dilemma that is currently facing the scientist/practitioner community: Researchers and clinicians commonly complain of a “disconnect”; clinicians feel researchers do not conduct clinically-relevant research and researchers feel that clinicians do not integrate research into practice (Strupp, 1996; Lutz, Rafaeli, Howard, \& Martinovich, 2002). Attempts to remedy these concerns have taken the form of improving dissemination of research results to (1) practitioners in the hopes of strengthening service delivery and (2) the public, with the aim of strengthening legitimacy for psychological treatments. Efforts to this end have included a call to "rename" psychotherapy as "psychological treatments" (Barlow, 2004) and perhaps most controversial, to establish lists of "empirically supported" (ESTs) or "empirically validated" treatments for specific disorders.

While efforts to identify effective treatments for specific disorders are one proposed way to bridge the research-practice gap, there is evidence to suggest that this may not be the best approach. Firstly, questions regarding the generalizability and applicability of ESTs to external generalized settings have been raised (i.e., patients with comorbid disorders, decreased accountability of therapists to adhere to treatment manuals). Other limitations include limited empirical support for efficacy of ESTs with ethnic minorities (Sue, 1998 as cited in Zane, Nagayama, Sue, Young, \& Nunez, 2004), the inescapability of researcher allegiance effects, exclusion of studies due to the use of non-manualized treatment interventions, and granting third party payers status as untrained supervisors (Henry, 1998 as cited in Lambert, Garfield, \& Bergin, 2004) owing to the fact that they can choose which treatments to pay for. 
Kazdin (2004) points out two limitations of the EST movement. First, the lists may stifle the progress of research, because treatments placed on the list are not likely to lose their status, and that other interventions may be very effective but "their use would be difficult to defend" because there are already treatments that have made the list. Second, the lists are dominated by cognitive behavioral treatments and approximately $50 \%$ of the studies in the child treatment literature have investigated cognitive behavioral methods ( $\mathrm{p}$. 553). The lists have also been criticized as being biased toward the treatment orientations of Task Force members (Lambert, Bergin, \& Garfield, 2004), which could also be viewed as an allegiance problem.

An alternative way to bridge the gap between research and practice is patientfocused research. Patient-focused research (Howard et al., 1996) arose partly out of an acknowledgement of the limitations inherent in efficacy (i.e. most ESTs) research, by seeking to determine empirically supported treatment at the level of the individual patient. Since the introduction of the patient-focused research paradigm, several quality assurance systems have been developed for monitoring and providing patient progress information (e.g., Barkham et al., 2001; Kordy, Hannover, \& Richard, 2001; Lambert, Hansen, \& Finch, 2001). Despite unique differences in the approach and system of each program, the universal underlying goal is the enhancement of an individual patient's treatment outcome (Beutler, 2001). In general, each approach favors continuous monitoring of patient treatment progress and providing feedback to clinicians during treatment with the goal of identifying possible treatment failures early in treatment, as research on the dose response relationship between number of session and improvement has shown that $50 \%$ of patients recover after 11 to 13 sessions, with more rapid improvement occurring in the earlier 
sessions of psychotherapy (Anderson \& Lambert, 2001; Haas, Hill, \& Lambert, 2002; Kadera, Lambert, \& Andrews, 1996). In 2001, the steering committee of the APA Division 29 taskforce (Ackerman et al.) submitted recommendations for empirically supported therapy relationships and listed the therapeutic alliance, empathy, and collaboration as demonstrably effective elements of the therapy relationship and added positive regard, feedback, and repair of alliance ruptures as promising and probably effective, regardless of therapeutic orientation. One of the recommendations made by the task force also stated the following as a way to enhance therapeutic outcome: "Practitioners are encouraged to routinely monitor patients' responses to the therapy relationship and ongoing treatment. Such monitoring leads to increased opportunities to repair alliance ruptures, to improve the relationship, to modify technical strategies, and to avoid premature termination (495)."

Believing that feedback could be used to determine the effectiveness of current treatment and assess the need for further treatment, many researchers have advocated the use of repeated assessments of patient progress over the course of treatment, and provision of feedback to therapists, supervisors, or case managers (e.g. Howard et al., 1996; Kordy et al., 2001; Lambert, Hansen, et al., 2001; Lueger, 1998). In addition, this paradigm offers the possibility to alter treatment for those patients who are not progressing at expected rates.

Patient deterioration is often compounded by the fact that the topic is rarely studied, and is frequently ignored by practicing clinicians who remain confident in their ability to judge patient treatment response, in spite of evidence that suggests that clinicians tend to fail to recognize deterioration and over-estimate improvement rates (Dew \& Riemer, 2003; Norcross, 2003). For example, Hannan et al. (2005) examined the ability of 48 therapists 
(26 trainees and 22 licensed staff at a university outpatient clinic) to predict which clients were likely to end treatment worse off than when they started treatment. Three $(.01 \%)$ of 550 clients were predicted to deteriorate, and only one of the 3 predicted to deteriorate had actually deteriorated at the end of therapy. Actual outcome data indicated that 40 clients (7.3\%) deteriorated by the end of therapy and that formal monitoring procedures were accurate in predicting $77 \%$ of these deteriorated cases. This research evidences the need for independent data to alert therapists when treatment is not having its intended effects. The results are consistent with past research on clinical versus actuarial predictions (Dawes, 1989; Grove \& Meehl, 1996; Grove et al, 2000), and support the conclusion that formal methods of monitoring client treatment response with the use of standardized measures and markers for predicting negative treatment response increases the likelihood that clinicians can take timely steps to reduce treatment failure.

The feedback-learning model in cognitive psychology suggests training is effective when feedback on success and failure of interventions is provided, much like when learning archery and using target "hits" and "misses" to guide technique (Sapyta, Reimer, \& Bickman, 2005).

This feedback information is necessary owing to the fact that experience alone, in the form of more years of training or practice, has not been shown to produce better outcomes (see Lambert \& Ogles, 2004 for a review). In contrast to level of experience, learning from experience in the form of systematic feedback may be necessary owing to the fact that clinicians often only have vague cues or markers by which to measure the success of their session-by-session interventions (Bickman, 1999). 
Patient-focused research programs have attempted to put this methodology into practice. Many of these research initiatives were described in a special issue of the Journal of Consulting and Clinical Psychology (Lambert, 2001) and in a special issue of the Journal of Clinical Psychology: In Session (Lambert, 2005). These research programs employ varying outcome measures and methods, but are generally similar in that they are seeking to routinely assess outcomes with the goal of using outcome information to inform service delivery. For example, a research program undertaken at Northwestern University, and continuing at other institutions, uses hierarchical linear modeling to estimate an expected treatment response for patients (Lueger et al., 2001). Within this program, patients are repeatedly administered the COMPASS, a battery of measures consisting of patient and therapist measures of well being, symptoms, therapeutic bond, and life functioning. Therapists are provided with 3-4 page reports following each administration of the COMPASS detailing the patient's treatment response, and including estimates of treatment outcome.

Similar to the COMPASS system, researchers in the United Kingdom have developed an outcome measure that is intended for national use. In response to a review by the U.K. Department of Health calling for routine use of outcome data to guide psychotherapy services, researchers in England developed the Clinical Outcomes in Routine Evaluation-Outcome Measure (CORE-OM). The instrument assesses four areas of patient functioning: subjective well-being, symptoms, functioning, and risk and was designed for use in a national quality assurance system (Barkham et al., 2001). Aggregated feedback based on CORE-OM results for groups of service practitioners is currently being provided to therapists in order to provide estimates of how groups of 
providers compare to normative samples (Evans, Connell, Barkham, Marshall, \& MellorClark, 2003).

The Stuttgart-Heidelberg quality assurance model (Kordy et al., 2001) is an additional outcome monitoring strategy that is underway in Germany. The model provides therapists with frequent feedback on the client's actual symptom state at any session in time. Contrary to other feedback systems, the feedback is not referenced to an expected course of treatment, but instead is based on a "random walk" statistical model. This model suggests that the presence of significant dysfunction at any moment in time indicates a client should continue in treatment while remediation of symptoms at any session in treatment indicates discharge or a stepped-down level of care should be enacted. Percevic (2002, as cited in Percevic, Lambert, \& Kordy, 2004) provided feedback on present symptom level to a randomly selected subset of 218 patients and withheld feedback on the remaining 372 patients. Results indicated that feedback decreased treatment length, with patients in the feedback condition achieving clinically significant improvement and leaving treatment within 46 days, while patients in the no feedback group achieved a similar status in 57 days.

The final development necessary for researchers to predict outcome is the relationship between initial level of severity and early progress in therapy. Using large data sets consisting of repeated measures of patient progress, Brown and Lambert (1998) were able to detect predictors of final outcome. They found that the initial level of severity combined with early change, defined as pretreatment through session three, was a formidable predictor of total change, accounting for $40 \%$ of the variance in final outcome status. Additionally, the results of their analysis suggested that patients with severe levels 
of distress required more treatment sessions to recover, or reach clinical significance. Change is considered clinically significant when a client's score falls into the nonclinical range of functioning, or below a score of 64 on the OQ-45 (Lambert et al., 2006).

To integrate the dose-response model, the relationship between severity level and early progress in therapy, and the operational definitions of reliable and clinically significant change, Lambert (1998) developed algorithms. He theorized these algorithms could be used to predict the likely outcome of a patient, in addition to identifying patients who depart from therapy prior to receiving therapeutic benefit, or those who are at risk of experiencing a negative treatment outcome. Using this information, a patient's level of distress is located in a matrix representing the functional or dysfunctional range of symptomatology, immediately prior to each session. To account for some of the instability that may typically occur in a patient's progress during the course of therapy, the algorithms vary somewhat as a function of the number of sessions a patient has received. For example, a patient who has worsened at session three may not engender the same concern as a patient who has responded similarly after nine sessions of treatment.

In theory, the algorithms developed by Lambert (1998) can be used to generate feedback about a patient's progress for each session as only two data points are required: a patient's level of severity at intake and a change score reflecting the difference between the session of interest and the initial level of severity prior to treatment. Believing that feedback could be used to determine the effectiveness of current treatment and the need for further treatment, many researchers have advocated the use of repeated assessments of patient progress over the course of treatment and provision of feedback to therapists, supervisors, or case managers (e.g. Howard et al., 1996; Kordy et al., 2001; Lambert, 
Hansen et al., 2001; Lueger, 1998). In addition, this paradigm offers the possibility to alter treatment for those patients who are not progressing at expected rates.

In developing the RCI, Jacobson and Truax (1991) effectively answered the question, what is the probability of the observed change occurring in the distribution of difference scores, assuming that no actual change in the patient has occurred. Using this methodology, the authors were able to designate those change scores that rarely occur $(\mathrm{p}<$ .05) without actual change. Their operational definition of clinical significance helped to assign meaning to the posttest scores of patients. Patients whose posttest scores are indistinguishable from scores of the functional population are considered recovered, provided that the change in scores from pretest to posttest is statistically reliable.

Whereas the reliable change index (RCI) formula, developed by Jacobson and Truax, (1991) addressed the chance fluctuations that occur in an assessment instrument, clinical significance established a definition of meaningful change. Combined, they have provided a systematic method to determine the clinical meaningfulness of individual patient improvement.

Among patient focused research initiatives, Lambert and colleagues have an ongoing research program aimed a reducing treatment failure by providing therapists and/or patients with weekly progress feedback (see special issue of Journal of Clinical Psychology: In Session; Lambert, 2005). The feedback system is based on a set of algorithms for identifying potential treatment failures. The accuracy of the algorithms was reported by Lambert, Whipple, Bishop, et al. (2002) as well as Speilman, Masters, and Lambert, (2006). The algorithms used information regarding the dose response relationship, initial level of severity, and typical patient response patterns to create decision 
rules for identifying patients who are not improving as expected from psychotherapy. The algorithms function by using two data points, the client's initial level of severity and severity at the session of interest, to place the client within an expected response category at the session of interest. Based on the algorithms, the client is placed within one of four color-coded feedback conditions that have corresponding messages regarding the patient's level of progress and expected outcome. Clients who are progressing as expected are designated as "On Track" (OT) and therapists are given feedback suggesting that therapy is progressing as expected and the client is likely to have a good outcome from psychotherapy. Clients who are not progressing and in fact deteriorating are designated as "Not On Track" (NOT) and therapists are advised that changes in the ongoing treatment may be warranted.

Previous Findings from the Current Line of Research

To determine the effects of providing feedback to therapists, Lambert, Whipple, et al. (2001) provided feedback to therapists of patients who were randomly assigned to treatment (feedback) or treatment as usual control (TAU) groups. TAU or feedback assignments were made within therapist blocks, so that each therapist saw both types of cases in approximately equal amounts. Feedback consisted of graphs accompanied by color-coded progress markers corresponding to a message describing a patient's progress. Lambert and colleagues (2001) focused on the proportion of patients obtained from a university counseling center who did not meet expected levels of progress, as determined by the decision rules (Lambert,1998). Specifically, they hypothesized that these identified patients representing the treatment (feedback) condition would experience better outcomes than those similarly identified patients in the TAU control condition. After controlling for 
initial severity, the results of their study suggested that non-responding patients in the experimental condition (feedback) reported levels of improvement that were found to be statistically significantly different (more healthy) from the TAU control condition.

Of more pertinence to the current focus on deteriorating or non-responding patients, results of a replication study (Lambert, Whipple, Vermeersch et al., 2002) confirmed the main finding of the original study; feedback to therapists treating NOT (signal-alarm) patients resulted in better outcomes than similar patients treated by the same therapists who did not receive feedback.

Despite finding statistically significant and clinically meaningful differences favoring the feedback condition the effects of feedback were not so substantial as to affect all clients and many experimental group (feedback) clients remained disturbed upon termination from treatment. After reviewing the problem solving literature in medicine, Whipple et al., (2003) created an intervention strategy involving assessment and decision trees. This type of intervention had been used in medicine primarily for the purpose of managing medication dosage, diagnosis, and treatment method. In a review of 65 studies on the effects of decision support systems, Hunt, Haynes, Hanna, and Smith (1998) reported that $43(66 \%)$ of the studies, found at least some benefit. Six (43\%) of the 14 studies provided documentation for improved patient outcome with the use of a decision tree for problem solving.

Whipple et al.(2003) identified three client variables that could be measured and provided to therapists: alliance with the therapist, readiness to change, and degree of social supports The decision tree that was provided to therapists encouraged problem solving through examination of alliance ratings, motivation, social support, diagnostic 
reformulation, and referral for medication consultation, in that order. This intervention also included suggested interventions for specific problems that were identified. The intervention was placed in a user manual and given the title of Clinical Support Tools Manual (CST). In a replication of the earlier progress feedback studies, the CST intervention was added as an additional intervention, targeting those clients who still did not respond effectively to the therapist feedback intervention. Results indicated that a strengthened feedback condition in which therapists of clients predicted to have a poor outcome were given CSTs, did have an incremental effect for improving patient outcome for clients predicted to be treatment failures. The combined intervention of providing both progress feedback and CST feedback reduced deterioration rates among those identified as Not-On-Track from $21 \%$ to $8 \%$ and increased success rates from $21 \%$ to $50 \%$.

\section{Clinical Support Tools}

Clinical support tools are an empirically based problem solving strategy aimed at directing therapists' attention to certain factors known to be important in psychotherapy, and are arranged hierarchically in a decision tree (Whipple et al., 2003). These factors, which may or may not be of particular concern in each specific case, include the therapeutic relationship, patient motivation, the patient's social support network, perfectionism, reevaluating diagnostic formulations, and an indication for medication referral. Brief measures were provided to quantitatively assess the first four levels of the decision tree (i.e., relationship, motivation, and social support) and possible interventions based on these assessments are recommended to therapists.

Clinical support tools have the possibility of assisting both the clinician and case manager as they attempt to pinpoint particular problems that may need a solution in 
patients whose progress is in doubt. With such cases a "stepped-care" approach, in which the failing patient is stepped up or down to more or less intensive treatment, may be indicated. Otherwise, the clinician may act alone, and in the case of the failing patient, act more out of resignation than objective judgment (Schulte-Bahrenberg \& Schulte, 1991, 1993). The case manager on the other hand, does not typically know the patient and is in need of norm-based assessments in order to determine how to support or enhance the practitioner's treatment efforts.

Over the last 25 years, comparable methods have been utilized in medical research and practice to manage interventions related to drug dosages, diagnosis, preventative care, and patient outcomes. These interventions are often employed in a stepwise approach that assists physicians in decision-making and provides recommendations to improve the quality of patient healthcare (Hunt et al., 1998). Of the 65 studies reviewed by Hunt and colleagues on the effects of decision support systems on clinician performance $43(66 \%)$ found at least some benefit. These included $9(60 \%)$ of 15 studies on drug dosages, $1(20 \%)$ of 5 on diagnostic aids, $14(74 \%)$ of 19 on preventative care systems, and $6(43 \%)$ on the 14 studies that documented enhanced patient outcome. Within the approach taken by Lambert and colleagues the original CSTs intervention have consisted of three constructs: Alliance, motivation, and perceived social support. The fourth construct, described below, is an addition to the current study.

Therapeutic alliance. Empirical support for the importance of the therapeutic relationship in outcome spans well over four decades hundreds of research articles. It is one of the most widely studied constructs, with a search for "alliance", "therapeutic alliance" and "working alliance" yielding over two thousand hits (Horvath, 2001). Its 
value was first explored by Freud in his descriptions of transferential relationships between client and therapist and then re-conceptualized in pantheoretical terms in light of awareness of the importance of the alliance across theoretical orientations (Horvath, 2001). It is often acknowledged as the primary necessary curative factor in successful psychotherapy. Of specific interest is the correlation between outcome and early ratings of the therapeutic relationship. Numerous studies have demonstrated that patient ratings of the therapeutic relationship between the third and fifth sessions are significant and possibly the best predictors of treatment outcome (Lambert \& Bergin, 1994). These data suggest that when a patient shows a negative treatment response, therapists need to be particularly alert to the patient's level of comfort and satisfaction with the therapeutic relationship (Hill, NuttWilliams, Heaton, Thompson, \& Rhoads, 1996).

The therapeutic alliance is frequently conceptualized as having three components: tasks, goals, and bonds (Bordin, 1979). The tasks consist of the actual work of therapy and might include, for example, homework that is completed in session, or a two-chair exercise intended to resolve unfinished business. Goals consist of the objectives the client and therapist have for the therapy course. This might include a goal to be more independent of mother or to take a flight in an airplane for a phobic person. Finally, the bonds of the therapeutic alliance consist of the positive attachment that occurs between client and therapist. This is frequently characterized by feelings of warmth, trust, and acceptance.

De Roten et al. (2004) examined the relationship between patient ratings of the therapeutic alliance and final outcome and identified two patterns of alliance development: a stable alliance that remains at nearly the same level over time, and a linear growth pattern 
that reveals improvement of alliance over time. These alliance patterns were predictive of symptom improvement and social adjustment at termination.

In a review of the relationship between alliance and outcome, Horvath combined data from two previous meta-analyses (Horvath \& Symonds, 1991; Martin, Garske, \& Davis, 2000) with 10 more recent published studies (i.e. 1997-2000) and found an effect size of .21 between alliance and outcome (Horvath, 2001). Horvath notes that when this is compared with the effect size of .39 for overall treatment effect of psychotherapy (Smith \& Glass, 1977), and when treatment components are assumed to be quasi-independent, the alliance accounts for approximately half of the positive effect derived from psychotherapy.

Motivation for treatment. Deviations from an expected treatment response may also reflect the possibility that a patient has entered psychotherapy with a less than favorable motivation for seeking treatment. Furthermore, a sizable percentage of clients continue to drop out of treatment prematurely, fail to comply with their therapeutic regimen, and encounter difficulty in maintaining improvements affected by the therapeutic process (Garfield \& Bergin, 1994; Mash \& Hunsley, 1993). By matching therapeutic techniques with a patient's motivation for treatment, Pelletier suggested that final outcomes and treatment compliance could be improved. Deci and Ryan (1985) distinguished between different types of motivation and presented clear hypotheses regarding the therapeutic conditions predicted to hinder or facilitate clients' motivation to change, outlined various consequences that are associated with different types of motivation, and addressed the issue of internalization, the process by which therapeutic changes that were initially reinforced by external sources (e.g., the therapist) become integrated within the individual to form a permanent part of his or her character. Deci and Ryan further 
suggested that motivation is a dynamic concept and that a client having one motivation type at a particular point in therapy may change to a different type depending on situational influences. Based on a review of research, (Gordon, 1976; Kanfer \& Grimm, 1978; Mendonca \& Brehm 1983; Patterson \& Forgatch, 1985; Miller, Benefield, \& Tonigan, 1993) and their own findings, Pelletier, Tuson, and Haddad (1997) concluded that when clients perceived their motivation for therapy to be more self-determined, they were more likely to experience less tension, less distraction, and more positive moods during therapy; they considered therapy to be more important, reported higher levels of satisfaction with therapy, and had stronger intentions of continuing in therapy. When clients perceived their motivation to be less self-determined, they showed the opposite pattern of associations. Similarly, Drum and Baron (1998) found that final outcome could be predicted and enhanced by assessing a patient's readiness to change and matching it with appropriate therapeutic interventions.

Prochaska and Norcross (2003) propose five distinct stages representing varying degrees of readiness for change in therapy; Precontemplation, Contemplation, Preparation, Action, and Maintenance. Efforts to match therapy techniques, even therapeutic orientations, with the unique readiness for change that clients exhibit are proposed to be helpful. For example, for clients in the Precontemplation stage of change, motivational interviewing is recommended, while clients in the Contemplation stage might respond best to Rational-Emotive Behavior Therapy or existential therapy. Specific application of the processes of change to the unique stages of change has also been suggested by Prochaska $\&$ DiClemente (1992). They further state that using consciousness-raising interventions (observations, interpretations, etc.) and dramatic relief (e.g. psychodrama or Gestalt two- 
chair to raise emotions) are helpful in guiding clients from precontemplation to contemplation stages. Petrocelli (2002) also suggests that providing the client with feedback on their stage of change assessment is helpful in intensifying positive change.

Social support. Whipple et al. (2003) noted that time spent in therapy is but a very small fraction of the time in an individual's life with clients being dependent on their social network as a central means of coping with stressors. Conservative estimates indicate patients spend less than $1 \%$ of their waking hours in psychotherapy sessions. In a review of more than 100 published studies, Lambert and Barley (2001; Lambert, 1992) estimated the size of impact various predictors made on outcome and estimated that extratherapeutic factors are responsible for $40 \%$ of the change in psychotherapy patients. These factors are separate from therapy techniques (estimated at 15\%), common factors (30\%) and expectancy/placebo effects (15\%) and consist of all interaction the client has outside of therapy.

Consequently, patients predicted to have a poor treatment outcome may not have adequate social support networks to initiate or maintain gains acquired in therapy. Furthermore, the adequacy of social support is directly related to a patient's reported severity of symptoms and can mediate stressful life events and the development of psychological symptoms (Monroe, Imhoff, Wise, \& Harris, 1983). For such patients, therapists may need to identify what social support resources a patient already has in their current situation or community that can be put to use to achieve a better treatment outcome (Bankoff \& Howard, 1992). Despite the fact that social supports are an extra-therapeutic factor it is possible for psychotherapists to intervene in these systems and change their impact on clients. 
Perfectionism Inventory. The Perfectionism Inventory is an instrument that was added to the current study, in an effort to intensify the CST intervention effects. This measure was added after a thorough review of the literature regarding the presence (or absence) of those aspects that are most likely to lead to a poor outcome in psychotherapy. According to a report, based on a large sample of college students who were in counseling, over $26 \%$ of the women and $21 \%$ of the men stated that perfectionism was "quite distressing" to them (Research Consortium of Counseling and Psychological Services in Higher Education, 1993). Research on perfectionism supports the idea that perfectionism is related to psychopathology and presenting concerns as well as therapeutic outcome. Blatt and Zuroff (2002) suggest that pretreatment level of perfectionism affects therapeutic outcome by "disrupting the patients' quality of interpersonal relations both in the treatment process and in social relationships outside of treatment." Hartley and Strupp (1983) found that patients' contributions to the therapeutic alliance mediated the effect of pretreatment perfectionism on treatment outcome at termination.

Johnson and Slaney (1996) found that perfectionists had higher standards and order than non-perfectionists, while Rice and Preusser (2002) found the core dimension of "concern about making mistakes" to be related to perfectionism, as well as "hypersensitivity about making mistakes." Self-defeating attitudes are seen in persons who suffer from depression (Burns, 1980; Hewitt \& Dyck 1986; Blatt, 1995; Frost, Marten, Lahart, \& Roseblate, 1990; Hewitt \& Flett, 1991a; Pacht, 1984; Preusser, Rice, \& Ashby, 1994; Rice, Ashby \& Slaney, 1998), anxiety (Burns, 1980, Flett, Hewitt, \& Dyck, 1989; Hamachek, 1978; Hewitt \& Flett, 1991a; Hewitt \& Flett, 1991b; Pacht, 1984), OCPD (Johnson \& Slaney, 1996), eating disorders (Cash \& Szymanski, 1995; Cooper, Cooper, \& 
Fairburn, 1985; Minarik \& Ahrens, 1996; Mizes, 1988), suicide (Burns, 1980; Hewitt, Flett, \& Turnbull-Donovan, 1992), chemical use and abuse (Nerviano \& Gross, 1983; Pacht, 1984), chronic pain (Liebman, 1978; Van Houdenhove, 1986), and coronary heart disease (Pacht, 1984; Smith \& Brehm, 1981).

Burns's idea that perfectionism has important implications for interpersonal relationships has been incorporated into numerous scales (Burns 1980; Frost et al., 1990; Hewitt \& Flett, 1991b; Horney, 1950; Pacht, 1984) and has been supported by research conducted by others (Zuroff et al., 2000). Furthermore, Burns specifically suggested that perfectionists have disturbed personal relationships; a "disclosure phobia" based on "their fear of appearing foolish or inadequate." This is evidenced by the fact that relationship issues are frequently brought to counseling (Research Consortium of Counseling and Psychological Services in Higher Education, 1994). Burns also implied that perfectionists may have problems in the counseling relationship where disclosure is most often a prerequisite to effective therapeutic interaction.

As Johnson and Slaney (1996) have suggested that it is first important to determine whether the client's perfectionism is maladaptive or adaptive, the PI assesses both maladaptive perfectionism as it relates to interference with the therapeutic process, as well as adaptive perfectionism. The PI was developed by Hill and colleagues (2004) as a way of combing two previous measures of perfectionism (Frost et al., 1990; Hewitt \& Flett, 1991b) into one scale that captures domains from both previous scales.

A limitation of the Whipple, et al. study was the failure to assign clients to the CST condition on a random basis and the failure to administer CSTs to the TAU control group in order to assess for the effects of each individual CST measure( i.e., does simply 
completing the measures enhance outcome?). While this design was an important test of the effects of using CSTs in a practical, routine setting in which randomization was to the CST group did not occur, the lack of randomization made it impossible to determine if clients in the CST condition had greater improvement as a result of CSTs or as a result of selection bias. For example, it is possible that therapists chose to use the CSTs with clients who they thought would enjoy completing the CSTs, or those clients whom the therapist believed they had a good relationship with, and avoided giving them when they thought the client would balk at the CSTs (less compliant cases, more negative cases). The results were then compared to the clients who were not selected by their therapist to complete the CSTs.

The need to enhance the effects of feedback also inspired an additional strategy aimed at providing feedback directly to clients. Hawkins et al. (2004) looked at the effect of providing both therapists and clients with ongoing feedback regarding their progress in psychotherapy in an outpatient community setting. The results of Hawkins's study suggest that giving clients feedback, in addition to therapists, improved outcome for clients who were predicted to have a poor treatment response (NOT) as well as for clients who were on track (OT). Specifically, those clients in the treatment condition who received feedback and whose therapists received feedback had better outcomes on average than clients in the therapist-only feedback condition or the TAU (No progress feedback) condition.

The most recent published study in this ongoing line of research, was conducted by Harmon, et al., (2007) and patterned after both Hawkins, et al., (2004) and Whipple, et al., (2003). In this extension of the research the benefits of using CSTs and providing feedback to clients and therapists while remedying methodological shortcomings in earlier analyses was undertaken. Harmon's study improved upon Whipple's research by randomly 
assigning clients to the CST condition. By adding random assignment to the CST condition, this study provided an important controlled test of the effects of CSTs on outcome for clients predicted to have a poor treatment response. An additional goal of Harmon's study was to investigate the utility of the CSTs as pre-treatment predictors of outcome. Having all clients complete the CSTs at intake was beneficial in establishing a baseline measure for client responses on the CSTs and enabled comparisons between the NOT and OT groups and also in investigating where the significant differences lie with regard to the three CST domains when comparing NOT to OT groups.

Results from Harmon's study suggested that for social supports (the MSPSS), NOT clients had significantly lower scores on the domain of friends and significant others at time of intake compared to OT clients. The NOT group also had significantly lower scores on all domains (family, friends, and significant other) at the time of signal compared to the OT group scores at intake and the control group scores. The OT, the NOT group, and both groups combined (NOT and OT) also had significantly lower scores on all domains at the time of intake compared to the control group. For the HAQ-II (Luborsky et al., 1996), the items assessing primarily the collaboration on tasks within the session by the client and the therapist and in-session cooperation has been the area where the main differences have been found between the two groups (OT and NOT). Finally, results suggest that for the Stages of Change Scale (SCS), there were no individual item or overall differences between the NOT and OT groups or between clients and a student-control group, suggesting that the SCS was not contributing to the strength of the CST intervention. This is not to say that a client's motivation is not correlated with outcome, rather, the SCS measure was not an adequate tool for the population in the current research setting: The 
SCS was designed to assess readiness for change with a specific behavior in mind and is, therefore, better suited for assessment in populations that are dealing with substance abuse, sexual addictions, and other more specific domains of maladaptive behaviors. A new scale, the Client Motivation for Therapy Scale-Revised (CMOTS-R), was adopted by Harmon, et al. as a hypothesized solution for the limitations to the SCS. This scale is discussed in the instruments section of the current proposal. Harmon also employed an experimental group replicating Hawkins's Patient/Therapist feedback intervention condition, but was unable to replicate the findings of an added effect for direct standardized feedback to clients.

The differences between Hawkin's study (suggesting support for client/therapist feedback) and the Harmon study (lack of replication for client/therapist feedback) is the setting in which each study was conducted. The Hawkins study was conducted in an outpatient clinic, as opposed to the Harmon study, which was conducted in a college counseling center. As a result of the client population differences, one of the major differences regarding factors affecting treatment responsiveness was the higher initial distress level of the clients at the outpatient clinic, providing more room for improvement during treatment.

\section{Time Limitations}

A general limitation of all of the previous studies is an issue of not giving progress feedback (OQ-45 change) to therapists and/or clients regarding the clients' progress in therapy until the next scheduled appointment, usually a week after the data are collected. Feedback was delayed for a week, as it was necessary to administer the measures, enter the clients' data, score it, and then create paper-based feedback for the therapist and client. 
Consequentially, this also delayed the dissemination of the CST measures that the clients were asked to complete at time of initial signal.

\section{Current Study}

A major goal of the present study was to replicate the differential effects of using modified CSTs on client outcome by including an assessment of perfectionism as it relates to its hindering effects on the therapeutic process. Support for the inclusion of a perfectionism measure is addressed in the methods/measures section of the current dissertation. Another major goal of the present study was to ameliorate the constraint of delayed feedback by providing Immediate Electronic Feedback (IEF) and comparing it with archival data in which feedback had been delayed by one week. The final goal of this study was to assess for a differential benefit of providing both clients and therapists with IEF regarding their progress in therapy, as compared to IEF for the therapist only. This aspect of the study also sought to replicate the client feedback studies of Hawkins, et al., (2004) and Harmon et al., (2007)

The following hypotheses were tested (see appendix A): The following hypotheses were tested: (1) NOT clients whose therapists received OQ-45 IEF will have better outcomes compared to NOT clients whose therapist received week-delayed progress feedback, (data for the latter group were archival), (2) NOT clients whose therapists received OQ-45 IEF or week-delayed feedback will have better outcomes compared to NOT clients in the TAU (no feedback) condition (data for the latter group were archival), (3) the OQ-45 IEF experimental group in which both NOT clients and their therapists received feedback will have better outcomes than the experimental IEF group in which only therapists received feedback on client progress, (4) the OQ-45 IEF experimental group 
in which both NOT clients and their therapists received feedback will have better outcomes than the NOT TAU condition (data for the TAU condition were archival), and (5) NOT clients whose therapists received the CST feedback will fare better than clients whose therapists did not receive the CST feedback. 


\section{Chapter 3: Method}

\section{Participants}

A total of 1101 adult clients seeking treatment for personal problems at a large university counseling center were invited to participate as part of the center's intake procedure. Seventeen percent $(n=192)$ declined to participate at intake and one client requested to be removed mid-study, reporting he did not want to complete the CST measures. Two groups of clients $(n=1445$ from studies 1 thru 3 , and $n=1373$ from study 4) from the prior four feedback studies were used as comparison groups for feedback type (No Feedback, Therapist Feedback, Client/Therapist feedback) and feedback timing groups (Treatment as Usual, Week-Delayed, and Immediate Electronic Feedback). (1. Lambert et al., 2001; 2, Lambert, Whipple, Vermeersch, et al., 2002; 3. Whipple et al., 2003; 4. Harmon et al., 2007). This yielded a total sample of 3919 clients.

For the Immediate Electronic Feedback group, 118 clients did not return for a second session and all returning clients completed the outcome measure more than once. The Immediate Electronic Feedback sample ranged in age from 19 to 49 years $(M=24.25$, $S D=3.29$ ) and was 57.5\% female, 42.5\% male, 83\% Caucasian, 7\% Hispanic, $2.5 \%$ Asian, 1\% Pacific Islander, 1\% African American, 1\% Native American, and 4.5\% other ethnicity. Clients in the counseling center are routinely diagnosed by the treating clinician and no attempt was made to have clients undergo structured diagnostic interviews. Clients in the counseling center are routinely diagnosed by the treating clinician and no attempt was made to have clients undergo structured diagnostic interviews. Seventy-seven percent of the clients were diagnosed, while the remaining $23 \%$ had their diagnosis deferred at intake and never had a formal diagnosis recorded in the database. Because the reliability of these 
diagnoses is unknown, they are only provided for descriptive purposes. Formal clinical diagnoses included 22\% mood disorder, 5\% adjustment disorder, 9\% anxiety disorder, 3\% eating disorder, $28 \%$ received a $\mathrm{V}$-code diagnosis, with the rest of the participants $(33 \%)$ receiving a variety of other diagnoses.

The archival sample ranged in age from 17 to 58 years $(M=22.65, S D=3.68)$ and was $64 \%$ female, $36 \%$ male, $88 \%$ Caucasian, 5\% Hispanic, 1\% Asian, 2\% Pacific Islander, 1\% African American, 1\% Native American, and 2\% other ethnicity. Seventy-one percent of the clients were diagnosed, while the remaining $29 \%$ had their diagnosis deferred at intake and never had a formal diagnosis recorded in the database. Because the reliability of these diagnoses is unknown, they are only provided for descriptive purposes. Formal clinical diagnoses included $22 \%$ mood disorder, $10 \%$ adjustment disorder, $9 \%$ anxiety disorder, 4\% eating disorder, 24\% received a V-code diagnosis, with the rest of the participants (31\%) receiving a variety of other diagnoses.

Of the total sample of 3919 clients, 416 clients did not return for a second session and 53 clients did not complete the outcome measure more than one time. All clients who consented to the study were included in the data analysis with last observation carried forward procedures used for the 469 clients with a single observation on the outcome measure with the intent of providing a conservative estimate of the impact of the experimental treatment in a naturalistic setting. This procedure was not followed with signal-alarm cases as it is necessary for clients to attend at least 3 sessions in order to receive a feedback signal (or otherwise) message, and upon receiving their fist signal, must attend two additional sessions to assess for impact of CST feedback to the therapist on treatment. 
Therapists were 74 counseling center staff consisting of 28 doctoral level psychologists and 46 doctoral students in training (including interns). Therapists had a variety of treatment orientations, with most subscribing to an integration of two or more theoretical systems. The most commonly declared orientations were cognitive/behavioral (42\%), psychodynamic/interpersonal (19\%), humanistic/existential (16\%), behavioral $(6 \%)$, or other $(16 \%)$. Therapists were either salaried faculty of the university or students in training, and did not receive a direct fee for services provided.

\section{Measures}

Outcome Questionnaire-45. The OQ-45 (OQ-45; Lambert, et al., 2004) is a 45item, self-report measure of psychological functioning. Items are measured on a 5 point Likert scale: $0=$ never, $1=$ rarely, $2=$ sometimes, $3=$ frequently, $4=$ almost always. The range of scores possible on the OQ-45 is 0 to 180 , with higher scores reflecting more severe distress. The OQ-45 assesses three broad domains of patient functioning: (1) subjective discomfort, (2) interpersonal relationships, and (3) social role performance. The 45 items encompass many items that are characteristic of persons with a psychological disorder, but also includes 9 items that target positive functioning and are reverse scored. This questionnaire was recently made available as a software application-OQ-Analyst, making it possible to deliver feedback with the increased efficiency and immediacy.

Previous studies have provided information about the psychometric properties of the OQ-45. The internal consistency of the OQ-45 was .93, and the three-week test-retest reliability was .84 (Lambert, et al., 2004). Concurrent validity of the OQ-45 has been demonstrated through correlates with the Symptom Checklist-90-R ( $r=.78$; Derogatis, 1983), Beck Depression Inventory ( $r=.80$; Beck, Ward, Mendelson, Mock, \& Erbaugh, 
1961), Zung Depression Scale ( $r=.88$; Zung, 1971), Taylor Manifest Anxiety Scale $(r=$ .86; Taylor, 1953), State-Trait Anxiety Inventory (State Anxiety = .64; Trait Anxiety $r=$ .80; Spielberger, 1983; Spielberger, Gorsuch, \& Lushene, 1970), Inventory of Interpersonal Problems ( $r=.53$; Horowitz, Rosenberg, Baer, Ureno, \& Villasenor, 1988) and Social Adjustment Scale $(r=.65$; Wiessman $\&$ Bothwell, 1976). The development of norms for the OQ-45 was based on data collected both locally and nationally (Lambert et al., 1996; Umphress, Lambert, Smart, Barlow, \& Clouse, 1997).

Clinical Support Tools measures. The CSTs consist of four measures: the Client Motivation for Therapy Scale-Shortened Version (CMOTS-S; Pelletier, Tuson, \& Haddad, 1997), the Revised Helping Alliance Questionnaire (HAq-II; Luborsky et al., 1996), the Multidimensional Scale of Perceived Social Support (MSPSS; Zimet, Dahlern, Zimet, \& Farley, 1988), and the Perfectionism Inventory (PI) (Hill et al., 2004). These Measures are attached in Appendix E.

The HAq-II (Luborsky et al., 1996) was used to assess the therapeutic relationship. The HAq-II consists of 19 items each rated on a six point Likert scale. The HAq-II measures common characteristics that are thought to be indicative of a positive therapeutic relationship. Below average therapeutic alliance was signified by a score that was one or more standard deviations below the mean. A modified approach to the use of the HAq-II was, in addition to providing feedback regarding the overall score on the signal client's HAq-II, any single item that was endorsed in a negative manner regarding the therapeutic relationship were included in the feedback given to the therapist whose client was in the NOT CST feedback group in order to strengthen the intervention of the HAq-II. 
The CMOTS-R was used to assess the client's motivation to engage in therapy. Given the previously addressed issues with the SCS, which is a 32-item scale, it was replaced by this12-item scale that assessed a client's general motivation to enter therapy, rather than their readiness to change a specific behavior. This 12-item scale, which was created for the current study, is a shortened version of the Client Motivation for Therapy Scale (CMOTS). The original scale is a 24 -item scale that measures six different types of motivation. Those subscales deemed most able to assess differences in clients' motivation for therapy levels were included in the shortened version; intrinsic motivation was hypothesized to be associated with more positive outcomes, while external regulation and amotivation were hypothesized to be associated with less positive therapeutic outcomes (Pelletier, Tuson, Najwa, \& Haddad, 1997). This measure is attached in. The domain with the highest score was identified as the client's current type of motivation. Those falling in the amotivation or external regulation domain were identified as having motivation for seeking treatment that was hypothesized to be related to unfavorable outcomes.

The MSPSS was used to assess the client's level of support from friends, family, and significant others. The MSPSS consists of four questions for each of the three areas of social support (friends, family, and significant other) scored on a 7 point Likert scale. For purposes of this study, clients who scored one standard deviation or more below the mean were determined to have below average social support.

The Perfectionism Inventory was the instrument added to the current study, in an effort to intensify the CST intervention effects. The purpose of the perfectionism scale was to assess for the following domains that were hypothesized to capture the construct of conscientious perfectionism and self-evaluative perfectionism: The conscientious domain 
includes the following subscales: (1) High standards for others (2) Organization (3) Striving for Excellence and (4) Planfulness. The self-evaluative perfectionism domain includes the following subscales: (1) Parental pressure (2) Concern over mistakes (3) Rumination and (4) Need for approval. The first four scales are used to assess adaptive perfectionism. The remaining scales are used to assess maladaptive perfectionism. For purposes of this study, clients who scored 1.25 standard deviations or more above the given sample mean for each subscale and for the total score were determined to have above average perfectionism on the respective subscale or overall domain.

\section{OQ-45 Feedback.}

Feedback to the therapist consisted of an electronic progress graph indicating the client's status, as well as a specific feedback message corresponding to the client's progress, as measured by the OQ-45. The electronic feedback also included information and alerted the therapist to crucial item responses to the OQ-45. For example, if a client endorsed "sometimes" to the question assessing suicidality this item, which is considered to be one of four critical items, would appear in RED on the electronic feedback. Therapists were encouraged to use this feedback to assist them in treating clients, but their actions were not reviewed or managed in the study. They treated clients in accordance with their best judgment. As a fidelity check, a periodic email was sent, asking therapists, "over the last week, for what percentage of clients did you view OQ feedback?"

Feedback to clients consisted of the same color-coded progress graph as provided to therapists. The feedback messages, however, were modified to include a blend of positive and negative language with the intent of avoiding content that might be discouraging to the client (Hawkins et al., 2004). The feedback consisted of (1) client's current self-reported 
level of distress according to the OQ-45, (2) progress since intake, and (3) prognosis given current progress. Additionally, clients who were designated as Not-On-Track for a good outcome were encouraged to discuss personal concerns about their progress, ideas for therapy modification, and goals for therapy with their therapist. The client's feedback was printed out at the receptionist's desk and given to the client on the way to their session, with the instruction to review their progress information in the company of their therapist. The therapist was instructed to invite the client to read the feedback information and answer any questions/concerns the client had regarding the feedback. Therapists were also encouraged to discuss the feedback with their clients; again, their actions were not reviewed or managed in the study, thus more closely approximating applications in routine care that a clinical trial. An example of a progress graph and accompanying feedback messages for the clients, along with therapist messages, are presented in Appendix C. Clinical Support Tools Feedback and Decision Tree.

When the decision rules identified a client as Not-On-Track (red or yellow warning), clients were sent an email, requesting the following: "Dear [Client], Please click on the link below and complete the questionnaire prior to your next scheduled appointment so that your therapist may better help you." The questionnaires were administered only once to each NOT client, whether they signaled once or multiple times. The measures were scored and feedback was delivered to the therapist's work mailbox on the morning of the client's next session. Clinical Support Tools feedback consisted of a copy of the decision tree and a report of the client's scores referenced to the norms for the measure, with intervention suggestions at the bottom of the feedback, targeting the CST domains that were weak or needed attention. For example, if a client's social support was met the cut- 
off for being problematic, suggestions as to how the therapist could help the client build their social support, were included at the bottom of the CST feedback. Additionally, the feedback directed the therapist to review a copy of the CST Manual (Lambert et al., 2006), an organized compilation of therapeutic intervention suggestions culled from the psychotherapy research literature for improving therapeutic alliance, motivation for therapy, social support, and perfectionism (contact the second author for a copy of the manual). The Clinical Support Tools decision tree and feedback intervention was designed to guide the therapist through a hierarchy of decisions to improve therapy response by specifically targeting the therapeutic relationship, motivation for therapy, social support, perfectionism, and/or need for a medication referral. For example, if a Not-On-Track client was given the clinical support measures and scored below average on the helping alliance measure, the therapist notified, as well as given feedback regarding the specific items that were less than "neutral" on the Likert scale. They were also encouraged to examine the list of suggestions for strengthening the relationship (e.g., discuss the client's ratings of the relationship, explore relationship ruptures). If the client's alliance rating was not below average the therapist would proceed to evaluation of the client's motivation, and so forth.

Therapist use of the suggested clinical support interventions was not monitored; once feedback was provided, therapists used their clinical judgment to decide how to use the CSTs to maximize therapy response. This procedure was used in order to maximize the external validity of the Clinical Support Tool feedback intervention, but at the cost of some internal validity.

Follow-up was conducted to see that the clients did, indeed attend the session where CST feedback was given to their therapist. If a client "no showed" to a session, attempts 
were made to re-deliver the CST feedback to the therapist prior to the next scheduled appointment. Therefore, feedback was still able to be delivered to these clients upon the visit following the initial signal-alarm. If feedback was unable to be delivered to the session immediately following the signal session, thereby diluting or negating the possible effects of the CST feedback intervention, they were removed from the final Clinical Support Tools feedback analysis.

\section{Procedure}

Over a 16 month period, upon presentation at the center and consent to participate, clients were randomly assigned to one of two treatment conditions: a therapist only feedback condition, and a client/therapist feedback condition. To test for the effects of the use of clinical support tools on client outcome, the first randomization was followed by a second randomization for all clients whose progress indicated they were NOT. Clients who were NOT (had received a red or yellow warning) were divided into two groups, one group whose therapists received feedback on the clinical support tools, and one group whose therapists did not receive feedback on the clinical support tools. Thus, the second randomization occurred continuously as signal cases were identified.

In all, there were fourteen experimental groups: 1) IE Therapist only feedback $(\mathrm{OT}), 2)$ IE Therapist only feedback (NOT), 3) IE Therapist FB only (NOT) + CST , 4) IE Patient/Therapist Feedback (OT), 5) IE Patient/Therapist Feedback (NOT), 6) IE Patient/Therapist FB (NOT) + CST, 7) WD Therapist FB only (OT), 8) WD Therapist FB only (NOT), 9) WD Therapist FB only (NOT) + CST, 10) WD Patient/Therapist FB (OT), 11) WD Patient/Therapist FB (NOT), 12) WD Patient/Therapist FB (NOT) + CST, 13) TAU (OT), and 14) TAU (NOT) (see Appendix A, Figure 1.1, 1.2, and 1.3). 
The control groups for this study consisted of the Treatment As Usual (TAU) control patients from existing feedback study datasets (Lambert, Hansen et al., 2001; Lambert, Whipple, Vermeersch, et al., 2002; Whipple et al., 2003). Another archival group was used to compare the effects of Week-Delayed Feedback with the effects of data collected in the current study-Immediate Electronic Feedback.

Archival groups were utilized for two reasons. Prior studies have consistently shown that feedback to therapists improves outcome for clients predicted to leave psychotherapy with a poor outcome. Because of these positive findings the center no longer offers treatment to clients in the absence of therapist feedback and TAU is no longer available to clients. Since it was desirable for feedback interventions to be compared with TAU, archival data were needed. The decision to forgo the use of TAU maximized the number of NOT experimental conditions that could be utilized, adding statistical power for each experimental condition.

Upon presentation for treatment at the Center, and prior to each treatment session thereafter, all clients completed the OQ-45. Only those clients who receive a red/yellow signal completed the CSTs upon the advent of their initial signal. While all signal cases were given the CSTs only those clients in the CST experimental condition had feedback given to their therapist. These clients were also referred to as "signal-alarm" cases, a term used in other research aimed at quality improvement to designate patients who were at risk for a treatment failure (Kordy et al., 2001). Upkeep was performed daily to ensure that all signal alarm cases were given the CSTs immediately following their first alarm, in an effort to reduce the time (in session) it takes to deliver feedback to the therapist. As the CST intervention was not yet available as part of the OQ-Analyst software, the CST feedback 
was delayed a week, rather than two - compared to previous feedback studies where feedback was delivered. 


\section{Chapter 4: Results}

\section{Pretreatment}

Prior to testing the effectiveness of the feedback interventions, preliminary analyses were completed in order to test for pre-intervention equivalence of groups. A one-way ANOVA was conducted to assess for comparability of the mean OQ-45 scores at pretreatment for each feedback group and for each feedback timing group. Tables 1 and 2 show the means and standard deviations of the three feedback groups (Therapist Feedback, Client/Therapist Feedback, and Treatment as Usual), and three feedback timing groups (Treatment as Usual, Week-delayed feedback, and Immediate Electronic Feedback). No statistically significant between-groups differences were found for both feedback type, $\left(F_{(2,}\right.$ $2543)=2.70, p>.05)$ and feedback timing $\left(F_{(2,3919)}=1.07, p>.30\right)$. These results suggest that randomization was effective in creating groups that had similar levels of initial disturbance and that the clients in the different feedback timing groups had essentially equivalent scores at intake.

Clients whose response to treatment resulted in classification as On-Track versus Not-On-Track differed in mean intake OQ-45 score. As expected, the mean Not-On-Track initial OQ-45 score $(M=79.51, S D=19.40)$ was significantly higher than the mean score for their On-Track counterparts $(M=68.08, S D=22.70)$, suggesting that as a group, NotOn-Track clients begin therapy more disturbed than On-Track clients $\left(F_{(1,3917)}=200.19, p\right.$ $<.001)$. Further, $78.5 \%$ of clients in the NOT group began treatment in the dysfunctional range (OQ-45 $>63)$, compared to $57.5 \%$ of OT clients. As can be seen in Table 1, both OT and NOT clients had equivalent pretreatment OQ-45 scores within their assigned feedback conditions (Treatment as Usual, Client Feedback, Client/Therapist Feedback; $F_{(2,3919)}=$ 
$.298, p>.70)$, providing support for equivalence of groups at pre-treatment. Both OT and NOT clients had equivalent pretreatment OQ-45 scores within their assigned feedback timing conditions as well, (Treatment as Usual, Week-Delayed, and Immediate Electronic Feedback; $\left.F_{(2,3919)}=.270, p>.70\right)$, again providing support for equivalence of groups at pretreatment. Based on these results, it appears that randomization procedures were effective in producing equivalence on the dependent variable before the experimental manipulation occurred.

Pre-Post Changes

Table 1 shows means and standard deviations of OQ-45 pre- and post treatment scores. Paired $t$ tests were conducted to assess within-group treatment effects for the feedback groups as well as the feedback timing groups. Results indicated significant improvement for each feedback group, (Treatment as Usual: $t_{(1444)}=17.79, p<.001, d=$ .37 ; Immediate Electronic Therapist OQ-45 Feedback: $t_{(551)}=13.65, p<.001, d=.50$; Immediate Electronic Client/Therapist OQ-45 Feedback $t_{(548)}=14.48, p<.001, d=.53$ ), and each feedback timing group (Treatment as Usual: $t_{(1444)}=17.79, p<.001, d=.37$; Week-Delayed Feedback: $t_{(1372)}=25.42, p<.001, d=.57$; Immediate Electronic Feedback: $\left.{ }_{(1100)}=19.90, p<.001, d=.50\right)$.

Disregarding assignment to treatment condition, over the course of therapy, clients improved with an average change of 11.17 OQ-45 points $\left(S D=19.24 ; t_{(3918)}=36.34, \mathrm{p}<\right.$ $.001, d=.48$ ), the equivalent of complete remission of almost 3 full symptoms (e.g. moving from having headaches, feeling no interest in things, and irritation "almost always" to "never", etc.). The improvement was even larger for clients $(n=2461,62.8 \%)$ who began treatment in the dysfunctional range (OQ-45 score of 64 or above), as they improved 
by an average of 15.3 points $\left(S D=20.04 ; t_{(2461)}=37.88, \mathrm{p}<.001, d=.82\right)$. Of clients beginning treatment in the "dysfunctional" range, 33\% were classified as having achieved clinically significant change by the end of treatment, with an additional $15 \%$ meeting criteria for reliable improvement.

The Effect of Feedback

A 2 X 3 MANCOVA comparing the two progress conditions (On-Track vs. NotOn-Track) and three feedback conditions (Treatment as Usual, Immediate Electronic OQ45 Therapist Feedback, Immediate Electronic OQ-45 Client/Therapist Feedback) was performed, with pre-treatment OQ-45 score as the covariate and the client's OQ-45 change score, calculated as the difference between the pre-treatment OQ-45 and last available OQ45, and number of sessions as the dependent variables. MANCOVA yielded significant multivariate effects for progress status $\left(F_{(2,2538)}=497.69, p<.001\right)$, feedback condition $\left(F_{(4,5076)}=12.21, p<.001\right)$, and the progress by feedback interaction $\left(F_{(4,5076)}=8.52 . p<\right.$ $.001)$, suggesting that the ANCOVA effects presented next are due to reliable group differences, and not merely due to conducting multiple ANCOVAs on correlated measures.

A second 2 X 3 MANCOVA was run to ensure reliable group differences for feedback timing condition and progress status. MANCOVA yielded significant multivariate effects for progress status $\left(F_{(2,3911)}=883.11, p<.001\right)$, feedback timing group (Treatment as Usual versus Week-Delayed OQ-45 Feedback versus Immediate Electronic Feedback $)\left(F_{(4,7822)}=41.54, p<.001\right)$, and the progress by feedback timing interaction $\left(F_{(2,}\right.$ 3912) $=24.77 . p<.001)$,

For feedback type, results indicated significant effects for the two progress conditions (On-Track vs. Not-On-Track; $\left.F_{(1,2539)}=184.87, p<.001\right)$ and the three 
feedback conditions (Treatment as Usual, Therapist Feedback, Client/Therapist Feedback; $\left.F_{(2,2539)}=24.13, \mathrm{p}<.001\right)$. The model suggested clients who were designated as On-Track for a positive outcome left treatment with a change score 11.37 points higher (more improved; $\beta=8.08, p<.001)$ than their Not-On-Track counterparts. When compared to clients in the Feedback conditions, clients in the Treatment as Usual condition left treatment with a change score that was 5.40 points less (less improvement; $\beta=-9.43, p<$ .001) while the difference for Therapist Feedback vs. Client/Therapist feedback did not reach statistical significance $(\beta=-1.64, p>.3)$.

For feedback timing, results indicated significant effects for the two progress conditions (On-Track vs. Not-On-Track; $\left.F_{(1,3912)}=384.31, p<.001\right)$ and the three feedback conditions (Treatment as Usual, Therapist Feedback, Client/Therapist Feedback; $\left.F_{(2,3912)}=38.22, \mathrm{p}<.001\right)$. The model suggested clients who were designated as On-Track for a positive outcome left treatment with a change score 12.71 points higher (more improved; $\beta=9.25, p<.001)$ than their Not-On-Track counterparts. When compared to clients in the Feedback conditions, clients in the Treatment as Usual condition left treatment with a change score that was 5.85 points less (less improvement; $\beta=-8.62, p<$ .001). The difference between Week-Delayed OQ-45 Feedback and Immediate Electronic OQ-45 Feedback did not reach statistical significance $(ß=-1.06, p>.2)$.

Planned comparisons were used to test these main hypotheses under consideration regarding feedback type: (1) Clients in both experimental feedback conditions will have better outcomes than clients in the Treatment As Usual (No Feedback) condition (2) Clients who receive formal immediate feedback about their progress (i.e. feedback to both client and therapist) will have better outcomes than clients who do not receive formal immediate 
feedback about their progress (i.e. feedback to therapist only). When considering the total sample for feedback type, Helmert contrasts yielded a significant contrast estimate of -5.39 $(p<.001)$ between the feedback (Immediate Electronic OQ-45 Therapist Feedback and Immediate Electronic OQ-45 Client/Therapist Feedback, $n=1101)$ and no feedback (Treatment as Usual, $n=1445$ ) groups. The therapist feedback versus client/therapist feedback comparison was not statistically significant (Helmert contrast estimate $=-.49, p>$ .6).

Planned comparisons were used to test these main hypotheses under consideration regarding feedback timing: (1) Clients in both experimental feedback timing conditions will have better outcomes than clients in the Treatment as Usual (No Feedback) condition and (2) Feedback that is delivered immediately prior to the session will have a greater effect on outcome than feedback that is provided the next session, one week after the client completes the measure. When considering the feedback timing sample, Helmert contrasts yielded a significant contrast estimate of $-5.85(p<.001)$ between the Treatment as Usual and the feedback groups combined. There were no significant differences between WeekDelayed and Immediate Electronic Feedback groups (contrast estimate $=.91, \mathrm{p}>.2$ ). These results suggest that, when considering timing of feedback, the provision of feedback improves outcome compared to no feedback, while the provision of immediate electronic feedback does not significantly improve outcome when compared to the provision of weekdelayed feedback; however, the number of sessions attended was reduced by the provision of immediate electronic feedback, while maintaining the same degree of progress, on average. Table 1 provides details of average change scores by feedback timing group and by treatment group. 
On-Track. Owing to the significant effect for the two progress conditions, separate analyses were conducted for On-Track and Not-On-Track clients. Considering only those clients whose therapy response designated them as On-Track for a positive outcome, contrast estimates yielded a significant difference for feedback timing conditions, with feedback groups combined indicating a significantly greater amount of improvement compared to Treatment as Usual (Helmert contrast estimate $=-3.62, p<.001$ ), and WeekDelayed OQ-45 Feedback indicating a statistically significant amount of improvement over Immediate Electronic OQ-45 Feedback (Helmert contrast estimate $=2.86, p<.001$ ).

Regarding feedback type, there were significant differences between feedback conditions combined, and Treatment as Usual (Helmert contrast estimate $=-2.18, p<$ .001). The differences between Therapist Immediate Electronic OQ-45 Feedback and the Client/Therapist Immediate Electronic OQ-45 Feedback group were not significant $($ Helmert contrast estimate $=.60, p>.6)$.

Not-On-Track. Owing to the fact that improving outcomes for non-responding clients is the main focus of this research program, and there were significant pre-treatment differences between the On Track and Not On Track progress conditions, the following hypotheses were tested using planned comparisons for feedback type within the Not-OnTrack group: (1) Signal-alarm patients in both Immediate Electronic Feedback conditions will have better outcomes compared to signal-alarm patients in the Treatment as Usual (no feedback) condition (2) Signal-alarm patients in the Immediate Electronic Feedback conditions who receive feedback in addition to the feedback given to their therapist, will have better outcomes than clients who do not receive feedback (Immediate Electronic OQ45 Therapist feedback only). Helmert contrasts yielded a significant contrast estimate of - 
8.66 between the feedback (Immediate Electronic Therapist Feedback and Immediate Electronic Client/Therapist Feedback, $n=328)$ and Treatment As Usual, $(n=286)$ groups, with no significant differences between Immediate Electronic Therapist Feedback and Immediate Electronic Client/Therapist feedback (Helmert contrast estimate $=-1.32, p>.5$ ) for NOT clients. These results suggest that the addition of client feedback to therapist-only feedback did not enhance client outcomes for Not-On-Track clients.

The following hypotheses were tested using planned comparisons for feedback timing, within the Not-On-Track group: (1) Signal-alarm patients in the feedback conditions (Immediate Electronic and Week-Delayed) will have better outcomes compared to Treatment as Usual. (2) The experimental groups in which feedback is immediate will have better outcomes than the experimental feedback groups in which feedback is delayed by one week. Regarding the feedback timing condition, there were significant differences between Treatment as Usual $(n=286)$ and feedback (Week-Delayed and Immediate Electronic Feedback, $n=697$, Helmert contrast estimate $=-8.079, p<.001$ ), but there were no differences between Week-Delayed and Immediate Electronic Feedback (Helmert contrast estimate $=-1.18, p>.4)$. These results suggest that the provision of Immediate Electronic feedback did not enhance client outcomes for Not-On-Track clients, beyond the effects of Week-Delayed Feedback.

Session Effects An additional interest of the study was to assess the effect of feedback on session utilization. Table 2 shows average number of sessions by progress, feedback condition, and feedback timing condition. For feedback condition, the results indicated rates of attendance were significantly different for the two progress conditions (On-Track, $n=1932$ vs. Not-On-Track, $\left.n=614 ; F_{(1,2539)}=546.55, p<.001\right)$ and the 
feedback conditions (Treatment as Usual; $n=1445$, Immediate Electronic OQ-45 Therapist Feedback $n=552$, Immediate Electronic OQ-45 Client/Therapist Feedback $n=549 ; F_{(2,}$ $2539)=6.232, p<.05)$. For On-Track clients, Helmert contrasts yielded significant estimates between Treatment as Usual $(n=1159)$ and the feedback groups combined $\quad(n$ $=773$; Helmert contrast $=.42, p<.05)$, but the differences between Immediate Electronic Therapist OQ-45 feedback and Immediate Electronic Client/Therapist OQ-45 feedback did not reach significance $($ Helmert contrast $=.01, p>.9)$. For Not-On-Track clients there was a significant session difference between feedback conditions $\left(F_{(2,610)}=7.13, p<.01\right)$. Helmert contrasts yielded a significant contrast estimate of $-1.82(p<.001)$ between Treatment as Usual $(n=286)$ and the feedback groups $(n=328)$. The Immediate Electronic OQ-45 Therapist Feedback $(n=164)$ versus Immediate Electronic Client/Therapist Feedback $(n=164)$ comparison did not reach statistical significance (Helmert contrast estimate $=-.42, p>.5)$, indicating that Not-On-Track clients in the feedback conditions received significantly more sessions than their Treatment As Usual counterparts.

For feedback timing, the results indicated rates of attendance were significantly different for the two progress conditions (On-Track, $n=2936$ vs. Not-On-Track, $n=983$; $\left.F_{(1,3912)}=899.3, p<.001\right)$ and the feedback conditions (Treatment as Usual; $n=1445$, Week-Delayed OQ-45 Feedback $n=1373$, Immediate Electronic OQ-45 Feedback $n=$ $\left.1101 ; F_{(2,3912)}=55.04 p<.05\right)$. For On-Track clients, comparisons indicated significant differences between all three feedback timing groups $\left(F_{(2,2932)}=7.55, p<.01\right)$, with clients in the Immediate Electronic Feedback attending significantly less sessions compared to Treatment as Usual (Mean Difference $=.562, \mathrm{p}<.05)$ and Week-Delayed feedback (Mean 
Difference $=1.63, \mathrm{p}<.001)$. For Not-On-Track clients there was a significant session difference between feedback timing conditions $\left(F_{(2,979)}=29.13, p<.01\right)$. Helmert contrasts yielded a significant contrast estimate of $-2.97(p<.001)$ between the Treatment as Usual group $(n=286)$ and the Feedback timing conditions combined $(n=697)$. Helmert contrasts also yielded a significant contrast estimate of $2.30(p<.001)$ between WeekDelayed OQ-45 Feedback and Immediate Electronic OQ-45 Feedback, indicating that for Not-on-Track clients, on average, those in the Treatment as Usual condition, attended 8 sessions $(\mathrm{SE}=.40)$, those in the Week-Delayed OQ-45 feedback condition attended 12 sessions $(\mathrm{SE}=.37)$, and those in the Immediate Electronic OQ-45 feedback condition attended 9.8 sessions $(\mathrm{SE}=.38)$.

\section{Effect of Clinical Support Tools on Outcome}

An additional aim of this research was to test the following hypotheses for Feedback type. (1) Signal-alarm patients whose therapists receive the clinical support tools feedback will fare better than signal-alarm patients whose therapists do not receive the clinical support tools feedback, (2) Signal-alarm patients in the Week-Delayed CST Feedback condition will fare better than those signal-alarm patients in the Two-WeekDelayed CST Feedback group.

Prior to testing the effectiveness of the Clinical Support Tools intervention, a oneway ANCOVA, with pre-treatment OQ-45 as covariate, was conducted to assess for equivalence of groups at time of random assignment into a Clinical Support Tools condition (i.e. at session of first alarm-signal) within the CST Feedback type (No CST Feedback and CST Feedback) and CST Feedback timing (Week-Delayed CST feedback and Two-Week Delayed CST feedback). 
For feedback type, there were no significant differences on OQ-45 scores between the CST Feedback $\left(M_{\mathrm{adj}}=88.34, \mathrm{SE}=.71\right)$ and No CST Feedback $\left(M_{\mathrm{adj}}=88.28, \mathrm{SE}=.71\right)$ groups $\left(F_{(1,325)}=.004, p>.90\right)$ at the time of random assignment into CST feedback conditions. Additionally, a one-way ANOVA found no significant pre-treatment OQ-45 score differences for the CST Feedback $(M=80.83, S D=20.17)$, and No CST Feedback $(M=77.08 ; S D=18.65)$ groups $\left(F_{(1,326)}=3.06, p>.05\right)$.

For feedback timing the mean OQ-45 score at time of first signal for Two-Week delayed CST feedback clients $\left(M_{\mathrm{adj}}=87.95, \mathrm{SE}=.45\right)$ was not significantly different than the mean first signal OQ-45 score for Week-Delayed CST feedback clients. $\left(M_{\text {adj }}=88.68\right.$, $\left.\mathrm{SE}=.48, F_{(1,694)}=1.19, p>.2\right)$. Additionally, a one-way ANOVA found no significant pre-treatment OQ-45 score differences for the Two-Week-Delayed CST Feedback $(M=$ 80.04, $S D=19.17)$ and Week-Delayed CST Feedback $(M=78.96, S D=19.49)$ groups $\left(F_{(1,695)}=.54, p>.40\right)$.

Given that the setting of the study is naturalistic, (therapists decide what to do with the feedback and clients may terminate at any time), combined with the fact that signalalarm clients are traditionally likely to end treatment before experiencing significant benefit, there was some attrition within the NOT sample before the CST feedback intervention was offered. That is to say, if a client signals at week three of therapy, and then completes the measure during the week, before his/her next appointment, she/he may not return, thereby making it impossible to deliver an intervention based on the client's CST responses. Furthermore, if the client signals at week three of therapy, completes the measure during the week, and returns for the next session, he/she will still need to attend yet another session in order to complete the OQ-45, so as to measure the effects of the CST 
feedback and the intervention that the therapist may (or may not, given the setting) have used. A client is considered to have completed the course of the CST intervention if they completed at least 3 of the 4 domains of interest (alliance, motivation for therapy, social support, and perfectionism) and attended two or more sessions of therapy after the CST feedback was delivered to their therapist.

For feedback type, of those who signaled and were in the Week-Delayed CST Feedback condition $(n=328), 13.7 \%(n=23)$ did not return for any additional sessions following their first signal. An additional 14.9\% $(n=25)$ didn't complete the Clinical Support Tools questionnaires, $16.1 \%(n=27)$ failed to show up for their session on the day feedback was given to their therapist (decreasing the likelihood feedback was used in session $), 4.8 \%(n=8)$ completed the CSTs but never returned to therapy, and .6\% $(n=1)$ were not given the questionnaires due to administrative error. This yielded a final CST Feedback sample of 85 clients. Similarly, of those who signaled and were in the No CST Feedback condition, $14.4 \%(n=23)$ did not return for additional sessions following their first signal. An additional $8.8 \%$ did not complete the CST questionnaires. This yielded a final No CST sample of 122 clients.

For feedback timing $(n=356)$, of those who signaled and were in the CST feedback conditions (Week-Delayed CST feedback and 2-Week-Delayed CST feedback), $12.1 \%(n=$ 43) did not return for any additional sessions following their first signal. An additional $12.6 \%(n=45)$ didn't complete the Clinical Support Tools questionnaires, $15.2 \%(n=54)$ failed to show up for their session on the day feedback was given to their therapist (decreasing the likelihood feedback was used in session), $8.4 \%(n=30)$ completed the 
CSTs but never returned to therapy, and $1.1 \%(n=4)$ were not given the questionnaires due to administrative error. This yielded a final CST Feedback sample of 180 clients.

Table 3 shows the means and standard deviations for the CST groups. A 1 X 3 ANCOVA, with intake OQ-45 score as the covariate, for Feedback Type was performed to test the hypothesis that delivery of CST feedback would provide an additive outcomeenhancing effect for clients predicted to end treatment with negative change, compared to those whose therapists do not receive CST feedback. Results indicate significant effects for condition $\left(F_{(2,489)}=37.68, p<.001\right)$. Clients in the CST Feedback condition left treatment with an additional 6.7 points improvement $(\beta=10.85, p<.001)$ than their No CST Feedback counterparts, and 14.2 points more improvement $(\beta=17.56, p<.001)$ than the clients in the Treatment as Usual condition.

Another 1 X 3 ANCOVA comparing CST feedback timing conditions, was performed to test the main hypothesis that earlier delivery of CST feedback (due to more timely delivery of OQ-45 progress feedback), as well as the improvements made to the CST feedback protocol, would provide an added outcome-enhancing effect for clients predicted to end treatment with negative change. Pretreatment OQ-45 score was included as a covariate, with the client's OQ-45 change score as the dependent variable. A comparison between the feedback timing indicated significant differences between groups $\left(F_{(2,462)}=44.13, p<.001\right)$. Compared to Treatment as Usual, combined feedback groups yielded at significant contrast estimate of $-16.13(p<.001)$, but the contrast estimate between Week-Delayed CST feedback and 2-week-Delayed CST feedback groups did not reach statistical significance (contrast estimate $=-2.72, p>.3$ )._The Week-Delayed CST feedback condition resulted in average post scores that were .5 points below the cutoff for 
the functional range (63), in contrast with the 2-Week-Delayed CST feedback condition, where clients ended treatment, on average, 1.25 points above the cut-off, and Treatment as Usual, where clients ended treatment 17 points above the cutoff, on average. Figures 2.1 and 2.2 provide a graphical representation of the average change scores for the feedback and feedback timing conditions.

Session Effects. Because of the significant session differences between feedback type and feedback timing groups for the total NOT sample (completers and noncompleters), an ANOVA was conducted to test for session effects for NOT completers in both feedback type and feedback timing groups.

There were significant session differences between the CST Feedback conditions $\left(F_{(2,490)}=26.08, p<.001\right)$. Helmert contrasts yielded a significant contrast estimate of $3.86(p<.001)$ between the CST feedback and no CST feedback groups combined $(n=$ $207)$ and Treatment as Usual $(n=286)$ and between CST feedback $(n=85)$ and No CST feedback $(n=122$; contrast estimate $=-2.33, \mathrm{p}<.01)$.

Differences were also significant for the feedback timing conditions $\left(F_{(2,463)}=\right.$ 71.02, $p<.001)$. Helmert contrasts yielded a significant estimate of $-6.64(p<.001)$ between combined feedback conditions (Week-Delayed and 2-Week-Delayed CST Feedback $(n=180)$ and Treatment as Usual $(n=286)$, and between Week-Delayed $(n=$ 85), and 2-Week-Delayed CST Feedback $(n=95$; contrast estimate $=3.23, \mathrm{p}<.001)$.

It should be noted that these session differences are partly due to the fact that clients in each condition were required to attend an unequal amount of sessions in order to be considered completers in their respective conditions and because clients in the CST 
feedback condition, who did not fill out at least one OQ-45 (attend an additional session) post delivery of CST feedback, were excluded from analyses.

Analysis of Clinical Significance

To further assess the meaningfulness of the feedback and Clinical Support Tools interventions, clients were categorized into final outcome classifications based on Jacobson and Truax's (1991) criteria for reliable or clinically significant change. These data are presented in Table 4. Because there were no significant outcome differences between the Therapist Feedback and Client/Therapist Feedback conditions within the Immediate Electronic Feedback condition, these groups were combined into a single OQ-45 Immediate Electronic Feedback group. Furthermore, because there were no significant outcome differences between the Therapist Feedback and Client/Therapist Feedback conditions within the Week-Delayed OQ-45 Feedback groups, they were combined into a single Week-Delayed OQ-45 Feedback group, as well. A chi-square comparison between the Feedback groups (Treatment as Usual, No CST Feedback, and CST Feedback) was significant $\left(\chi^{2}=57.82, \mathrm{n}=493, p<.001\right)$. CST feedback condition resulted in a $16.6 \%$ reduction in deterioration ( $4.7 \%$ of clients in this group deteriorated) as compared to the no CST feedback group, which resulted in a $12.3 \%$ reduction $(9.0 \%$ of clients in this group deteriorated), compared to the $21.3 \%$ deterioration rate for clients in the Treatment as Usual Group. Further, while $21 \%$ of clients in the treatment-as-usual condition showed reliable improvement or clinically significant change, $61.2 \%$ in the CST feedback condition and $38.5 \%$ in the No CST Feedback condition reached this same level of improvement in therapy. Essentially the use of Immediate Electronic Feedback plus CST feedback nearly 
tripled $(61.2 \%$ versus $21 \%)$ the number of clients who were rated as recovered/reliably improved according the Jacobson/Truax criteria.

Differences between feedback timing conditions were also significant $\left(\chi^{2}=59.57\right.$, $\mathrm{n}=466, p<.001)$. Immediate Electronic OQ-45 Feedback with Week-Delayed CST feedback resulted in a $16.6 \%$ reduction in deterioration $(4.7 \%$ of clients in this group deteriorated) as compared to the Week-Delayed OQ-45 Feedback with two-week delayed CST feedback group, which resulted in a $13.9 \%$ reduction $(7.4 \%$ of clients in this group deteriorated), compared to the $21.3 \%$ deterioration rate for clients in the Treatment as Usual Group. Further, while $21 \%$ of clients in the treatment-as-usual condition showed reliable improvement or clinically significant change, $61.2 \%$ in the Immediate Electronic OQ-45 feedback with Week-Delayed CST feedback condition and 42.1\% in the WeekDelayed OQ-45 Feedback with two-week delayed CST feedback group reached this same level of improvement in therapy. That is to say, providing therapists with information about the client's responses on the CST measures in a more timely manner nearly doubled the percentage of clients who showed reliably improved or clinically significant change (19.1\% difference between groups) compared to clients whose therapists received CST feedback two-weeks after the time of first signal.

Due to the increase in percentage of clients who were classified as reliably improved or clinically significant change, the percentage of clients classified in the no change group decreased from $57.7 \%$ for clients in the Treatment as Usual group to $50.5 \%$ for clients in the 2-Week Delayed CST feedback group, and 34.1\% for clients in the WeekDelayed CST feedback condition. 


\section{Chapter 5: Discussion}

Although the benefits of therapy have been well-documented in the psychotherapy literature, also well-documented are the clients who terminate treatment showing little to no improvement or, who leave treatment worse-off than when they began (Lambert \& Ogles, 2004; Hansen et al., 2002). Findings from previous studies (Whipple et al., 2003, Harmon et al., 2007) approximate that, on average, $20 \%$ of clients are identified as signal-alarm cases, having made little progress, or deteriorated, during the current course of therapy. Without feedback, only $20 \%$ of these signal-alarm cases are identified as improved/recovered, according to the Jacobson-Truax criteria, at termination.

Recent attempts to investigate therapist treatment effects provides further evidence as to the need for monitoring and feedback systems in an attempt to alter likely negative treatment outcomes (Okiishi et al., 2006). Okiishi noted significant differences between the average number of sessions therapists saw clients, speed of client change, and overall change, based on OQ-45 scores. Of particular disconcert, is their observation that the top and bottom $10 \%$ of therapists had clients whose outcome was statistically and clinically different. For example, the rate of deterioration of clients seen by the bottom-ranked therapists was double that found in clients of the top-ranked therapists. However, data from this study was archival and random assignment of clients to therapists was not employed. Okiishi and colleagues made the following recommendations based on their findings and in consideration of the best interest of the client: (a) Through administrative procedures, have clients assigned to therapists according to therapist rank order, thereby maximizing client contact with the most-effective therapists; (b) make outcome information available to clients and allow them to choose their therapist; (c) request that some therapists... who had exceptionally high-deterioration rates, change their job role 
from providing counseling to other tasks, have their work more carefully observed, or engage in continuing education; and (d) request that therapists who have higher than average change slopes... lower than average sessions, and lower than average pre- to post improvement consider seeing clients for more sessions. Okiishi parallels this outcome monitoring system to the dramatic effects of making outcome data more transparent. For example, life expectancy increased from 5 to 20 years after providers and treatment centers took the risk of making death rates public.

The current program of research is patient-focused, and seeks to 1) identify clients who are at risk-for not benefiting from treatment or worsening and 2) alter the course of treatment for clients designated as Not-On-Track for a positive outcome, by providing feedback to their therapists. The benefits of providing feedback to therapists have been established on a consistent basis in the current line of research. Past research (within the current program of research) aimed at reducing treatment failure (Hawkins et al., 2004; Lambert, Whipple, et al., 2001; Lambert, Whipple, Vermeersch, et al., 2002; Whipple et al., 2003, Harmon et al., 2007) has repeatedly demonstrated that feedback to therapists about poor patient progress improved therapy outcomes for clients predicted to have a negative outcome.

Providing formal (standardized and direct weekly patient feedback, in addition to feedback to therapists, has provided less clear evidence as to its effectiveness. Hawkins et al. (2004) provided evidence for the effectiveness of patient feedback in a community hospital-based outpatient clinic, where initial OQ-45 scores were 15 points higher, on average, than the intake score for the Harmon et al. (2007) sample. Harmon did not find evidence for this same effectiveness in a college counseling center setting. The evidence 
favoring the value of providing additional assessment information (CSTs) is more substantial. While one of previous studies provided support for the use of CSTs (Whipple et al., 2003) this intervention had never been tested with random assignment to treatment until Harmon et al. (2007), where the findings of Whipple were replicated.

Notable limitations of the previous studies include a feedback protocol in which feedback for the client's current session was not delivered until the following session, as it was necessary to collect the questionnaire from the client, scan, score, and create feedback for the therapist with the use of research assistants, by the client's next scheduled appointment. Arising from the aforementioned difficulty is the effect that week-delayed OQ-45 feedback had on the time it took to deliver CST feedback to the therapist, on average taking two weeks from the time of initial signal to the time the therapist receives feedback about the client's responses on the CST measures. For example, in previous studies (Harmon et al., 2007; Whipple et al., 2003), if a client came in on session 2 and signaled, at session 3, the therapist would receive a red/yellow warning message informing them of their client's NOT status. Also at session 3, the client was asked to complete the CST measures which they returned to the therapist before they left that day. At the third session, (two weeks after the client provided a signal-alarm response profile), the therapist was given additional information from the CSTs that could aid in creating a more positive outcome for the client. The current study is an attempt to deliver feedback in a more efficient manner, thereby intervening sooner, with the hope of altering the course of treatment for those who are at-risk for a likely early termination with little or no benefit. Although the Whipple and Harmon studies showed the value of using the CST intervention, the CST was not considered entirely suitable. In an attempt to increase the 
usefulness and viewing frequency of the CST feedback and CST manual interventions, changes were made in the CST feedback. The revised CST manual added suggested intervention strategies aimed at those domains in which the client indicated a less-thanaverage score. Added to the current CST feedback, were specific item responses that were below average and that indicated further attention to specific areas of concern, along with the traditional provision of overall scores for each domain, with an indication as to those that required attention. The lack of specificity that the Stages of Change Scale provided in differentiating each client's motivational level from the next was solved by substituting another motivational measure. A measure of perfectionism was added the assessment package. Increased efforts were expended to encouraged and remind therapists about the study and the design protocol, such as reminders on all of their computer monitors to view feedback before each session, and reminders at weekly team treatment meetings. Ultimately therapists were free to view (or not view) the OQ-45 and CST feedback, and to act according to their judgment, but as the study went forward on a daily basis for over a year, such efforts were deemed necessary.

The current study differed from previous studies in three major ways: (1) the use of immediate electronic feedback, and (2) emailing of questionnaires to clients in the same week that they signaled such that CST feedback was delivered in the very next session following a red or yellow (signal-alarm) warning, and (3) altering the content of the clinical support tools feedback and the content, and availability, of the manual-based intervention strategies. It was hoped that such procedures would increase the impact of this intervention and possibly extend our understanding of the mechanisms underlying the positive consequences of using CSTs. 
The purpose of the current study was to remedy the preceding problems by further testing the effects of feedback (Therapist versus Patient/Therapist, Week-Delayed OQ-45 feedback versus Immediate Electronic OQ-45 feedback, CST Feedback versus No CST Feedback, 2-Week-Delayed CST feedback versus Week-Delayed CST Feedback, more useful and accessible CST suggestions). The effects of these interventions were also compared with two large archival samples; (Treatment as Usual/No Feedback, WeekDelayed OQ-45 Feedback/2-Week-Delayed CST Feedback), drawn from the earlier studies.

The present study identified $29.8 \%$ of clients as potential treatment non-responders or deteriorators (Not-On-Track for a good outcome). It was hypothesized that the provision of OQ-45 progress feedback and CST feedback in a more timely manner would lead to a greater improvement in treatment effects, as measured by the OQ-45. Results from the current study indicate that, while the Week-Delayed CST feedback condition did not achieve a statistically greater change scores, compared to their 2-Week-Delayed CST feedback counterparts, the same level of change was reached in a significantly fewer amount of sessions. The results of the different feedback interventions reflect an effect size of .93 for Immediate Electronic OQ-45 Feedback + CST feedback, an effect size of .69 for Week-Delayed OQ-45 Feedback + 2-Week-Delayed CST Feedback, and .47 for Immediate Electronic Feedback no CST Feedback. The Mean number of sessions for each group was $12.99,16.23$, and 10.29 , respectively. The results of the current study suggest that the same amount of change (in terms of OQ-45) can occur in 3 sessions less, when OQ-45 feedback is available immediately (one week sooner) and when CST feedback is delivered 
in a more timely manner (one week sooner). The following is cited from Harmon's dissertation (2007):

An increase in the number of sessions attended in the feedback conditions suggests the possibility that therapists may be helping mainly by keeping clients around longer. When positive outcomes are obtained without increased treatment length another mechanism is suggested - such as the use of more effective therapeutic techniques. At this point it seems fair to conclude that the positive effects of feedback can be obtained both with, and without, extending the length of time the patient stays in treatment (number of treatment sessions).

When considering the Jacobson-Truax model of identifying deteriorated, no change, and improved/recovered clients, recovery rates increased by approximately $20 \%$ with each added intervention, from a baseline of $20 \% \mathrm{improved} / \mathrm{recovered} \mathrm{for} \mathrm{Treatment} \mathrm{as} \mathrm{Usual,}$ approximately 40\% for Week-Delayed OQ-45 Feedback + 2-Week-Delayed CST Feedback, and approximately $60 \%$ for those in the Immediate Electronic OQ-45 Feedback condition + Week-Delayed CST Feedback, supporting the potential value of research and practice focused on quality management for individual patients (i.e., patient-focused research). In addition to a greater amount of NOT clients identified as improved/recovered, the rate of clients in the deteriorated category decreased from $21.3 \%$ to $7.4 \%$ to $4.7 \%$ respectively, with each intervention (Treatment as Usual, 2-Week-Delayed CST Feedback, and Week-Delayed CST Feedback).

It should also be noted that in studies where OQ-45 and CST feedback was investigated, including the current study, comparisons were made between CST feedback groups, but one of the difficulties with the interpretation of session utilization are that the 
session attendance requirements are inherently different between the No CST feedback, 2Week-Delayed CST feedback, and Week-Delayed CST feedback conditions. The addition of the Clinical Support Tools to feedback conditions meant that clients in the CST condition were required to attend more sessions in order for the intervention to be implemented and examined. Following session of alarm signal, clients had to attend at least two more sessions (one session for the therapist receive the feedback and to (theoretically) intervene using the CST manual, and one more session to take the OQ-45 again following the dissemination of CST feedback). This is in contrast with the 2-WeekDelayed CST Feedback condition, in which clients were required to attend 3 additional sessions, and the Treatment as Usual comparison group, whose treatment response could be assessed if they attended at least one more session following their session of signal (one session to fill out the CST measures). While an examination of intake OQ-45 and OQ-45 at time of warning yielded no significant differences between clients who received the various CST interventions and those lost to attrition, the requirement of three additional sessions to complete the intervention should not be ignored by those who choose to replicate the current research. Keeping in mind the inherent session requirements, these differences still do not explain entirely the 3.75 session differences between the signal conditions that employ CST feedback (2-Weed-Delayed and Week-Delayed CST Feedback groups). The next feedback study in this line of research will minimize this possible design artifact through (1) the continued use of instantaneous electronic feedback, and (2) continued emailing of questionnaires to clients in the same week that they signal (3) emailing of CST feedback to therapist in the same week that the client completes the CST 
measures. Such procedures may allow us to extend our understanding of the mechanisms underlying the positive consequences of using CSTs.

Trends indicate it is relatively common for On-Track clients, regardless of feedback condition (including Treatment as Usual), to end treatment below the clinical cut-off. Of particular significance, however, is the difference in post-treatment OQ-45 scores for NotOn-Tack clients in the feedback conditions compared to their Treatment as Usual counterparts. Not-On-Track clients in the Treatment as Usual condition, ended therapy 17 points, on average, above the clinical cut-off. Their Not-On-Track Feedback counterparts ended treatment, on average, only 1 point above the clinical cut-off.

These findings, coupled with and compared to, those of Whipple, et al. (2003) and Harmon et al. (2007), support the conclusion that when therapists receive weekly information regarding their client's progress and assessment of the therapeutic relationship, motivation for therapy, social support system, and perfectionism, along with more specific feedback regarding the client responses to CST measures and more readily-available problem solving strategy approaches, outcome is enhanced in statistically and clinically meaningful ways. Furthermore, the current study suggests that providing the feedback described above, in a more timely manner, will result in statistically significant and clinically meaningful improvement, while significantly decreasing the amount of sessions attended in order to reach this treatment gain. While the maximization of external validity led to a decision by the researchers not to formally monitor feedback usage, the next study in this line of research will employ a tracking form emailed to the therapists along with the CST feedback each session in order to further assess the method/s by which the Clinical Support Tools feedback and decision tree is helpful. 
An additional aim of the study was to assess the impact of providing both therapists and patients with weekly progress information in a more timely manner, with the hypothesis that an integration of all of the interventions identified in past studies would result in the greatest benefit. This hypothesis was not supported, as statistically, there were no significant outcome differences between the Therapist Feedback and Client/Therapist Feedback groups for the Immediate Electronic Feedback. These findings are consistent with Harmon et al. (2007), but not with the Hawkins et al. (2004) study that was conducted in a hospital based outpatient setting

While the reasons for this inconsistency are currently unclear, the previous implication was thought to have been simply a failure to replicate, with a call for further studies in order to illuminate the circumstances under which formal feedback to patients will result in added benefits. One obvious difference was that the clients in the Hawkins et al. (2004) study were, on average, much more disturbed than clients in the current study (including archival data), having intake OQ-45 scores that were on average, approximately 15 points higher (3/4 of a standard deviation). Given this lack of replication, perhaps initial distress level may be a factor related to the effects of client feedback. Perhaps feedback is more meaningful or effective for clients who display higher levels of distress in therapy.

Other notable studies to include when considering feedback to clients are that of Finn and Tonsager (1992) and Newman and Greenway (1997) who found that receiving feedback on their MMPI-2 results increased self-esteem and decreased symptomatic distress as compared to controls. This is an area that has only been explored minimally by the current program of research, with current plans underway to conduct a qualitative 
study, investigating NOT clients' assessments of the mechanisms of action in therapy, with specific focus on the areas that the CSTs address.

One possible explanation for the difference in results may be the type of feedback provided. Aside from Hawkins et al., (2004) all other published studies on client feedback that we found employed feedback about the client's personal characteristics (i.e. MMPI profiles, PAI feedback, etc.) rather than progress in therapy. It is possible that the client feedback in the present study did not provide a significant impact because it may not have been sufficiently personal, or meaningful, to the client in the same way personality profile feedback is. In this way, progress feedback is designed to be therapeutic only in the sense that it alerts about progress status. It is not designed to provide insight into characterological status or to help clients understand themselves better.

It is worthwhile so consider the similarities between the content of the CST feedback that is given to therapists of Not-On-Track clients and the type of feedback referred to in previous studies (Finn \& Tonsager, 1992; Newman \& Greenway, 1997), where effects for client feedback has been found. This theoretical similarity regarding the content of feedback may provide insight into the possible explanations as to why CST feedback is effective. That is to say, if feedback to clients regarding certain characterological themes or personal attributes, is helpful, then perhaps this same type of feedback is helpful to therapists, but may be more meaningful to therapists when they have also been alerted that a particular client is at risk for not benefiting from treatment.

The tendency by therapists to reject negative feedback, which is congruent with the idea that in order to preserve one's self-integrity and avoid cognitive dissonance, can be curtailed by providing positive feedback the majority of the time. In the current study, 
feedback about signal clients (negative feedback) was given at a rate of 1:4 so that, on average, for every 4 times a therapist received a message stating that their client is on track (positive message), they receive only 1 message informing them of a signal-alarm case. It is also a common observation that clinicians are often very skeptical with regard to standardized outcome measures (Bickman et al., 2000). Thus there is reason to believe that in most cases mental health professionals will be biased against using the external feedback as a basis or judging their performance (client treatment response) if the feedback is negative (e.g., the client is more disturbed). However, given that the setting in which this study was conducted has employed therapist feedback for the past near-decade, it is possible that by simply introducing external objective feedback as standard practice, therapist resistance to this type of feedback may ameliorate over time.

It was also anticipated that more immediate feedback would yield greater improvement, but this hypothesis was not supported. There were no significant differences between feedback timing groups for Not-On-Track clients; however, for the On-Track groups there were significant differences. Somewhat puzzling is the observation that clients in the On-Track Week-Delayed OQ-45 Feedback conditions experienced a statistically significantly greater amount of change, and attended a significantly greater number of sessions, compared to their Immediate Electronic Feedback counterparts. However, compared to the Treatment as Usual condition, clients in the On-Track Immediate Electronic OQ-45 condition, had significantly greater treatment gains, and significantly less sessions. The main difference between previous studies and the current study is the method in which OQ-45 feedback is delivered (Electronic versus Paper-based) and it is possible that this could have made a difference in OQ-45 feedback effectiveness 
due to the possibility that therapists were not viewing feedback consistently, but this is a possibility, in other forms, in all of the previous studies as well. For the current study, a periodic informal email to therapists was sent, asking, "For what percentage of your clients did you view OQ-45 feedback for in the past week?" Approximately 60\% of therapist responded each time this request was emailed. Frequency of viewing ranged from $0 \%$ to $100 \%$, with an average of $74 \%$ weekly viewing for therapists responding.

Keeping in mind that, on average, all three On-Track feedback conditions attained treatment gains below the cut-off for the "functional" range, it may be that greater efforts should be made to understand the factors that contribute to a positive outcome for Not-OnTrack clients, as there is still even greater room for improvement within this client population. However, the benefit of providing feedback to On-Track clients can be seen in the apparent decrease in the amount of sessions needed in order to reach the same amount of benefit.

The finding that clients identified as Not-On-Track attend significantly more sessions than On-Track clients, is congruent with previous studies investigating similar feedback interventions, (Hawkins et al., 2004: Lambert, Whipple, et al., 2001; Lambert, Whipple, Vermeersch et al,, 2002; Whipple et al., 2003, Harmon et al., 2007). This is expected in light of the fact that these clients began treatment more severely disturbed. OnTrack clients in the IEF condition attended a significantly less amount of sessions than those in the Week-Delayed feedback condition, but had statistically significantly less improvement, and attended approximately the same amount of sessions as their TAU counterparts, but displayed significantly greater change scores. Essentially, past research has found that feedback to OT clients has reduced the number of sessions of treatment they 
received without reducing positive outcomes thus making the use of feedback costeffective (Lambert et al., 2003). The current study supports this general conclusion, although it does not support the use of Immediate Electronic OQ-45 Feedback to On-Track clients over the use of Week-Delayed OQ-45 Feedback.

The finding that Not-On-Track clients who were in either the Therapist Feedback or Client/Therapist Feedback conditions attended more sessions than their No Feedback counterparts is consistent with three of the prior studies (Lambert, Whipple, et al., 2001; Lambert, Whipple, Vermeersch et al., 2002, Harmon et al., 2007) but was not found in two others (Hawkins et al., 2004; Whipple et al., 2003). The discrepancy in findings across the various studies raises some confusion in interpreting the mechanisms of action for improved outcomes in the feedback condition. An increase in the number of sessions attended in the feedback conditions suggests the possibility that therapists may be helping mainly by keeping clients around longer. However, when positive outcomes are obtained without increased treatment length, as is the case in the current study, another mechanism is suggested - such as the use of more effective therapeutic techniques hypothesized to be a result of the Immediate Electronic OQ-45 Feedback and Week-Delayed CST Feedback.

The results of the current study, and the previous studies in this line of research, support the assessment that a care setting in which therapists routinely assess the client's social support network, motivation for therapy, helping alliance, perfectionism, and/or other decision support tools when they first receive information that a client is Not-OnTrack would likely decrease attrition and keep Not-On-Track clients in treatment longer. Furthermore, it is also indicated that by providing this type of feedback in a more timeefficient manner, will provide for statistically greater amount of NOT individuals 
terminating treatment having improve/recovered, according to the Jacobson/Truax definitions. At this point it also appears that when clients stay in treatment and have a chance for their therapist to get the CST information, they have better outcomes.

Furthermore, when they receive this CST feedback in a more timely manner, the amount of sessions required to reach this same effect is significantly decreased. These conclusions are open to empirical analysis.

Percevic, Lambert, and Kordy (2006) investigated the assumption that early response to treatment predicts better outcomes, and concluded, "It appears that the more and the faster a patient deteriorates in the first 2 weeks of therapy, the faster the patient will improve in the further course of therapy" (368). They caution the reader to interpret this observation carefully because regression to the mean could also account for this finding. They also noted that early improvement is predictive of the overall outcome of therapy if length of therapy is standardized. They cite an example of a patient with a slow response or a negative response: she or he first has to make up the initial delay or deterioration to achieve the same outcome as rapid responders.

While the primary focus of the current study was on non-responding clients, the present study found mixed effects for On-Track clients, although the consistent finding that on average, clients in the OT condition end therapy below the cut-off line for the functional range, can be found across all experimental groups (including On-Track Treatment as Usual). The On-Track clients in the Immediate Electronic Feedback Conditions indicated less improvement as a result of OQ-45 feedback compared to Week-Delayed OQ-45 Feedback(excluding CST feedback that was only used for Not-On-Track clients), and also attended, on average, .71 and .42 session less than the Week-Delayed OQ-45 Feedback 
condition and Treatment as Usual condition, respectively. This significant difference in improvement (compared to Treatment as Usual) occurred without the corresponding increase in sessions that was found for Not-On-Track clients, suggesting that for On-Track clients, feedback is working independent of any effect on therapy duration. On average, On-Track clients in the feedback conditions left treatment with significantly greater change scores (Immediate Electronic OQ-45 Feedback = 13.5, Week-Delayed OQ-45 Feedback = 16) as compared to the average change score of 11 points for Treatment As Usual clients. The finding of significantly improved outcomes for On Track clients compared to Treatment as Usual has been consistent in our earlier (Hawkins et al., 2004, Harmon et al., 2007) as well as the current study. However, session frequency for each study has manifested differing session rates for On-Track feedback groups. In general, with the exception of the Hawkins study, our past research has found that feedback to On-Track clients has reduced the number of sessions of treatment they received without reducing positive outcomes thus making the use of feedback cost-effective (Lambert et al., 2003). The current study supports this general conclusion.

In an attempt to replicate the recent work done by Lambert and colleagues, Trudeau implemented a feedback system where progress feedback, based on OQ-45 scores was given to therapists at each session, and did not detect any differences between feedback and treatment as usual groups. However, among other limitations, the sample size $(n=127$ at session $1, n=77$ at session 2, and $n=59$ at session 3 ) was not large enough to assess the effects of feedback for signal-alarm cases.

Some concerns may be raised about the risks posed to clients, if feedback is considered negative. Hawkins et al. (2004) assessed clients' responses to receiving 
feedback, with the overwhelming majority (99\%) of clients rating the feedback experience as an "8" or higher on a Likert Scale, ranging form 1-10, 10 being "Extremely Beneficial." However, clients in Hawkins's study were much more distressed at intake compared to the population in the current sample.

There are a number of inherent limitations to patient-focused naturalistic research. The use of a single, self-report, dichotomous response set instrument cannot fully capture the complexity of the client's experience. However, the benefits of capturing accurate meaningful information from clients, and providing timely progress information, necessitates the use of a brief instrument sensitive to change (Vermeersch et al., 2004), that can be administered often in a time and cost-efficient manner. However, it is unknown whether the results from the current line of research would be sustained if more elaborate progress and outcome assessments had been used. The demonstrated utility of providing therapists with feedback suggests that this is an important, relatively simple, intervention that can significantly improve outcomes for poorly responding clients.

Given that the method of feedback delivery to therapists was different for the two OQ-45 feedback groups, it is difficult to clearly assess whether the effects of these different feedback conditions are the result of the differences in timing or the method in which it was given (paper versus electronic). The next study in this current line of research will employ the electronic computerized OQ-45 feedback method as well, providing a more accurate assessment as to which aspects of feedback are related to increased positive outcome for On Track clients. The method of CST delivery remained the same (paper-based to the therapist's mailbox) between 2-Week-Delayed CST feedback and Week-Delayed CST Feedback, making conclusions regarding the effects of timing a little more convincing. 
Another limitation of the current study is the inability to asses whether the therapist's selfreported viewing rates of feedback are accurate.

Another criticism of the current analysis may be the comparison of archival data to the Immediate Electronic Feedback data that was collected in real-time. However, the systematic nature of this programmatic research (conducted in the same setting, equivalent demographic characteristics, controlled and documented consistent methods of providing feedback, similar or identical therapist characteristics), encourages the use of archival data for several reasons. Given the amount of evidence that has accumulated regarding giving therapist feedback and the effects it has on non-responding clients, the general consensus is that the withholding of feedback to therapists at this point would be unethical and treatment as usual is no longer available to clients. Since it was desirable for feedback interventions to be compared with TAU, archival data were needed. In this program of research, each study takes at least a year in order to collect enough signal-alarm cases to conduct meaningful analyses. The decision to forgo the use of TAU maximized the number of NOT experimental conditions that could be utilized, adding statistical power for each experimental condition.

Another limitation of the current line of research is that the data used in the current studies and the majority of previous studies, was collected from a college counseling center, where level of distress is much lower, on average, compared to clients in other settings, such as community hospital outpatient clinics.

Nevertheless, almost a decade of research has been conducted, demonstrating the utility of patient-focused research in the context of providing progress feedback to therapists, suggesting that it is an important intervention that can significantly improve 
outcomes for poorly responding clients. The feedback delivery system used to deliver feedback in the current study requires procedures that are simple and easy to implement in everyday clinical practice. We encourage other researchers to utilize feedback delivery systems and investigate the generalizability of the noted effects of feedback to other client populations and settings, and to create a greater understanding of the mechanisms involved in the effects of providing feedback. 


\section{Appendix A: Tables and Figures}

Table 1

Means, Standard Deviations, and Effect Sizes for Pre and Post Outcomes by Treatment Group

\begin{tabular}{|c|c|c|c|c|c|c|c|c|c|c|}
\hline \multicolumn{11}{|c|}{$\begin{array}{l}\text { Total Sample - Feedback Type } \\
\qquad(n=2546)\end{array}$} \\
\hline & \multicolumn{3}{|c|}{$\begin{array}{l}\text { Treatment as Usual } \\
\qquad(n=1445)\end{array}$} & \multicolumn{4}{|c|}{$\begin{array}{c}\text { Immediate Electronic OQ-45 } \\
\text { Therapist Feedback } \\
(n=552)\end{array}$} & \multicolumn{3}{|c|}{$\begin{array}{l}\text { Immediate Electronic OQ-45 } \\
\text { Client/Therapist Feedback } \\
\qquad(n=549)\end{array}$} \\
\hline & Pre- & Post- & ES (d) & Pre- & Post- & & (d) & Pre- & Post- & ES (d) \\
\hline $\begin{array}{l}\mathrm{M} \\
(\mathrm{SD})\end{array}$ & $\begin{array}{l}70.27 \\
(22.59)\end{array}$ & $\begin{array}{l}61.68 \\
(23.88)\end{array}$ & .37 & $\begin{array}{l}70.15 \\
(21.42)\end{array}$ & $\begin{array}{l}59.06 \\
(22.59)\end{array}$ & & 50 & $\begin{array}{c}72.85 \\
(22.764)\end{array}$ & $\begin{array}{l}60.77 \\
(23.14) \\
\end{array}$ & .53 \\
\hline$\Delta$ & \multicolumn{3}{|c|}{$8.61(18.36)$} & \multicolumn{4}{|c|}{$11.09(19.09)$} & \multicolumn{3}{|c|}{12.06} \\
\hline \multicolumn{11}{|c|}{$\begin{array}{l}\text { Total Sample }- \text { Feedback Timing } \\
\qquad(n=3919)\end{array}$} \\
\hline & \multicolumn{3}{|c|}{$\begin{array}{l}\text { Treatment as Usual } \\
\qquad(n=1445)\end{array}$} & \multicolumn{4}{|c|}{$\begin{array}{c}\text { Week-Delayed OQ-45 } \\
\text { Feedback } \\
(n=1373)\end{array}$} & \multicolumn{3}{|c|}{$\begin{array}{c}\text { Immediate Electronic OQ-45 } \\
\text { Feedback } \\
(n=1101)\end{array}$} \\
\hline & Pre- & Post- & ES (d) & Pre- & Post- & & (d) & Pre- & Post- & ES (d) \\
\hline $\begin{array}{l}\mathrm{M} \\
\text { (SD) }\end{array}$ & $\begin{array}{l}70.27 \\
(22.59)\end{array}$ & $\begin{array}{l}61.68 \\
(23.88)\end{array}$ & .37 & $\begin{array}{l}71.21 \\
(22.65)\end{array}$ & $\begin{array}{l}57.65 \\
(24.45)\end{array}$ & & 57 & $\begin{array}{l}71.49 \\
(22.07)\end{array}$ & $\begin{array}{l}59.91 \\
(23.87)\end{array}$ & .50 \\
\hline $\bar{\Delta}$ & \multicolumn{3}{|c|}{$8.61(18.35)$} & \multicolumn{4}{|c|}{$13.56(19.77)$} & \multicolumn{3}{|c|}{$11.57(19.30)$} \\
\hline \multicolumn{11}{|c|}{$\begin{array}{l}\text { On-Track Sample }- \text { Feedback Type } \\
\qquad(n=1932)\end{array}$} \\
\hline & \multicolumn{3}{|c|}{$\begin{array}{l}\text { Treatment as Usual } \\
\qquad(n=1159)\end{array}$} & \multicolumn{4}{|c|}{$\begin{array}{c}\text { Immediate Electronic OQ-45 } \\
\text { Therapist Feedback } \\
(n=388)\end{array}$} & \multicolumn{3}{|c|}{$\begin{array}{l}\text { Immediate Electronic OQ-45 } \\
\text { Client/Therapist Feedback } \\
\qquad(n=385)\end{array}$} \\
\hline & Pre- & Post- & ES (d) & Pre- & Pos & & ES (d) & Pre- & & $\mathrm{ES}(\mathrm{d})$ \\
\hline $\begin{array}{l}\mathrm{M} \\
(\mathrm{SD})\end{array}$ & $\begin{array}{l}68.01 \\
(22.71)\end{array}$ & $\begin{array}{l}57.12 \\
(22.36)\end{array}$ & .48 & $\begin{array}{l}67.22 \\
(21.86)\end{array}$ & $\begin{array}{l}54.0 \\
(21.9\end{array}$ & & .67 & $\begin{array}{l}69.4 \\
(22.81\end{array}$ & & .63 \\
\hline$\Delta$ & \multicolumn{3}{|c|}{$10.92(17.12)$} & \multicolumn{4}{|c|}{$13.14(18.862)$} & \multicolumn{3}{|c|}{13.27 (18.93) } \\
\hline \multicolumn{11}{|c|}{$\begin{array}{l}\text { On-Track Sample }- \text { Feedback Timing } \\
\qquad(n=2936)\end{array}$} \\
\hline & \multicolumn{3}{|c|}{$\begin{array}{l}\text { Treatment as Usual } \\
\quad(n=1159)\end{array}$} & \multicolumn{4}{|c|}{$\begin{array}{l}\text { Week-Delayed OQ-45 } \\
\text { Feedback } \\
(n=1004)\end{array}$} & \multicolumn{3}{|c|}{$\begin{array}{c}\text { Immediate Electronic OQ-45 } \\
\text { Feedback } \\
(n=773)\end{array}$} \\
\hline & Pre- & Post- & ES (d) & Pre- & Pos & & ES (d) & Pre & & ES (d) \\
\hline $\begin{array}{l}\mathrm{M} \\
(\mathrm{SD})\end{array}$ & $\begin{array}{l}68.01 \\
(22.71) \\
\end{array}$ & $\begin{array}{l}57.12 \\
(22.36)\end{array}$ & .48 & $\begin{array}{l}67.96 \\
(22.97) \\
\end{array}$ & $\begin{array}{l}52.0 \\
(22.7\end{array}$ & & .70 & $\begin{array}{l}68.3 \\
(22.3 \\
\end{array}$ & & .60 \\
\hline$\Delta$ & \multicolumn{3}{|c|}{$10.92(17.12)$} & \multicolumn{4}{|c|}{$15.95(18.05)$} & \multicolumn{3}{|c|}{$13.20(18.76)$} \\
\hline
\end{tabular}




\begin{tabular}{|c|c|c|c|c|c|c|c|c|c|}
\hline \multicolumn{10}{|c|}{$\begin{array}{l}\text { Not-on-Track Sample - Feedback Type } \\
\qquad(n=614)\end{array}$} \\
\hline & \multicolumn{3}{|c|}{$\begin{array}{l}\text { Treatment as Usual } \\
\qquad(n=286)\end{array}$} & \multicolumn{3}{|c|}{$\begin{array}{c}\text { Immediate Electronic OQ-45 } \\
\text { Therapist Feedback } \\
(n=164)\end{array}$} & \multicolumn{3}{|c|}{$\begin{array}{c}\text { Immediate Electronic OQ-45 } \\
\text { Client/Therapist Feedback } \\
(n=164)\end{array}$} \\
\hline & Pre- & Post- & ES (d) & Pre- & Post- & ES (d) & Pre- & Post- & ES (d) \\
\hline $\begin{array}{l}\mathrm{M} \\
(\mathrm{SD})\end{array}$ & $\begin{array}{l}79.44 \\
(19.64)\end{array}$ & $\begin{array}{l}80.17 \\
(20.74)\end{array}$ & -.036 & $\begin{array}{l}77.08 \\
(18.65)\end{array}$ & $\begin{array}{l}70.83 \\
(21.37)\end{array}$ & .60 & $\begin{array}{l}80.83 \\
(20.17)\end{array}$ & $\begin{array}{l}71.57 \\
(22.06)\end{array}$ & .44 \\
\hline$\Delta$ & \multicolumn{3}{|c|}{$-.72(20.19)$} & \multicolumn{3}{|c|}{$6.25(19.36)$} & \multicolumn{3}{|c|}{$9.21(20.61)$} \\
\hline \multicolumn{10}{|c|}{$\begin{array}{l}\text { Not-on-Track Sample }- \text { Feedback Timing } \\
(n=983)\end{array}$} \\
\hline & \multicolumn{3}{|c|}{$\begin{array}{l}\text { Treatment as Usual } \\
\qquad(n=286)\end{array}$} & \multicolumn{3}{|c|}{$\begin{array}{c}\text { Week-Delayed OQ-45 } \\
\text { Feedback } \\
(n=369)\end{array}$} & \multicolumn{3}{|c|}{$\begin{array}{c}\text { Immediate Electronic OQ-45 } \\
\text { Feedback } \\
(n=328)\end{array}$} \\
\hline & Pre- & Post- & ES (d) & Pre- & Post- & ES (d) & Pre- & Post- & $\mathrm{ES}(\mathrm{d})$ \\
\hline $\begin{array}{l}\mathrm{M} \\
\text { (SD) }\end{array}$ & $\begin{array}{l}79.44 \\
(19.64)\end{array}$ & $\begin{array}{l}80.17 \\
(20.74)\end{array}$ & -.036 & $\begin{array}{l}80.04 \\
(19.17)\end{array}$ & $\begin{array}{l}72.99 \\
(22.36)\end{array}$ & .34 & $\begin{array}{l}78.96 \\
(19.49)\end{array}$ & $\begin{array}{l}71.20 \\
(21.68)\end{array}$ & .38 \\
\hline$\Delta$ & \multicolumn{3}{|c|}{$-.72(20.19)$} & \multicolumn{3}{|c|}{$\frac{(22.56)}{7.05(22.59)}$} & \multicolumn{3}{|c|}{$7.73(20.02)$} \\
\hline
\end{tabular}




\section{Table 2}

Session Means by Treatment Group

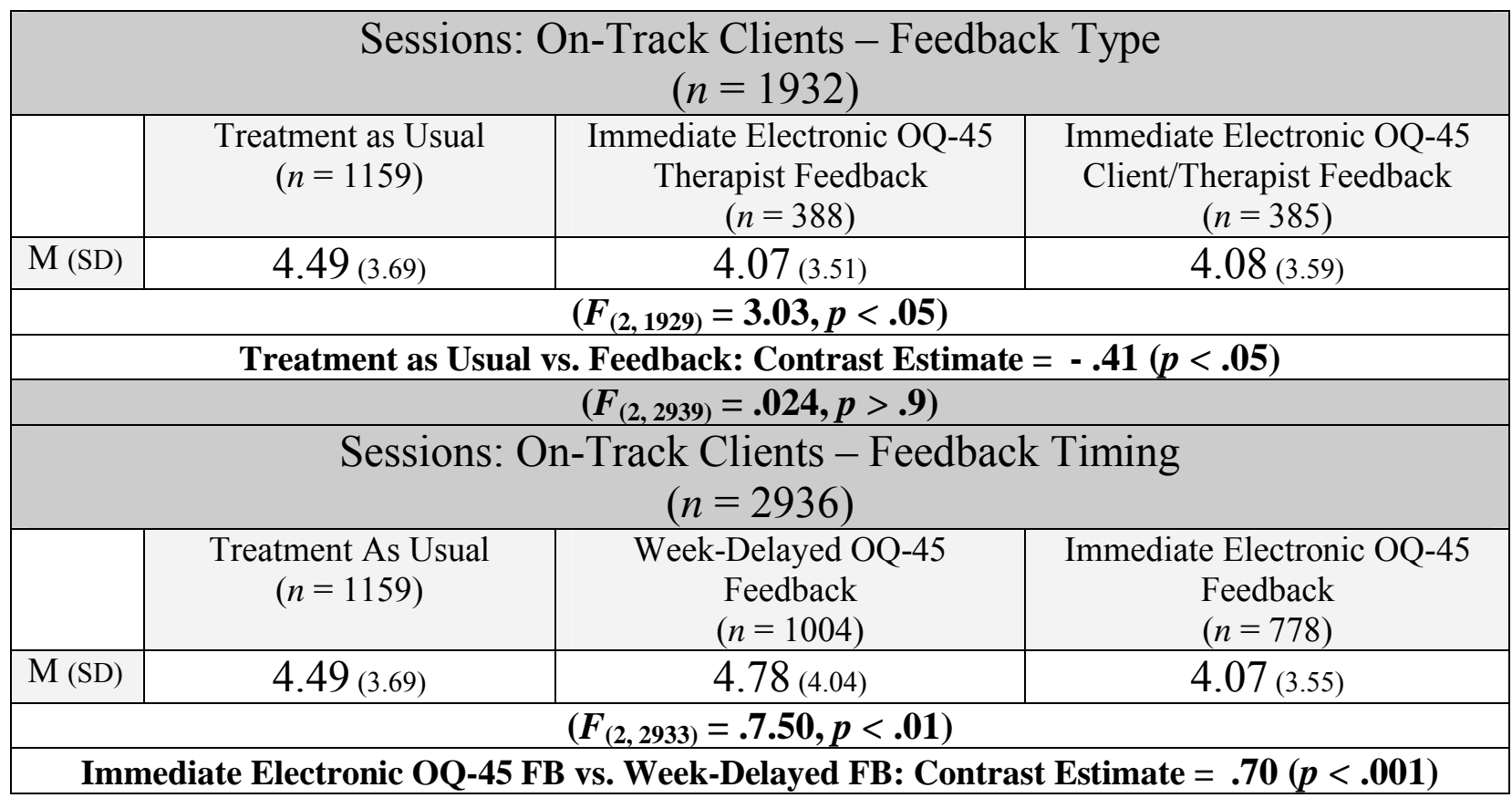

\begin{tabular}{|c|c|c|c|}
\hline \multicolumn{4}{|c|}{$\begin{array}{l}\text { Sessions: Not-On-Track Clients - Feedback Type } \\
\qquad(n=614)\end{array}$} \\
\hline & $\begin{array}{l}\text { Treatment as Usual } \\
\qquad(n=286)\end{array}$ & $\begin{array}{l}\text { Immediate Electronic OQ-45 } \\
\text { Therapist Feedback } \\
(n=164)\end{array}$ & $\begin{array}{l}\text { Immediate Electronic OQ-45 } \\
\text { Client/Therapist Feedback } \\
(n=164)\end{array}$ \\
\hline $\mathrm{M}(\mathrm{SD})$ & $7.98(4.49)$ & $9.59_{(6.95)}$ & $10.00(7.29)$ \\
\hline \multicolumn{4}{|c|}{$\left(F_{(2,611}=6.29, p<.01\right)$} \\
\hline
\end{tabular}

\begin{tabular}{|c|c|c|c|}
\hline \multicolumn{4}{|c|}{$\begin{array}{l}\text { Sessions: Not-On-Track Clients - Feedback Timing } \\
\qquad(n=983)\end{array}$} \\
\hline & $\begin{array}{l}\text { Treatment as Usual } \\
\quad(n=286)\end{array}$ & $\begin{array}{c}\text { Week-Delayed OQ-45 } \\
\text { Feedback } \\
(n=369)\end{array}$ & $\begin{array}{c}\text { Immediate Electronic OQ-45 } \\
\text { Feedback } \\
(n=328)\end{array}$ \\
\hline $\mathrm{M}(\mathrm{SD})$ & $7.98(4.9)$ & $12.09(8.43)$ & $9.80(7.11)$ \\
\hline \multicolumn{4}{|c|}{$\left(F_{(2,979)}=29.13, p<.01\right)$} \\
\hline \multicolumn{4}{|c|}{ Week-Delayed Feedback versus Immediate Electronic FB: Contrast Estimate $=2.3(p<.001)$} \\
\hline \multicolumn{4}{|c|}{ Treatment as Usual versus Feedback: Contrast Estimate $=-2.97(p<.001)$} \\
\hline
\end{tabular}




\begin{tabular}{|c|c|c|}
\hline \multicolumn{3}{|c|}{$\begin{array}{l}\text { Sessions: Not-On-Track Clinical Support Tools Completers - Feedback Type } \\
\qquad(\mathrm{n}=328)\end{array}$} \\
\hline & $\begin{array}{c}\text { Immediate Electronic OQ-45 Feedback } \\
\text { No CST Feedback } \\
(n=122)\end{array}$ & $\begin{array}{c}\text { Immediate Electronic OQ-45 Feedback + CST } \\
\text { Feedback } \\
(n=85)\end{array}$ \\
\hline $\mathrm{M}(\mathrm{SD})$ & $10.67(7.54)$ & $12.99(7.65)$ \\
\hline \multicolumn{3}{|c|}{$\left(F_{(2,490)}=26.08, p<.001\right)$} \\
\hline & CST Feedback vs. $n$ & $-2.33(p<.0$ \\
\hline
\end{tabular}

\begin{tabular}{|c|c|c|}
\hline \multicolumn{3}{|c|}{$\begin{array}{l}\text { Sessions: Not-On-Track Clinical Support Tools Completers - Feedback Timing } \\
\qquad(n=180)\end{array}$} \\
\hline & $\begin{array}{l}\text { 2-Week delayed CST Feedback } \\
(n=95)\end{array}$ & $\begin{array}{l}\text { Week-Delayed CST Feedback } \\
\qquad(n=85)\end{array}$ \\
\hline $\mathrm{M}(\mathrm{SD})$ & $16.23(8.71)$ & 12.99 (7.65) \\
\hline \multicolumn{3}{|c|}{$\left(F_{(2,463)}=71.02, p<.001\right)$} \\
\hline
\end{tabular}




\section{Table 3}

Means, Standard Deviations, and Effect Sizes for Pre and Post Outcomes by Treatment Group: Not-on-Track Clinical Support Tools comparison by CST Feedback Type and CST Feedback Timing

\begin{tabular}{|c|c|c|c|c|c|c|}
\hline \multicolumn{7}{|c|}{$\begin{array}{l}\text { NOT Clinical Support Tools Completers - Feedback Type } \\
\qquad(\mathrm{n}=207)\end{array}$} \\
\hline & \multicolumn{3}{|c|}{$\begin{array}{l}\text { Immediate Electronic OQ-45 Feedback } \\
\text { + No CST Feedback } \\
(n=122)\end{array}$} & \multicolumn{3}{|c|}{$\begin{array}{l}\text { Immediate Electronic OQ-45 Feedback + Week- } \\
\text { Delayed CST Feedback } \\
\qquad(n=85)\end{array}$} \\
\hline & Pre- & Post- & $\mathrm{ES}(\mathrm{d})$ & Pre- & Post- & ES (d) \\
\hline $\begin{array}{l}\text { M } \\
\text { (SD) }\end{array}$ & $\begin{array}{l}78.08 \\
(20.03)\end{array}$ & $\begin{array}{l}68.58 \\
(20.46)\end{array}$ & .47 & $\begin{array}{l}83.12 \\
(18.54)\end{array}$ & $\begin{array}{l}64.45 \\
(21.59)\end{array}$ & .93 \\
\hline$\Delta$ & \multicolumn{3}{|c|}{$9.50(20.37)$} & \multicolumn{3}{|c|}{18.55 (19.77) } \\
\hline \multicolumn{7}{|c|}{$\begin{array}{l}\text { NOT Clinical Support Tools Completers -Feedback Timing } \\
\qquad(n=180)\end{array}$} \\
\hline & \multicolumn{3}{|c|}{$\begin{array}{l}\text { Week- Delayed OQ-45 Feedback + 2- } \\
\text { Week-Delayed CST Feedback } \\
(n=95)\end{array}$} & \multicolumn{3}{|c|}{$\begin{array}{l}\text { Immediate Electronic OQ-45 Feedback + Week- } \\
\text { Delayed CST Feedback } \\
(n=85)\end{array}$} \\
\hline & Pre- & Post- & ES (d) & Pre- & Post- & ES (d) \\
\hline $\begin{array}{l}\mathrm{M} \\
\text { (SD) }\end{array}$ & $\begin{array}{l}79.45 \\
(18.56)\end{array}$ & $\begin{array}{l}65.39 \\
(22.06)\end{array}$ & .69 & $\begin{array}{l}83.12 \\
(18.54)\end{array}$ & $\begin{array}{l}64.45 \\
(21.59)\end{array}$ & .93 \\
\hline$\Delta$ & \multicolumn{3}{|c|}{$14.06(20.96)$} & \multicolumn{3}{|c|}{18.55 (19.77) } \\
\hline
\end{tabular}




\section{Table 4}

Percent of Not-On-Track Clients Meeting Criteria for Clinically Significant Outcome at Termination

\begin{tabular}{|l|c|c|c|}
\hline $\begin{array}{l}\text { Feedback Timing } \\
\text { Outcome Classification }\end{array}$ & $\begin{array}{c}\text { Treatment as Usual } \\
(n=286)\end{array}$ & $\begin{array}{c}\text { 2-Week-Delayed CST } \\
\text { Feedback } \\
(n=95)\end{array}$ & $\begin{array}{c}\text { Week Delayed CST } \\
\text { Feedback } \\
(n=85)\end{array}$ \\
\cline { 2 - 4 } $\begin{array}{l}\text { Deteriorated or } \\
\text { Reliable Worsening }\end{array}$ & $n(\%)$ & $n(\%)$ & $n(\%)$ \\
\hline No Change & $165(57.7 \%)$ & $48(50.5 \%)$ & $29(34.1 \%)$ \\
\hline $\begin{array}{l}\text { Reliable or Clinically } \\
\text { Significant Change }\end{array}$ & $60(21 \%)$ & $40(42.1 \%)$ & $52(61.2 \%)$ \\
\hline $\begin{array}{l}\text { Feedback Type } \\
\text { Outcome Classification }\end{array}$ & $\begin{array}{c}\text { Treatment as Usual } \\
(\mathrm{n}=286)\end{array}$ & $\begin{array}{c}\text { No CST Feedback } \\
(\mathrm{n}=122)\end{array}$ & $\begin{array}{c}\text { CST Feedback } \\
(\mathrm{n}=85)\end{array}$ \\
\cline { 2 - 4 } & $n(\%)$ & $n(\%)$ & $n(\%)$ \\
\hline $\begin{array}{l}\text { Deteriorated or } \\
\text { Reliable Worsening }\end{array}$ & $61(21.3 \%)$ & $11(9.0 \%)$ & $4(4.7 \%)$ \\
\hline No Change & $165(57.7 \%)$ & $64(52.5 \%)$ & $29(34.1 \%)$ \\
\hline $\begin{array}{l}\text { Reliable or Clinically } \\
\text { Significant Change }\end{array}$ & $60(21 \%)$ & $47(38.5 \%)$ & $52(61.2 \%)$ \\
\hline
\end{tabular}




\section{Figure 1.1}

Treatment as usual design

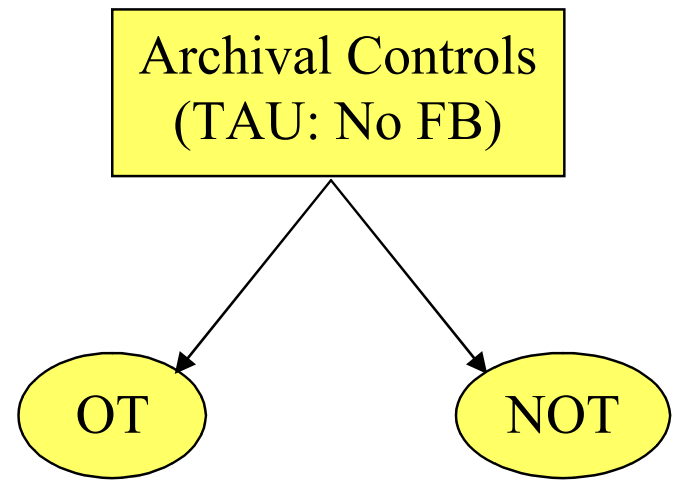

\section{Figure 1.2}

Week-Delayed OQ-45 feedback design

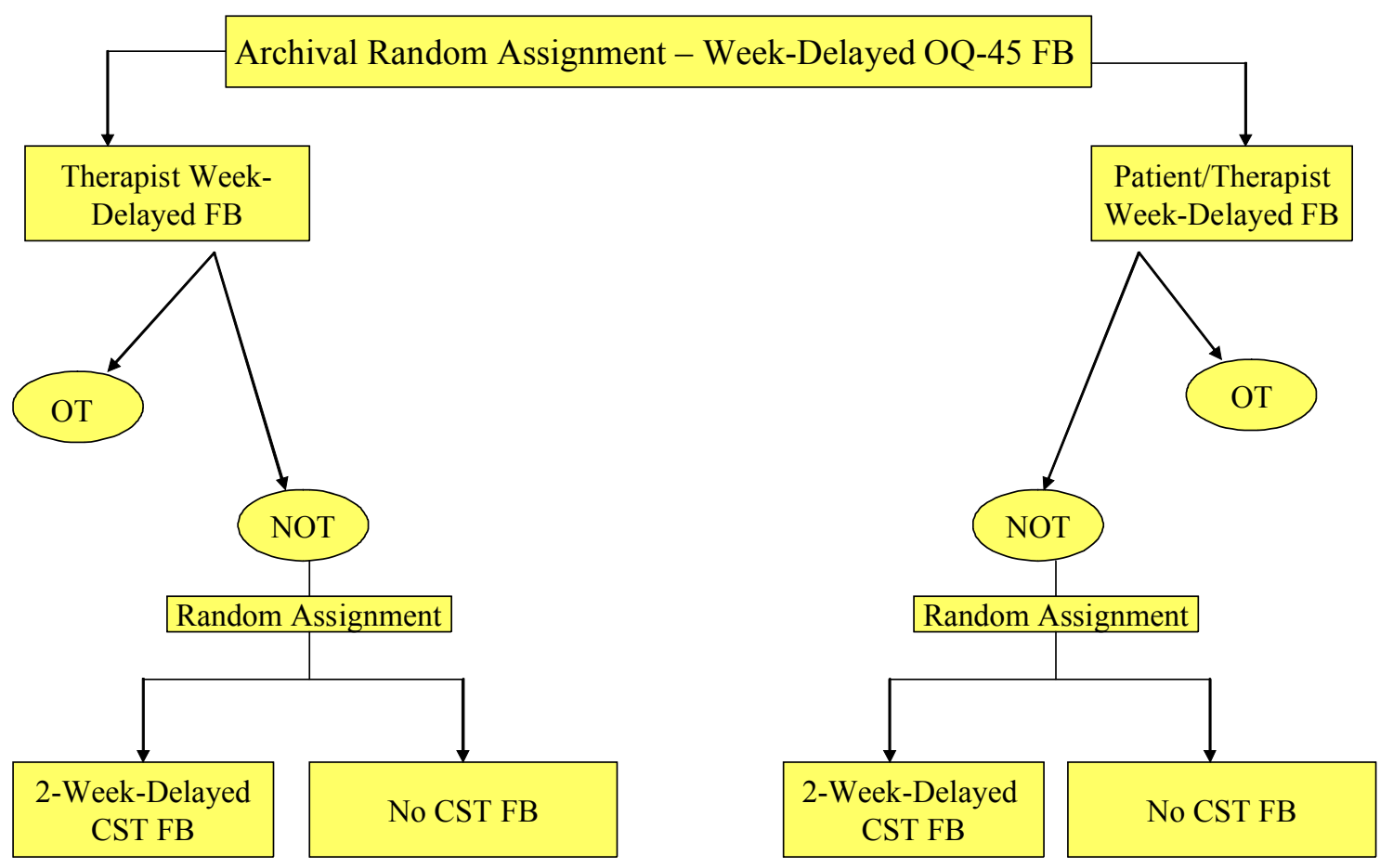




\section{Figure 1.3}

Immediate Electronic OQ-45 Feedback Design

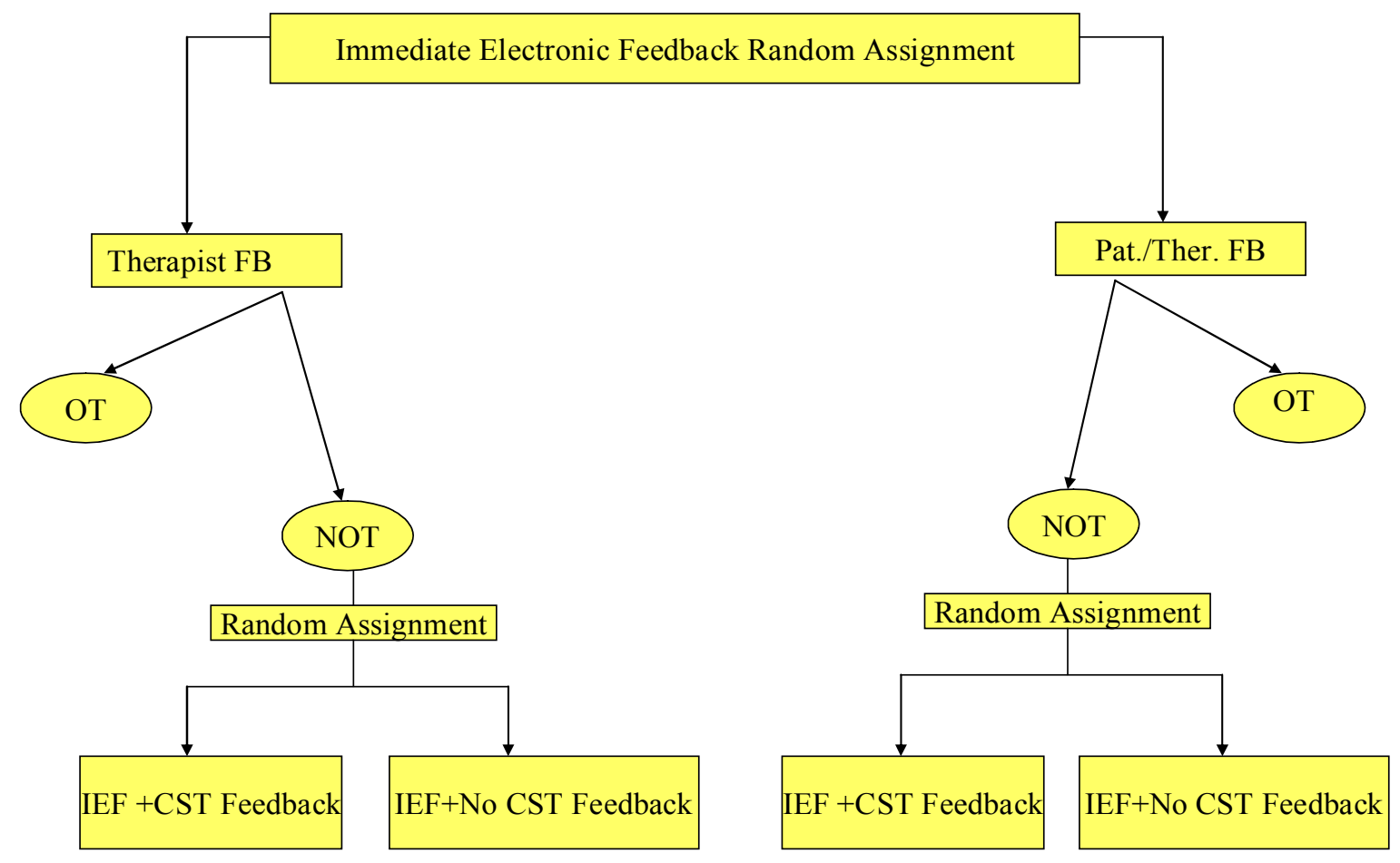




\section{Figure 2.1}

Average scores for the CST Feedback timing conditions at pretreatment, time of warning, and termination

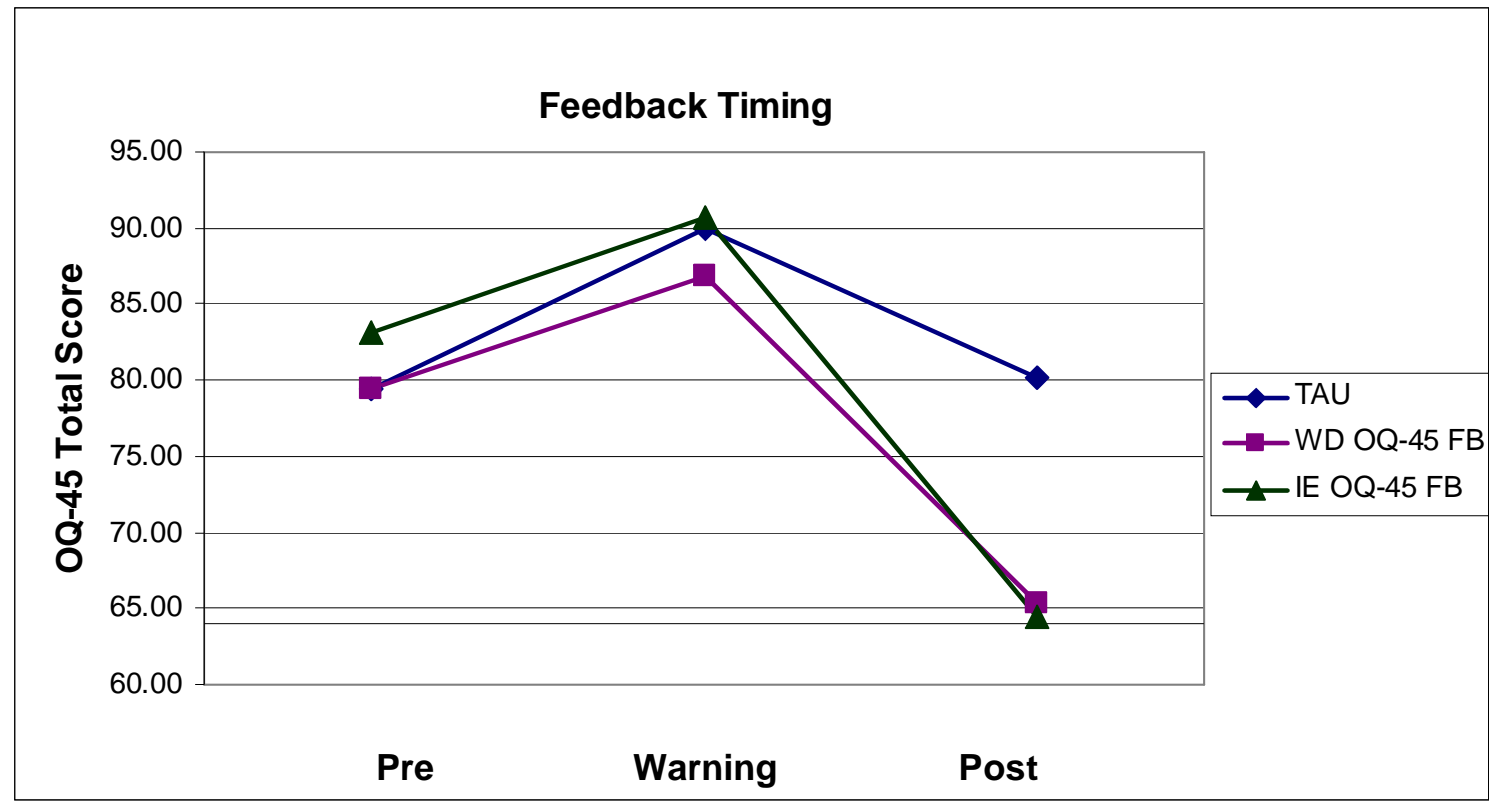

\section{Figure 2.2}

Average scores for the CST feedback conditions at pretreatment, time of warning, and termination

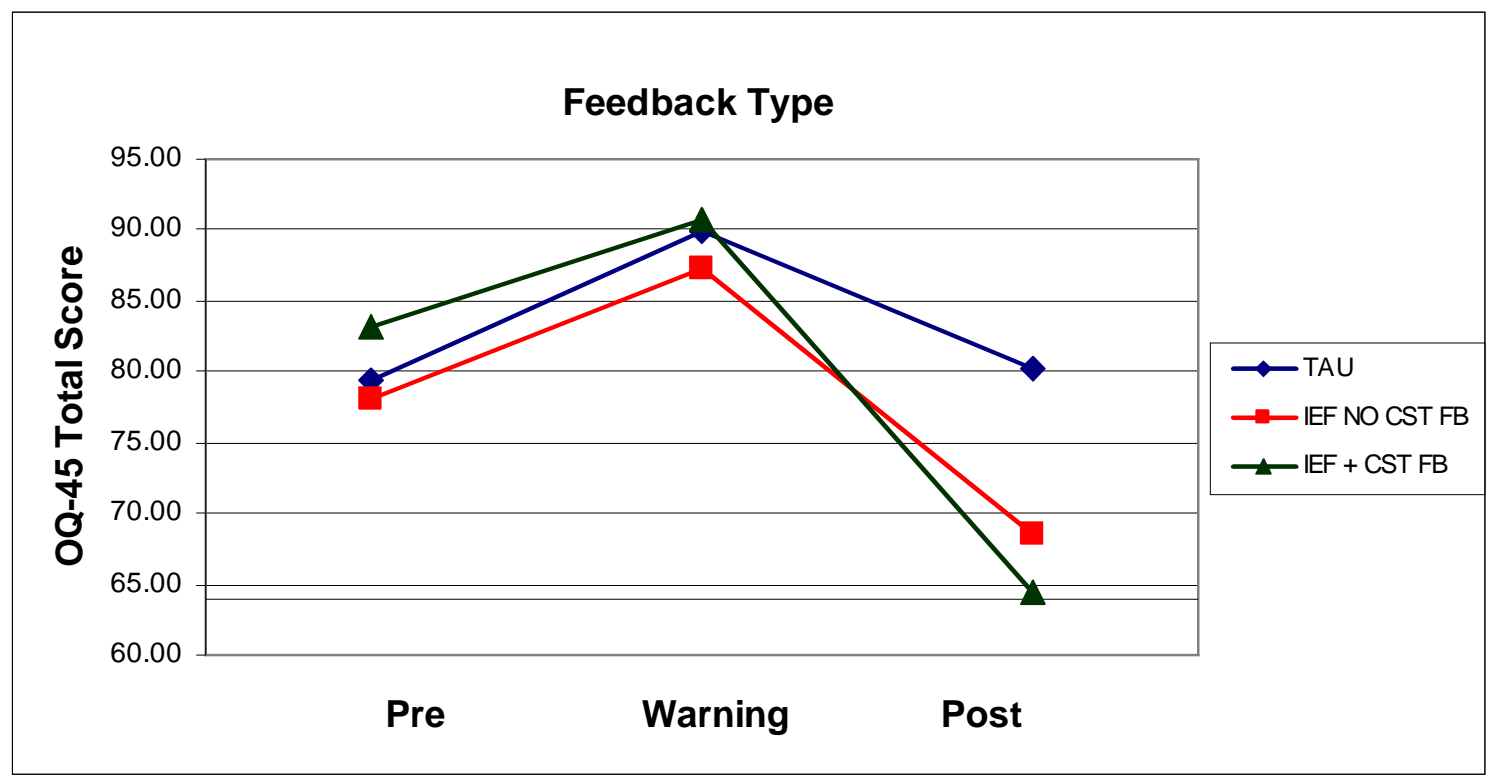




\section{Appendix B.1}

Sample of messages to be delivered to therapists

White Feedback Message

Sessions 2-4:

- The patient is functioning in the normal range. Consider termination.

\section{Green Feedback Message}

Sessions 5-8:

- The patient is functioning near the normal range and yet not reporting a significant benefit from treatment. Keep monitoring treatment response.

\section{Yellow Feedback Message}

9 or more sessions:

- The rate of change the patient is making is less than adequate.

Recommendation: be alert to the need to improve the therapeutic alliance, reconsider the clients readiness for change, intervene to strengthen social supports or possibly altering your treatment plan by intensifying treatment, shifting intervention strategies, and monitoring progress especially carefully. This patient may end up with no significant benefit from therapy. The patient is experiencing a high level of distress and although improving somewhat is clearly in need of further help.

\section{$\underline{\text { Red Feedback Message }}$}

\section{9 or more sessions:}

- The patient is not making the expected level of progress. Chances are they may drop out of treatment prematurely or have a negative treatment outcome. Steps should be taken to carefully review this case and identify reasons for poor progress. It may be helpful to assess the quality of the therapeutic alliance, the client's motivation, social support network, or decide upon a new course of action, such as referral for medication or intensification of treatment. The treatment plan may need to be reconsidered.. The patient is clearly in need of further help but the treatment is not having the expected positive impact and is not likely to have a positive result unless a way is found to strengthen the impact of treatment. 


\section{Apppendix B.2}

Sample of messages to be delivered to patients

\section{White Feedback Message}

\section{Sessions 2-4:}

- Please note that the information presented below is based on your responses to the questionnaire that you complete prior to each therapy session. It appears that you are experiencing low levels of distress as measured by your responses. If your level of progress is maintained, you will likely have a positive therapy outcome. Your responses to the questionnaire suggest that you feel more like those persons who are not overly burdened by their distress, and who do not believe they have a need for treatment. We encourage you to continue working as hard as you have to obtain the most you can from therapy.

\section{Green Feedback Message}

Sessions 5-8:

- Please note that the information presented below is based on your responses to the questionnaire that you complete prior to each therapy session. Currently, your level of progress approximates that accomplished by most clients in therapy. However, there is likely still time for additional improvement. We urge you to continue working as hard as you have to experience the greatest benefit possible from treatment. If you have not already done so, now may be the right time to discuss with your therapist the aspects of treatment that have been the most helpful, as well as aspects of treatment that have not been helpful.

\section{Yellow/Red Feedback Message}

Session 9 or greater:

- Please note that the following information is based on your responses to the questionnaire that you have completed prior to each therapy session. Despite the late stage of your treatment, compared to most clients, it does not appear as though you have experienced much relief from treatment. There is a strong possibility that you will not experience a noticeable benefit from therapy, unless something changes in your treatment. We strongly encourage you to consider, with your therapist, a new course of action aimed at providing the benefits that you would like from treatment. It may also require your willingness to complete additional questionnaires that may shed light about why you are not experiencing the expected rate of progress. 


\section{References}

Ackerman, S.J., Benjamin, L.S., Beutler, L.E., Gelso, C.J., Goldfried, M.R., Hill, C. et al., (2001). Empirically supported therapy relationships: conclusions and recommendations of the Division 29 Tack Force. Psychotherapy: Theory, Research, Practice, and Training, 38, 495-497.

Agostinelli, G., Brown, J. M., \& Miller, W. R. (1995). Effects of normative feedback on consumption among heavy drinking college students. Journal of Drug Education, 25, 31-40.

Ammons, R. B. (1956). Effects of knowledge and performance: A survey and tentative theoretical formulation. Journal of General Psychology, 54, 279-299.

Anderson, E. M., \& Lambert, M. J. (2001). A survival analysis of clinically significant change in outpatient psychotherapy. Journal of Clinical Psychology, 57, 875-888.

Aronson, E. (1999). The power of self-persuasion. American Psychologist, 54, 875-884.

Ashford, S. J., \& Cummings, L. L. (1983). Feedback as an individual resource: Personal strategies of creating information. Organizational Behavior and Human Decision Processes, 32, 370-398.

Baer, J. S., Marlatt, G. A., Kivlahan, K. R., Fromme, K., Larimer, M. E., \& Williams, E. (1992). An experimental test of three methods of alcohol reduction with young adults. Journal of Consulting and Clinical Psychology, 60, 974-979.

Bandura, A. (1982). Self-efficacy mechanism in human agency. American Psychologist, 37: $122-147$. 
Bandura, A. (1991). Social cognitive theory of self regulation. Organizational Behavior and Human Decision Processes, 50, 248-287.

Bankoff, E. A., \& Howard, K. I. (1992). The social network of the psychotherapy patient and effective psychotherapeutic process. Journal of Psychotherapy Integration, 2, 273-294.

Barkham, M., Margison, F., Leach, C., Lucock, M., Mellor-Clark, J., Evans, C., et al., (2001). Service profiling and outcomes benchmarking using the CORE-OM: Toward practice-based evidence in the psychological therapies. Journal of Consulting and Clinical Psychology, 69, 184-196.

Barlow, D.H. (2004). Psychological Treatments. American Psychologist, 59, 869-878.

Barone, D.F., Hutchings, P.S., Kimmel, H.J., Traub, H.L., Cooper, J.T., Marshall, C.M. (2005). Increasing empathic accuracy through practice and feedback in a clinical interviewing course. Journal of Social and Clinical Psychology,24, 156-171.

Bauer, S., Lambert, M. J., \& Nielsen, S. L. (2004). Clinical significance methods: A comparison of statistical techniques. Journal of Personality Assessment, 82, 60-70.

Baumeister, R. F., Hutton, D. G., \& Cairns, K. J. (1990). Negative effects of praise on skilled performance. Basic and Applied Social Psychology, 11, 131-148.

Beck, A. T., Ward, C. H., Medelson, M., Mock, J., \& Erbaugh, J. (1961). An inventory for measuring depression. Archives of General Psychiatry, 4, 561-571.

Beckstead, D. J., Hatch, A. L., Lambert, M. J., Eggett, D. L., Goates, M. K., \& Vermeersch, D. A. (2003).Clinical significance of the Outcome Questionnaire (OQ45.2). The Behavior Analyst Today, 4, 79-90. 
Beutler, L. E. (2001). Comparisons among quality assurance systems: From outcome assessment to clinical utility. Journal of Consulting and Clinical Psychology, 69, 197-204.

Bickman, L. (1999). Practice makes perfect and other myths about mental health services. American Psychologist, 54, 958-973.

Bickman, L., Rosof, J., Salzer, M.S., Summerfelt, W.T., Noser, K., Wilson, S.J., \& Karver, M.S. (2000). What information do clinicians value for monitoring adolescent client progress and outcome? Professional Psychology: Research and Practice 31, 70-74.

Blanton, H., Pelham, B.W., DeHart, T., \& Carvallo, M. (2001). Overconfidence as dissonance reduction. Journal of Experimental Social Psychology, 37, 373-385.

Blatt, S. (1995). The destructiveness of perfectionism: Implications for the treatment of depression. American Psychologist, 50, 1003-1020.

Blatt, S.J., \& Zuroff D.C. (2002) Perfectionism in the therapeutic process. In G.L. Flett \& P.L. Hewitt, Perfectionism: Theory research and treatment (pp. 393-406). Washington, D.C.: APA

Bordin, E. S. (1979). The generalizability of the psychoanalytic concept of the working alliance. Psychotherapy: Theory, Research and Practice, 16, 252-260.

Brown, G., \& Lambert, M. J. (1998, June). Tracking client progress: Decision making for cases who are not benefiting from psychotherapy. Paper presented at the annual meeting of the Society for Psychotherapy Research. Snowbird, UT.

Burns, D.D. (1980). The perfectionist's script of self-defeat. Psychology Today November, 34-52. 
Carver, C. S., \& Scheier, M. F. (1990). Origins and function of positive and negative affect: A control-process review. Psychological Review, 97, 19-35.

Cash, T.F., \& Szymanski, M.L. (1995). The development and validation of the Body-Image Ideals Questionnaire. Journal of Personality Assesssment, 64, 466-477.

Claiborn, C.D., Goodyear, R.K., \& Horner, P.A. (2001). Feedback. Psycotherapy: theory, research, practice, training, 38, 401-405.

Clark, M., Ghandour, F., Houston Miller, N., Taylor, C. B., Bandura, A., \& DeBusk, R. F. (1997). Development and evaluation of a computer-based system for dietary management of hyperlipidemia. Journal of the American Dietetic Association, 97, $146-150$.

Collins. D.R. \& Stukas, A.A. (2006). The effects of feedback self-consistency, therapist status, and attitude toward therapy on reaction to personality feedback. The Journal of Social Psychology, 146, $463-483$.

Cooper, Z., Cooper, P.J., \& Fairburn, C.G. (1985). The specificity of the eating disorder inventory. British Journal of Clinical Psychology, 24, 129-130.

Curry, S. J., McBride, C., Grothaus, L. C., Louie, D., \& Wagner, E. H. (1995). A randomized trial of self-help materials, personalized feedback, and telephone counseling with nonvolunteer smokers. Journal of Consulting and Clinical Psychology, 63, 1005-1014.

Dana, R. H., \& Graham, E. D. (1976). Feedback of client-relevant information and clinical practice. Journal of Personality Assessment, 40, 464-469.

Dawes, R. M. (1989). Experience and validity of clinical judgment: The illusory correlation. Behavioral Sciences and the Law, 7, 457-467. 
Deci, E.L., \& Ryan, R.M. (1985). Intrinsic motivation and self-determination in human behavior. New York: Plenum

Derogatis, L. R. (1983). The SCL-90: Administration, scoring, and procedures for the SCL-90. Baltimore: Clinical Psychometric Research.

Dew, S., \& Reimer, M. (2002). Why inaccurate self-evaluation of performance justifies feedback interventions. Vanderbilt University: Manuscript in progress.

Dew, S., \& Riemer, M. (2003). Why inaccurate self-evaluation of performance justifies feedback interventions. In L. Bickman (chair), Improving outcomes through feedback intervention. Symposium conducted at the $16^{\text {th }}$ Annual Research Conference, A System of Care for Children's Mental Health: Expanding the Research Base. Tampa: University of South Florida, The Louis de la Parte Florida Mental Health Institute, Research and Training Center for Children's Mental Health.

Drum, D. J., \& Baron, A. (1998). Highlights of the research consortium outcomes project. Presented at the annual meetings of the Association of University and College Counseling Center Directors, Santa Fe, New Mexico.

Duval, T. S., Duval, V. H., \& Mulilis, J. (1992). Effects of self-focus, discrepancy between self and standard, and outcome expectancy favorability on the tendency to match self to standard or to withdraw. Journal of Personality and Social Psychology, 62, $340-348$.

Earley, P. C. (1988). Computer-generated performance feedback in the magazinesubscription industry. Organizational Behavior and Human Decision Processes, 41, $50-64$. 
Evans, C., Connell, J., Barkham, M., Marshall, C., \& Mellor-Clark, John. (2003).

Practice-based evidence: Benchmarking NHS Primary Care Counselling Services at National and Local Levels. Clinical Psychology and Psychotherapy, 10, 374-388.

Festinger, L. (1954). A theory of social comparison processes. Human Relations, 7, 117 140.

Festinger, L. (1957). A theory of cognitive dissonance. Evanston, IL: Row Peterson.

Finn, S. E., \& Tonsager, M. E. (1992). Therapeutic effects of providing MMPI-2 test feedback to college students awaiting therapy. Psychological Assessment, 4, 278287.

Flett, G.L., Hewitt, P.L., \& Dyck, D.G. (1989). Self-oriented perfectionism, neurotocism, and anxiety. Personality and Individual Differences, 10, 731-735.

Flowers, J. V. (1979). The differential outcome effects of simple advice, alternatives and instructions in group psychotherapy. International Journal of Group Psychotherapy, 29, 305-316.

Frost, R.O., Marten, P., Lahart, C., \& Rosenblate, R. (1990). The dimensions of perfectionism. Cognitive Therapy and Research, 14, 449-468.

Giesler, R.B., Josephs, R.A., \& Swann, W.B. (1996). Self-verification in clinical depression: the desire for negative evaluation. Journal of Abnormal Psychology, 105, 358-368.

Garfield, S.L., \& Bergin, A.E. (Eds). (1994). Handbook of psychotherapy and behavior change. ( $4^{\text {th }}$ ed.). New York: Wiley. 
Goodyear, R. K. (1990). Research on the effects of test interpretation: A review. Counseling Psychologist, 18, 240-257.

Gordon, R.N. (1976). Effects of volunteering and responsibility on perceived value and effectiveness of a clinical treatment. Journal of Consulting and Clinical Psychology, 44, 799-801.

Grove, W. M. \& Meehl, P. E. (1996). Comparative efficiency of informal (subjective, impressionistic) and formal (mechanical, algorithmic) prediction procedures: The clinical-statistical controversy. Psychology, Public Policy, and Law, 2), 293-323.

Grove, W.M., Zald, D.H., Lebow, B.S., Snitz, B.E., \& Nelson, C. (2000). Clinical versus mechanical prediction: a meta-analysis. Psychological Assessment, 12, 19-31.

Gustafson, D. H., Hawkins, R., Boberg, E., Pingree, S., Serlin, R. E., Graziano, F. et al. (1999). Impact of a patient-centered, computer-based health information/support system. American Journal of Preventive Medicine, 16, 1-9.

Haas, E., Hill, R.D., Lambert, M.J. Do early responders to psychotherapy maintain treatment gains. Journal of Clinical Psychology, 58, 1157-1172.

Hamachek, D.E. (1978). Psychodynamics of normal and neurotic and neurotic perfectionism. Psychology, 15, 27-33.

Hannan, C., Lambert, M. J., Harmon, C., Nielsen, S. L., Smart, D. W., Shimokawa, K., et al. (2005). A lab test and algorithms for identifying clients at risk for treatment failure. Journal of Clinical Psychology: In Session, 61, 155-63.

Hansen, N. B., Lambert, M. J., \& Forman, E. M. (2002). The psychotherapy dose-response effect and its implications for treatment delivery services. Clinical Psychology Science \& Practice, 9, 329-343. 
Hanson, W. E., Claiborn, C. D., \& Kerr, B. (1997). Differential effects of two testinterpretation styles in counseling: A field study. Journal of Counseling Psychology, 44, 400-405.

Harmon, S.C., Lambert M.J., Smart, D.W., Hawkins, E.J., Nielsen, S.L., Slade, K, et al. (2007). Enhancing outcome for potential treatment failures: Therapist-client feedback and clinical support tools. Psychotherapy Research, 17, 379-392.

Harmon-Jones, E., \& Mills. J. (1999). Cognitive Dissonance- Progress on a pivotal theory in social psychology. Washington, DC: American Psychological Association.

Hartley D., \& Strupp H. (1983) The therapeutic alliance: its relationship to outcome in brief psychotherapy. Empirical Studies of Psychoanalytic Theories. $1^{\text {st }}$ edition Edited by Masling J. Hillsdale, NJ, Erlbaum.

Hawkins, E. J., Lambert, M. J., Vermeersch, D. A., Slade, K., \& Tuttle, K. (2004). The effects of providing patient progress information to therapists and patients. Psychotherapy Research, 31, 308-327.

Hewitt, P.L., \& Dyck, D.G. (1986). Perfectionism, stress, and vulnerability to depression. Cognitive Therapy and Research, 10, 137-142.

Hewitt, P.L., \& Flett, G.L. (1991a). Dimensions of perfectionism in universal depression. Journal of Abnormal Psychology, 100, 98-101.

Hewitt, P.L., \& Flett, G.L. (1991b). Perfectionism in the self and social contexts: Conceptualization, assessment, and association with psychopathology. Journal of Personality and Social Psychology, 60, 456-470.

Hewitt, P.L., Flett, G.L., \& Turnbull-Donovan, W. (1992). Perfectionism and suicide potential. British Journal of Clinical Psychology, 31, 181-190. 
Hill, C. E., Nutt-Williams, E., Heaton, K., Thompson, B., \& Rhoads, R. H. (1996). Therapist retrospective recall of impasses in long-term psychotherapy: A qualitative analysis. Journal of Counseling Psychology, 43, 207-217.

Hill, R.W., Huelsman, T.J., Furr, M.R., Kibler, J., Vicente, B.B., Kennedy, C. (2004). A new measure of perfectionism: The perfectionism inventory. Journal of Personality Assessment, 82, 80-91.

Hollenbeck, J.R., \& Klein, H.J. (1987). Goal commitment and the goal-setting process: problems, prospects, and proposals for future research. Journal of Applied Psychology. 72, 212-220.

Horney, K. (1950). Neurosis and human growth. New York: Norton.

Horowitz, L. M., Rosenberg, S. E., Baer, B. A., Ureno, G., \& Villasenor, V. S. (1988). Inventory of interpersonal problems: Psychometric properties and clinical applications. Journal of Consulting and Clinical Psychology, 56, 885-892.

Horvath, A. O. (2001). The alliance. Psychotherapy: Theory, Research, Practice, Training, 38, 365-372.

Horvath, A. O. \& Symonds, B. D. (1991). Relation between working alliance and outcome in psychotherapy: A meta-analysis. Journal of Counseling Psychology, 38, 139-149.

Howard, K. I., Moras, K., Brill, P. L., Martinovich, Z., \& Lutz, W. (1996). Evaluation of psychotherapy: Efficacy, effectiveness, and patient progress. American Psychologist, 51, 1059-1064.

Hsee, C. K., \& Abelson, R. P. (1991). Velocity relation: Satisfaction as a function of the first derivative of outcome over time. Journal of Personality and Social Psychology, 60, 341-347. 
Hunt, D. L., Haynes, B., Hanna, S. E., \& Smith, K. (1998). Effects of computer-based clinical decision support systems on physician performance and patient outcomes. Journal of the American Medical Association, 280, 1339-1346.

Johnson D.P., \& Slaney, R.B. (1996). Perfectionism: Scale development and a study of perfectionistic clients in counseling. Journal of College Student Development, 37, $29-41$.

Jacobson, N. S., \& Truax, P. (1991). Clinical significance: A statistical approach to defining meaningful change in psychotherapy research. Journal of Consulting and Clinical Psychology, 59, 12-19.

Kadera, S.W., Lambert, M.J., \& Andrews, A.A. (1996). How much therapy is really enough? A session-by-session analysis of the psychotherapy dose-effect relationship. Journal of Psychotherapy Practice and Research. 5, 132-151.

Kanfer, F.H., \& Grimm, L.G. (1978). Freedom of choice and behavior change. Journal of Consulting and Clinical Psychology, 46, 873-878.

Kazdin, A.E. (2004). Evidence-based treatments: challenges and priorities for practice and research. Child and Adolescent Psychiatric Clinics of North America. Special issue: Evidence-Based Practice, 13, 923-940.

Kivlighan, D. M. (1985). Feedback in group psychotherapy: Review and implications. Small Group Behavior, 16(3), 373-385.

Kluger, A. N., \& DeNisi, A. (1996). The effects of feedback interventions on performance: A historical review, a meta-analysis, and a preliminary feedback intervention theory. Psychological Bulletin, 119, 254-284. 
Kordy, H., Hannover, W., \& Richard, M. (2001). Computer assisted feedback drivenquality management for psychotherapy: The Stuttgart-Heidelberg model. Journal of Consulting and Clinical Psychology, 69, 173-183.

Lambert, M. J. (1992). Implications of outcome research for psychotherapy integration. In J. C. Norcross \& M. R. Goldstein (Eds.), Handbook of psychotherapy integration (pp. 94-129). New York: Basic Books.

Lambert, M. J. (1998, August). Patterns of patient improvement: Implications of research for treatment planning and responsible social policy. Paper presented at the Seventeenth World Conference of Psychotherapy, Warsaw, Poland.

Lambert, M. J. (2001). Psychotherapy outcome and quality improvement: Introduction to the special section on patient-focused research. Journal of Consulting and Clinical Psychology 69, 147-149

Lambert, M.J. (2005). Emerging methods for providing clinicians with timely feedback on treatment effectiveness: an introduction. Journal of Clinical Psychology, 61, 141144.

Lambert, M. J., \& Bergin, A. E. (1994). The effectiveness in psychotherapy. In A. E. Bergin \& S. L. Garfield (Eds.), Handbook of psychotherapy and behavior change. (pp. 143-189). New York, NY: Wiley.

Lambert, M. J., Hansen, N. B., \& Finch, A. E. (2001). Patient-focused research: Using patient outcome data to enhance treatment effects. Journal of Consulting and Clinical Psychology, 69, 159-172. 
Lambert, M. J., Hansen, N. B., Umphress, V. J., Lunnen, K., Okiishi, J., Burlingame, G. M. et al., (1996). Administration and scoring manual for the Outcome Questionnaire (OQ 45.2). Wilmington, DL: American Professional Credentialing Services.

Lambert, M.J., Morton, J.J., Hatfield, D.R., Harmon, C., Hamilton, S., Reid, R.C., Shimokawa, K., Christopherson, C., \& Burlingame, G.M. (2004). Administration and Scoring Manual for the OQ-45.2 (Outcome Questionnaire). American Professional Credentialing Services, L.L.C.

Lambert, M. J., \& Ogles, B. M. (2004). The efficacy and effectiveness of psychotherapy. In M. J. Lambert (Ed.), Bergin and Garfield's handbook of psychotherapy and behavior change (5 $5^{\text {th }}$ ed., pp. 139-193). New York: Wiley.

Lambert, M. J., Whipple, J. L., Bishop, M. J., Vermeersch, D. A., Gray, G. V., \& Finch, A. E. (2002). Comparison of empirically derived and rationally derived methods for identifying clients at risk for treatment failure. Clinical Psychology and Psychotherapy, 9, 149-164.

Lambert, M. J., Whipple, J. L., Harmon, C., Slade, K., Shimokawa, K., Christofferson, C. (2006). Clinical Support Tools Manual, Department of Psychology, Brigham Young University, Provo UT.

Lambert, M. J., Whipple, J. L., Hawkins, E. J., Vermeersch, D. A., Nielsen, S. L., \& Smart, D.W. (2003). Is it time for clinicians to routinely track patient outcome?: A metaanalysis. Clinical Psychology: Science \& Practice, 10, 288-301.

Lambert, M. J., Whipple, J. L., Smart, D. W., Vermeersch, D. A., Nielsen, S. L., \& Hawkins, E. J. (2001). The effects of providing therapists with feedback on client 
progress during psychotherapy: Are outcomes enhanced? Psychotherapy Research, 11, 49-68.

Lambert, M. J., Whipple, J. L., Vermeersch, D. A., Smart, D. W., Hawkins, E. J., Nielsen, S. L., et al. (2002). Enhancing psychotherapy outcomes via providing feedback on client progress: A replication. Clinical Psychology and Psychotherapy, 9, 91-103.

Lash, S. J., \& Blosser, S. L. (1999). Increasing adherence to substance abuse aftercare group therapy. Journal of Substance Abuse Treatment, 16, 55-60.

Lent, R.W., Brown, S.D., \& Larkin, K.C. (1987). Comparison of three theoretically derived variables in predicting career and academic behavior: Self-efficacy, interest, congruence, and consequence thinking. Journal of Counseling Psychology 34, 293298.

Lewin, K. (1947). Frontiers in group dynamics. II. Channels of group life; social planning and action research. Human Relations, 1, 143-153.

Liebman, W.M. (1978). Recurrent abdominal pain in children: A retrospective study on 119 patients. Clinical Pediatrics, 43, 149-153.

Lipkus, I.M. \& Prokhorov, A.V. (2007). The effects of providing lung age and respiratory symptoms feedback on community college smokers' perceived smoking-related health risks, worries and desire to quit. Addictive Behaviors, 32, 516-532.

Locke, E.A., Frederick, E., Lee, C., \& Bobko, P. (1984). Effect of self-efficacy, goals, and task strategies on task performance. Journal of Applied Psychology, 69, 241-251.

Locke, E. A., \& Latham, G. P. (1990). A theory of goal setting and task performance. Englewood Cliffs, NJ: Prentice Hall. 
Locke, E.A., Shaw, K.N., Saari, L.M., \& Latham, G.P. (1981). Goal setting and task performance: 1969-1980. Psychological Bulletin, 90, 125-152.

Luborsky, L, Barber, J.P., Siqueland, L., Johnson, S., Najavits, L. M., Frank, et al. (1996). The revised Helping Alliance questionnaire-II (HAq-II): Psychometric properties. Journal of Psychotherapy Practice and Research,5, 260-71.

Lueger, R. J. (1998). Using feedback on patient progress to predict the outcome of psychotherapy. Journal of Clinical Psychology, 54, 383-393.

Lueger, R. J., Howard, K. I., Martinovich, Z., Lutz, W., Anderson, E. E., \& Grissom, G. (2001). Assessing treatment progress of individual patients using expected treatment response models. Journal of Consulting and Clinical Psychology, 69, $150-158$.

Lunnen, K. M., \& Ogles, B. M. (1998). A multiperspective, multivariable evaluation of reliable change. Journal of Consulting and Clinical Psychology, 66, 400-410.

Lutz, W., Rafaeli, E., Howard, K. I., \& Martinovich, Z. (2002). Adaptive modeling of progress in outpatient psychotherapy. Psychotherapy Research, 12, 427-443.

Martin, D. J., Garske, J. P. \& Davis, K. M. (2000). Relation of the therapeutic alliance with outcome and other variables: A meta-analytic review. Journal of Clinical and Consulting Psychology, 68, 438-450.

Mash, E.J., \& Hunsley, J. (1993). Assessment considerations in the identification of failing psychotherapy: Bringing the negatives out of the darkroom. Psychological Assessment, 5, 292-301.

Maslach, C., Schaufeli, W.B., \& Leiter, M.P. (2000). Job burnout. Annual Review of Psychology, 52, 397-422. 
Mendonca, P.J., \& Brehm, H.M. (1983). Effects of choice on behavioral treatment of overweight children. Social and Clinical Psychology, 1, 343-358.

Mikulincer, M. (1988). Reactance and helplessness following exposure to unsolvable problems: The effects of attributional style. Journal of Personality and Social Psychology, 54, 679-686.

Mikulincer, M. (1994). Human learned helplessness: A coping perspective. New York: Plenum Press.

Mikulincer, M., Glaubman, H., Ben-Artzi, E., \& Grossman, S. (1991). The cognitive specificity of learned helplessness and depression deficits: The role of self-focused cognitions. Anxiety Research, 3, 273-290.

Miller, W.R., Benefield, R.G., \& Tonigan, J.S.(1993). Enhancing motivation for change in problem drinking: A controlled comparison of two therapist styles. Journal of consulting and clinical psychology, 61, 455-461.

Minarik, M.L., \& Ahrens, A.H. (1996). Relations of eating behavior and symptoms of depression and anxiety to the dimensions of perfectionism among undergraduate women. Cognitive Therapy and Research, 20, 155-169.

Mizes, J.S. (1988). Personality characteristics of bulimics and noneating disordered females controls: A cognitive behavioral perspective. International Journal of eating Disorders, 7, 541-550.

Mohr, D. C. (1995). Negative outcome in psychotherapy: A critical review. Clinical Psychology: Science and Practice, 2, 1-27.

Monroe, S. M., Imhoff, D. F., Wise, B. D., \& Harris, J. E. (1983). Prediction of psychological symptoms under high-risk psychosocial circumstances: Life events, 
social support, and symptom specificity. Journal of Abnormal Psychology, 92, 338350.

Nerviano, V.J., \& Gross, H.W. (1983). Personality types of alcoholics on objective inventories: A review. Journal of Studies on Alcohol, 44, 837-851.

Newman, M. L., \& Greenway, P. (1997). Therapeutic effects of providing MMPI-2 test feedback to clients at a university counseling service: A collaborative approach. Psychological Assessment, 9, 122-131.

Norcross, J. C. (2003). Empirically supported therapy relationships. In J. C. Norcross (Ed.), Psychotherapy relationships that work (pp.3-16). New York: Oxford University Press.

Okiishi, J.C., Lambert, M.J., Eggett, D., Nielsen, L., Dayton, D.D., \& Vermeersch ,D.A. (2006). An analysis of therapist treatment effects: toward providing feedback to individual therapists on their clients' psychotherapy outcome. Journal of Clinical Psychology, 62, 1157-1172.

Pacht, A.R. (1984). Reflections of perfection. American Psychologist, 39, 386-390.

Patterson, G.R., \& Forgatch, M.S. (1985). Therapist behavior as a determinant for client noncompliance: A paradox for the behavior modifier. Journal of Consulting and Clinical Psychology, 53, 846-851.

Pelletier, L.G., Tuson, K.M., Hadda, N.K. (1997). Client motivation for therapy scale: A measure of intrinsic motivation, extrinsic motivation, and amotivation for therapy. Journal of Personality Assessment, 68, 414-435.

Percevic, R., Lambert, M. J., \& Kordy, H. (2004). Computer-supported monitoring of patient treatment response. Journal of Clinical Psychology, 60, 285-299. 
Percevic, R., Lambert, M.J., \& Kordy, H. (2006). What is the predicted value of responses to psychotherapy for its future course? Empirical explorations and consequences for outcome monitoring. Psychotherapy Research, 16, 364-373.

Persons, J. B., \& Silberschatz, G. (1998). Are results of randomized controlled trials useful to psychotherapists? Journal of Consulting and Clinical Psychology, 66, 126-135.

Petrocelli, J. V. (2002). Processes and stages of change: Counseling with the transtheoretical model of change. Journal of Counseling and Development, 80,2230.

Podsakoff, P. M. (1989). Effects of feedback sign and credibility on goal setting and task performance. Organizational Behavior and Human Decision Processes, 44, 45-67.

Prochaska, J. O., \& DiClemente, C. C. (1982). Transtheoretical therapy: Toward a more integrative model of change. Psychotherapy: Theory, Research, and Practice, 19, 276-288.

Prochaska, J. O. \& DiClemente, C. C. (1992). The transtheoretical approach. In J. C. Norcross \& M. R. Goldfried (Eds.), Handbook of psychotherapy integration. New York: Basic Books.

Prochaska, J. O., DiClemente, C. C., Velicer, W. F., \& Rossi, J. S. (1993). Standardized, individualized, interactive, and personalized self-help programs for smoking cessation. Health Psychology, 12, 399-405.

Prochaska, J. O. \& Norcross, J. C. (2003). Systems of psychotherapy: A transtheoretical analysis ( $5^{\text {th }}$ edition). Pacific Grove, CA: Brooks/Cole.

Research Consortium of Counseling and Psychological Services in Higher Education. (1994). Nature and severity of college students' counseling concerns. 
Rice, K.G., Ashby, J.S., \& Slaney, R.B. (1998). Self-esteem as a mediator between perfectionism and depression: A structural equations analysis. Journal of Counseling psychology, 45, 304-314.

Rice, K.G., \& Preusser, K.J. (2002). The adaptive/maladaptive perfectionism scale. Measurement and Evaluation in Counseling and Development, 34, 210-221

Rose, G. R., \& Bednar, R. L. (1980). Effect of positive and negative self-disclosure and feedback on early group development. Journal of Counseling Psychology, 27, 6370.

Rotter, J. B. (1954). Social learning and clinical psychology. Englewood Cliffs, N.J.: Prentice Hall.

Sapyta, J. Reimer, M., \& Bickman, L. (2005). Feedback to clinicians: theory research and practice. Journal of Clinical Psychology, 61, 145-153.

Schulte-Bahrenberg, T., \& Schulte, D. (1991). Therapieziesielveranderungen bei Therapeuten [Change in psychotherapy goals in therapists]. In D. Schulte (Ed.), Therapeutische Entscheidungen [Therapeutic decisions] (pp. 43-56). Gottingen: Hogrefe.

Schulte-Bahrenberg, T., \& Schulte, D. (1993). Change in psychotherapy goals as a process of resignation. Psychotherapy Research, 3, 152-165.

Sherman, D.K., \& Cohen, G.L. (2002). Accepting threatening information: Self-affirmation and the reduction of defensive biases. Current Directions in Psychological Science, 11, 119-122.

Smith, M. L. \& Glass, G. V. (1977). Meta-analysis of psychotherapy outcome studies. America Psychologist, 32, 752-760. 
Smith, T.W., \& Brehm, S.S. (1981). Cognitive correlates of the Type A coronary-prone behavior pattern. Motivation and Emotion., 3, 215-223.

Snyder, C. R., Ingram, R. E., Handelsman, M. M., Wells, D. S., \& Huwieler, R. (1982). Desire for personal feedback: Who wants it and what does it mean for psychotherapy? Journal of Personality, 50, 316-330.

Spielberger, C. D. (1983). Manual for the State-Trait Anxiety Inventory STAI (Form Y). Palo Alto, CA: Consulting Psychologists Press.

Spielberger, C. D., Gorsuch, R. L., \& Lushene, R. E. (1970). The State Trait Anxiety Inventory Self Evaluation Questionnaire. Palo Alto, CA: Consulting Psychologists Press.

Speilman, G.I., Masters, K.S., \& Lambert, M.J. (2006). A comparison of rational versus empirical methods in the prediction of psychotherapy outcome. Clinical Psychology and Psychotherapy, 13, 202-214.

Strupp, H. H. (1996). Some salient lessons from research and practice. Psychotherapy, 33, 135-138.

Swann, W.B. \& Hill, C.A. (1982). When our identities are mistaken: Reaffirming selfconceptions through social interaction. Journal of Personality and Social Psychology, 43, 59-66.

Taylor, J. A. (1953). A personality scale of manifest anxiety, Journal of Abnormal and Social Psychology, 48, 285-290.

Taylor, M.S., Fischer, C.D., \& Ilgen, D.R. (1984). Individuals reactions to performance feedback in organizations: A control theory perspective. Research in Personnel and Human Resources Management, 2, 81-124. 
Trudeau, L.S. (2001). Effects of a clinical feedback system on client and therapist outcomes in a rural community mental health center. Dissertation Abstracts International: Section B: The Sciences and Engineering, 61, 5232

Umphress, V. J., Lambert, M. J., Smart, D. W., Barlow, S. H., \& Clouse, G. (1997). Concurrent and construct validity of the Outcome Questionnaire. Journal of Psychoeducational Assessment, 15, 40-55.

Van Houdenhove, B. (1986). Prevalence and psychodynamic interpretation of premorbid hyperactivity in patients with chronic pain. Psychotherapy and Psychosomatics, 45, 195-200.

Vermeersch, D. A., Whipple, J. L., Lambert, M. J., Hawkins, E.J., Burchfield, C.M., Okiishi, J.C. (2004). Outcome Questionnaire: Is it sensitive to changes in counseling center clients? Journal of Counseling Psychology, 51, 38-49.

Walster, E., Berscheid, E., \& Barclay, A.M. (1967). A determinant of preference among modes of dissonance reduction. Journal of Personality and Social Psychology, 7, 211-216.

Walters, S. T. (2000). In praise of feedback: An effective intervention for college students who are heavy drinkers. Journal of American College Health, 48, 235-239.

Wells, D.L., Moorman, R.H., and Werner J.M. (2007). The impact of the perceived purpose of electronic performance monitoring on an array of attitudinal variables. Human Resource Development Quarterly, 18, 121-138

Whipple, J. L., Lambert, M. J., Vermeersch, D. A., Smart, D. W., Nielsen, S. L., \& Hawkins, E. J. (2003). Improving the effects of psychotherapy: The use of early 
identification of treatment failure and problem solving strategies in routine practice. Journal of Counseling Psychology, 58, 59-68.

Wiessman, M. M. \& Bothwell, S. (1976). Assessment of social adjustment by patient self-report. Archives of General Psychiatry, 33, 1111-1115.

Wicklund, R.A., \& Brehm, J.W. (1976). Perspectives on cognitive dissonance. Hillsdale, NJ: Lawrence Erlbaum Associates.

Wills, T. A. (1981). Downward comparison principles in social psychology. Psychological Bulletin, 90, 245-271.

Wilson, C., Boni, N., \& Hogg, A. (1997). The effectiveness of task classification, positive reinforcement and corrective feedback in changing courtesy among police staff. Journal of Organizational Behavior Management, 17, 65-99.

Young, J.E., Klosko, J.S., \& Weishaar, M.E. (2003). Schema therapy: A practitioner's guide. New York, NY; Guilford Press.

Zane, Nagayama, Sue, Young, \& Nunez, 2004

Zimet, G. D., Dahlem, N. W., Zimet, S. G., \& Farley, G. K. (1988). The multidimensional scale of perceived social support. Journal of Personality Assessment, 52, 30-41.

Zung, W.K. (1971). A rating instrument for anxiety disorders. Psychosomatics, 12, 371379.

Zuroff, D.C., Blatt, S.J., Sotsky, S.M., Krupnick, J.L., Martin, D.J., Sanislow, C.A. III, \& Simmens, S. (2000). Relation of therapeutic alliance and perfectionism to outcome in brief outpatient treatment of depression. Journal-of-Consulting-and-ClinicalPsychology, 68, 114-124. 